Isabela Ferreira Duarte

Essays on Education: Subsidies to Higher Education, Major Choice, and the Impact of Water Scarcity

Tese de Doutorado

Thesis presented to the Programa de Pós-graduação em Economia, do Departamento de Economia da PUC-Rio in partial fulfillment of the requirements for the degree of Doutor em Economia.

Advisor: Prof. Juliano Assunção 

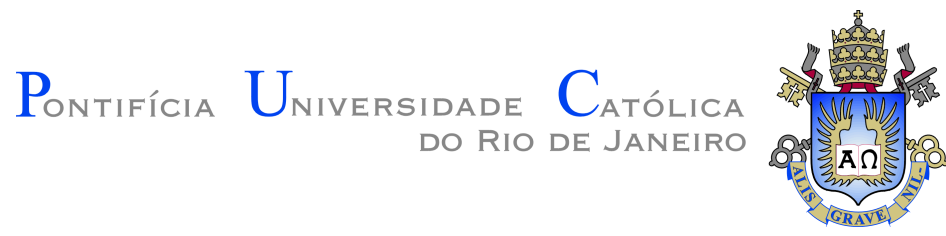

Isabela Ferreira Duarte

\section{Essays on Education: Subsidies to Higher Education, Major Choice, and the Impact of Water Scarcity}

Thesis presented to the Programa de Pós-graduação em Economia da PUC-Rio in partial fulfillment of the requirements for the degree of Doutor em Economia. Approved by the Examination Committee:

Prof. Juliano Assunção

Advisor

Departamento de Economia - PUC-Rio

Prof. Gustavo Gonzaga

Depeartamento de Economia - PUC-Rio

Prof. Claudio Abramovay Ferraz do Amaral Vancouver School of Economics - UBC and PUC-Rio

Prof. Cecília Machado

Escola de Pós-Graduação em Economia - FGV/EPGE

Prof. Michela Carlana

Harvard Kennedy School - HKS

Rio de Janeiro, September the 10th, 2020 
All rights reserved.

\section{Isabela Ferreira Duarte}

Completed her Bachelor of Arts degree in Economics from Universidade de Brasília in 2012 and obtained her Master of Science degree in Economics from PUC-Rio in 2014.

Bibliographic data

Duarte, Isabela Ferreira

Essays on Education: Subsidies to Higher Education, Major Choice, and the Impact of Water Scarcity / Isabela Ferreira Duarte; advisor: Juliano Assunção. - 2020.

160 f: il. color. ; $30 \mathrm{~cm}$

Tese (doutorado) - Pontifícia Universidade Católica do Rio de Janeiro, Departamento de Economia, 2020.

Inclui bibliografia

1. Economia - Teses. 2. Educação. 3. Avaliação de Políticas. 4. Subsídios ao Ensino . I. Assunção, Juliano. II. Pontifícia Universidade Católica do Rio de Janeiro. Departamento de Economia. III. Título.

CDD: 330 


\section{Acknowledgments}

To my advisor, Juliano Assunção, for his valuable insights and generous guidance.

To CNPq and CAPES for their financial support to this study.

To the Instituto Nacional de Estudos e Pesquisas Educacionais Anísio Teixeira (INEP) for authorizing access to the data required for this research and to the staff at Serviço de Acesso a Dados Protegidos (Sedap/INEP) for their valuable support.

To all faculty and staff at PUC-Rio's Department of Economics for the lessons, comments, shared knowledge, and patience throughout my master's and doctorate years.

To the members of the Examination Committee for dedicating their time to contribute to this work.

To João Manoel de Mello, Michela Carlana, and Desmond Ang for being supportive of my research during my tenure at Ministério da Fazenda and at Harvard Kennedy School.

To Adriana, Alexia, Ashley, Camila, Lya, Lorrayne, Mariana, and all the other amazing women in my life for their support and friendship.

To my mother, Eline, and my sisters, Valéria and Elisa, for always encouraging me to achieve my goals.

To my niece, Manuela, and my nephew, Arthur, for being incredibly cute.

To my father, Djalma, who is no longer with us in flesh, but has remained with me in spirit throughout this journey.

To my partner, Gustavo, for his unconditional love and companionship.

This study was financed in part by the Coordenação de Aperfeiçoamento de Pessoal de Nível Superior - Brasil (CAPES) - Finance Code 001. 


\section{Abstract}

Duarte, Isabela Ferreira; Assunção, Juliano (Advisor). Essays on

Education: Subsidies to Higher Education, Major Choice, and the Impact of Water Scarcity. Rio de Janeiro, 2020. 160p. Tese de Doutorado - Departamento de Economia, Pontifícia Universidade Católica do Rio de Janeiro.

This doctoral thesis, is comprised of three chapters. In the first chapter, we explore a discontinuity in eligibility for financial aid for private higher education in Brazil to investigate: (i) if students in the lower end of the ability distribution change their behavior in response to a policy designed to subsidize access to private higher education, and (ii) how students react when they are given the chance to choose between public tuition-free institutions and subsidized access to private higher education. We show that eligibility for financial aid increases students' likelihood of enrolling and persisting in higher education. We also find that eligible students are less likely to enroll in public tuition-free institutions, with no clear impact on the choice of quality at the program level. In the second chapter, we develop a structural discrete choice model of demand to investigate the determinants of major choice. We use this model and the expansion of a government-funded student credit program in Brazil to evaluate how the availability of credit impacts major choice when - as in Brazil - tuition varies at the major level. We find that tuition and expected labor market returns are the main factors determining students' choice between different majors. We also find that, when student credit is available, studentsespecially lower income - are less sensitive to price variations at the major level. In the final chapter, we investigate whether water shortages caused by an extreme climate event impact educational performance. We answer this question exploring the consequences of a water rationing policy that affected some neighborhoods in Brazil's Distrito Federal. Comparing the academic performance of students enrolled in schools located in neighborhoods affected by the rationing against the performance of students enrolled in non-affected neighborhoods, we find that water rationing has a negative and significant impact on students' performance. In particular, we show that the impact is significantly stronger for students enrolled in schools with poor infrastructure.

\section{Keywords}

Education; Policy Evaluation; Subsidies for Education;. 


\section{Resumo}

Duarte, Isabela Ferreira; Assunção, Juliano. Ensaios sobre Educação: Subsídios ao Ensinos Superior, Escolha de Curso e o Impact the Escassez de Água. Rio de Janeiro, 2020. 160p. Tese de Doutorado - Departamento de Economia, Pontifícia Universidade Católica do Rio de Janeiro.

A presente tese de doutorado é dividida em três capítulos. No primeiro capítulo, exploramos descontinuidades em elegibilidade à auxílio financeiro para matrícula em instituições de Ensino Superior privado no Brasil para investigar: (i) se estudantes alteram suas decisões em resposta a uma política pública desenhada para subsidiar acesso ao Ensino Superior privado, e (ii) como estudantes reagem quando podem optar entre obter subsídios para matrícula no ensino privado ou se matricular em instituições públicas gratuitas. Nossos resultados mostram que elegibilidade à subsídios aumenta a probabilidade de que estudantes se matriculem e permaneçam matriculados no Ensino Superior. Também concluímos que elegibilidade reduz probabilidade de matrícula em instituições públicas e que não há impacto em investimento em qualidade ao nível do curso. No segundo capítulo, desenvolvemos um modelo estrutural de demanda com escolha discreta para investigar quais fatores influenciam a escolha de estudantes entre diferentes cursos. Utilizamos esse modelo e a expansão de um programa federal de crédito estudantil no Brasil para avaliar como disponibilidade de crédito influencia escolha de curso quando os custos associados variam ao nível do curso. Nossos resultados mostram que os dois fatores com maior influência na escolha de estudantes entre diferentes cursos são mensalidade e o retorno esperado no mercado de trabalho. Nossos resultados também mostram que, quando há disponibilidade de crédito, estudantes - especialmente estudantes de menor renda - são menos sensíveis à variações de mensalidade. No capítulo final, investigamos se restrições no acesso à água encanada causadas por um evento climático extremo afetam desempenho escolar. Respondemos a essa pergunta avaliando as consequências de uma política de racionamento de água imposta pelo governo do Distrito Federal. Ao comparar o desempenho acadêmico de estudantes matriculados em escolas localizada em vizinhanças atingidas pelo racionamento contra o desempenho de estudantes matriculados em vizinhanças não afetadas, concluímos que o racionamento de água teve um impacto negativo e significante em desempenho acadêmico. Em especial, nossos resultados mostram que esse impacto é significativamente maior para estudantes matriculados em escolas de pior infraestrutura.

\section{Palavras-chave}

Educação; Avaliação de Políticas; Subsídios ao Ensino. 


\section{Table of contents}

1 The Impact of Subsidies to Higher Education on LowAbility Students: Evidence from Brazil 12

$\begin{array}{lll}1.1 & \text { Introduction } & 12\end{array}$

1.2 Investment in Higher Education Model 20

$\begin{array}{lll}1.3 & \text { Institutional Framework } & 25\end{array}$

$\begin{array}{lll}1.4 & \text { Data } & 33\end{array}$

1.5 Empirical Strategy 39

$\begin{array}{lll}1.6 & \text { Results } & 45\end{array}$

$\begin{array}{lll}1.7 & \text { Discussion } & 68\end{array}$

$\begin{array}{lll}1.8 & \text { Conclusion } & 70\end{array}$

2 The Effect of Credit Constraints on Major Choice: Evidence from a Large Scale Student Loan Program in Brazil $\quad 73$

2.1 Introduction $\quad 73$

$\begin{array}{lll}2.2 & \text { Data and Descriptive analysis } & 77\end{array}$

2.3 Institutional Background: FIES and the 2010 Intervention 85

$\begin{array}{lll}2.4 & \text { Reduced Form Evidence } & 87\end{array}$

2.5 A Simple Model of Major Choice 93

2.6 Model of Major Choice - Empirical Implementation 98

$\begin{array}{lll}2.7 & \text { Model of Major Choice - Results } & 101\end{array}$

$\begin{array}{lll}2.8 \text { Conclusion } & 109\end{array}$

3 The Impact of Water Scarcity on Educational Outcomes: Evidence from a Water Rationing Policy in Brazil 110

$\begin{array}{lll}3.1 & \text { Introduction } & 110\end{array}$

$\begin{array}{lll}3.2 & \text { Institutional Framework } & 112\end{array}$

$\begin{array}{lll}3.3 \text { Data } & 115\end{array}$

$\begin{array}{lll}3.4 & \text { Empirical Strategy } & 116\end{array}$

$\begin{array}{lll}3.5 & \text { Mechanisms } & 120\end{array}$

$\begin{array}{lll}3.6 & \text { Conclusion } & 127\end{array}$

A Appendix: The Impact of Subsidies to Higher Education on LowAbility Students: Evidence from Brazil $\quad 141$

A.1 Robustness Analysis 142

B Appendix: The Effect of Credit Constraints on Major Choice: Evidence from a Large Scale Student Loan Program in Brazil 149

$\begin{array}{lll}\text { B.1 Definitions } & 149\end{array}$

B.2 Elasticities 150

C Appendix: The Impact of Water Scarcity on Educational Outcomes: Evidence from a Water Rationing Policy in Brazil 152

$\begin{array}{lll}\text { C.1 Descriptive Statistics } & 153\end{array}$

$\begin{array}{lll}\text { C.2 Additional Results - Mechanisms } & 156\end{array}$ 


\section{List of figures}

Figure 1.1 Higher Education Enrollment Model 22

Figure 1.2 Higher Education Enrollment Model - No Credit Constraints

Figure 1.3 Higher Education Enrollment Model - Subsidizing Higher Education

Figure 1.4 Enrollment with FIES loans 29

Figure 1.5 Enrollment with PROUNI scholarships (thousand) 30

Figure 1.6 Histogram - ENEM Average Grade 42

Figure 1.7 Manipulation Test - ENEM Average Grade 43

Figure 1.8 Eligibility Effect: Access to Subsidies to Private Higher Education

Figure 1.9 Eligibility Effect: Persistence by end of year x 50

Figure 1.10 Eligibility Effect: Enrollment and Persistence 51

Figure 1.11 Eligibility Effect: Persistence year x 53

Figure 1.12 Eligibility Effect: Enrollment by Income Quintile 55

Figure 2.1 Distribution of Major-Institutions' Performance on the 2010 National Quality Evaluation

Figure 2.2 Correlation Between Costs and Returns from Different Majors

Figure 2.3 Students Enrolled in Private Higher Education and FIES Funding

Figure 2.4 Major-HEI Quality Score - Kernel Density 90

Figure 2.5 Impact of Credit Availability on Enrollment 91

Figure 2.6 Higher Education Enrollment Model 97

Figure 3.1 Precipitation Accumulated Between Rainy Seasons (mm) 114 Figure 3.2 Water Volume at the End of the Month (\% of Total Capacity) 114

Figure 3.3 Distrito Federal Map - Treatment and Control Groups 115

Figure 3.4 Impact of Water Rationing on Academic Performance 118 


\section{List of tables}

Table 1.1 Descriptive Statistics - ENEM Grade Distribution 36

Table 1.2 Descriptive Statistics - Students' Characteristics 37

Table 1.3 Descriptive Statistics - Students' Decision to Enroll in Higher Education $\quad 39$

Table 1.4 Test for Discontinuity in Covariates 44

Table 1.5 Eligibility Effect: Financial Aid 47

Table 1.6 Eligibility Effect: Enrollment by Income Quintile 56

Table 1.7 Eligibility Effect: Enrollment of Black Students 58

Table 1.8 Eligibility Effect: Enrollment by Income Quintile and Race 59

Table 1.9 Eligibility Effect: Major-Institution Level Characteristics 61

Table 1.10 Eligibility Effect: Institution Level Characteristics 62

Table 1.11 Eligibility Effect: Major Choice 64

Table 1.12 Descriptive Statistics: Students' Choice Around the Eligibility Threshold 66

Table 1.13 Eligibility Effect: Students Graduating from Public or $\begin{array}{ll}\text { Private High Schools } & 67\end{array}$

Table 2.1 Descriptive Statistics - Characteristics at the MajorInstitution Level

Table 2.2 Descriptive Statistics - Characteristics at the majormarket level

Table 2.3 Reduced Form Estimation $\quad 89$

Table 2.4 Major Market Share Evolution 93

Table 2.5 Demand for Higher Education Estimation 104

Table 2.6 Counterfactual Exercise - Average Market Share Change 106

Table 2.7 Average Price Elasticity of Demand 107

Table 2.8 Demand for Higher Education Estimation - Robustness 108

Table 3.1 Descriptive Statistics - Treatment vs. Control Groups 117

Table 3.2 Treatment Effect: Water Rationing on Academic Performance

120

Table 3.3 Treatment Effect : Reasons for Students' Poor Performance122

Table 3.4 Heterogeneous Treatment Effect by School Characteristics 124

Table 3.5 Heterogeneous Treatment Effect by Student Characteristics127

Table 6 Eligibility Effect: Enrollment

142

Table 7 Eligibility Effect: Attainment - Enrolled by the end of 1st year 143

Table 8 Eligibility Effect: Attainment - Enrolled by the end of 2nd year 144

Table $9 \quad$ Eligibility Effect: Attainment - Enrolled by the end of 3rd year 145

Table 10 Robustness: - Enrollment in Higher Education Varying RD Cutoff $\quad 146$

Table 11 Robustness: - Enrollment in Private Higher Education Varying RD Cutoff 
Table 12 Robustness: - Enrollment in Public Higher Education Varying RD Cutoff 148

Table 13 Descriptive Statistics - Students' Sample 153

Table 14 Descriptive Statistics - School Sample 154

Table 15 Teachers' Survey - Reasons for Students' Poor Performance155

Table 16 Heterogeneous Treatment Effect by School Characteristics - Infrastructure 156

Table 17 Heterogeneous Treatment Effect by School Characteristics - Safety 157

Table 18 Heterogeneous Treatment Effect by School Characteristics - Resources

Table 19 Heterogeneous Treatment Effect by Student Characteristics - Student

Table 20 Heterogeneous Treatment Effect by Student Characteristics - Parents 


\section{List of Abreviations}

AR - Administrative Region

CODEPLAN-Companhia de Planejamento do Distrito Federal

CC-Conceito de Curso

CBO-Classificação Brasileira de Ocupações

CPC-Conceito Preliminar de Curso

ENADE-Exame Nacional de Desempenho dos Estudantes

INEP - Instituto Nacional de Estudos e Pesquisas Educacionais Anísio Teixeira

IRP J-Imposto de Renda para Pessoa Jurídica

FIES - Fundo de Financiamento Estudantil

FNDE - Fundo Nacional de Desenvolvimento da Educação

PROUNI - Programa Universidade para Todos

RAIS-Relação Anual de Informações Sociais

RDD-Regression Discontinuity Design

SAEB -Sistema de Avaliação da Educação Básica 


\section{The Impact of Subsidies to Higher Education on Low-Ability Students: Evidence from Brazil}

\section{1 \\ Introduction}

Investment in human capital and skill formation are a crucial feature of any effective development strategy, as human capital accumulation is related to differences in individual income both between and within countries (Hanushek and Woessmann (2008), Acemoglu and Dell (2010), Gennaioli et al. (2013)). Across the world, governments adopt different strategies to subsidize-fully or partially - enrollment in higher education with the goal of promoting the productivity gains and prosperity often associated with increased educational attainment. Much remains unknown on the impact of these policies and the incentives they create. In this paper, we explore a discontinuity in eligibility for financial aid for private higher education in Brazil to investigate: (i) if students in the lower end of the ability distribution change their behavior in response to a policy designed to subsidize access to private higher education, and (ii) how students react when they are given the chance to choose between public tuition-free institutions and subsidized access to private higher education.

To understand how different policies for higher education impact the decision of students with different ability profiles, we develop a simple model of higher education investment. In our model, students live for two periods and must decide, in the first period, whether they want to enroll in higher education. Students are heterogeneous in their ability, which affects their skill premium, and parental transfers, which affects their ability to pay tuition and smooth consumption while investing in human capital. Our model illustrates the impact of different policies on students' educational decisions. It shows that a pure credit policy (without implicit or explicit subsidies) only impacts the decision of lower-income higher-ability individuals. The behavior of lower ability individuals only changes in response to subsidy policies designed to alter relative prices and increase net returns to higher education. There are a few reasons why policymakers would like to increase the enrollment rates of lower ability individuals. These individuals might, for instance, underestimate 
the social or private returns to higher education. Our model shows that policies intended to increase enrollment rate for this group of individuals must subsidize, at least in part, the costs of higher education.

Estimating the causal impact of subsidy policies for higher education is challenging. Unobserved factors determine students' participation in such policies and the human capital investment decisions they make. We handle this identification challenge exploring a discontinuity in eligibility for financial aid for private higher education in Brazil. The country's federal government subsidize access to private higher education through two different programs: a scholarship program-PROUNI - and a subsidized credit program-FIES. Eligibility for PROUNI and FIES is restricted to students who meet a minimum academic performance requirement. Specifically, students are required to obtain the minimum grade of 450 in the national standardized evaluation for high school students (ENEM) to be considered eligible for subsidies. This minimum performance requirement is set at the low end of the national ability distribution - it represents the percentile 23 of the distribution of ENEM grade. Thus, lower ability students are the ones most affected by the eligibility rule.

We explore the discontinuity in access to subsidies to empirically evaluate how eligibility for financial aid impact the human capital investment decisions of lower ability individuals. In our analysis, we make use of a detailed data set that links students' performance on the national standardized evaluation to their decision to enroll or not in any higher education institution in the country. The identifying assumption is that students who obtain a grade just above and just below the eligibility threshold are comparable in all relevant factors except eligibility for financial aid. To obtain an estimate of the causal impact of eligibility for financial aid on the decisions of low ability individuals, we compare students on both sides of the eligibility threshold through a Regression Discontinuity Design (RDD).

We evaluate, first, the impact of eligibility on students' decision to enroll in higher education and to persist up to three years after initial enrollment. Results show that eligibility for financial aid increases students' likelihood of enrolling in higher education by approximately $10 \%$. It also increases the likelihood of persisting one, two and three years after initial enrollment.

Several countries are facing growing demand for tuition-free alternatives to higher education (Espinoza and Urzúa (2015), Murphy, Scott-Clayton and Wyness (2019), Nguyen (2019)). Much remains unknown on how tuition-free publicly funded institutions affect students' decisions and the dynamics of the higher education market. Peltzman (1973) argues that in-kind subsidies- 
such as free-tuition public higher education - can distort students' decision, crowding out productive investment in private education. In our framework, some of the students who become eligible for financial aid for private education are also likely to qualify for public tuition-free education. To evaluate if students would change their educational choices if they were given the chance to choose how to apply subsidies between public and private schools, we estimate the impact of becoming eligible for subsidies for private education on students' decision to enroll in public higher education. We find that eligibility for subsidies decreases the likelihood of enrolling in public higher education, a finding consistent with Peltzman's model.

We then evaluate how the eligibility effect varies by family income and what is the eligibility impact for black students. Our results show that the eligibility effect is increasing with income up to the income level in which students are restricted from applying to financial aid. This result is consistent with the design of subsidy allocation under FIES and PROUNI. In both programs, subsidies are distributed, in case of excess demand, to students with the highest grades in the national evaluation of high schools students (ENEM). If income and academic ability are positively correlated - as it is the case in our framework - students in the higher end of the income distribution of potential beneficiaries are more likely to obtain subsidies.

Estimating the eligibility impact for black students, we find that black students react more strongly to eligibility for subsidies. Black students are two times more likely to enroll in higher education in response to becoming eligible for subsidies than non-black students. We argue that this result could reflect a higher sensitivity of black students to subsidy availability. Finally, we show that eligibility is increasing with income also for the sample of only black students. These results highlight the importance of allocation rules for subsidy programs. If subsidies are allocated according to academic performance and income is not a factor explicitly considered for allocation, higher income students are more likely to obtain subsidies, even when we consider a sample of students over-represented among low income students.

Finally, we explore how eligibility for financial aid impact students' decision to invest in quality both at the program - major-institution - and at the institution level. In our setting, the supply of financial aid is constrained. Students apply for subsidies at the major-institution level and aid is distributed according to students' performance in the national standardized evaluation (ENEM). This framework might induce students to strategically choose lower quality programs in order to increase their chances of qualifying for aid. We show that eligibility for financial aid does not have a consistent impact 
on investment in quality at the major-institution level. On the other hand, we find that the impact on quality at the institution level is negative. This result is consistent with a framework in which students choose less selective institutions to qualify for financial aid to programs they believe are a better fit for their needs. We further explore this hypothesis, investigating if eligibility for aid impacts major choice. ${ }^{1}$ To investigate if students adjust their investment decision between different programs by choosing specific majors, we estimate how eligibility for financial aid impacts major choice. We show that students eligible for aid are more likely to choose technical majors with higher than average costs of enrollment and labor market returns. Results suggests that, in a framework in which students choose major during the application process, students eligible for financial aid tend to prioritize higher return majors over institutions' prestige.

From a policy point of view, it is important to understand how students in Brazil respond to subsidies for higher education for at least two reasons. First, investment in skill formation is a crucial part of any policy that aims to increase the productivity of labor. Brazil's stagnant productivity levels are often considered one of the main culprits for the country's disappointing economic performance (Dutz (2018), Spilimbergo and Srinivasan (2019)). Understanding what impacts students' decision to invest in human capital is important for the design of productivity enhancing policies. Second, it is crucial to understand how low ability students react to these policies from an equity perspective. Investment in basic education in the country is highly correlated with parental income (Almeida and Packard, 2018). Performance at the national standardized evaluation is considerably worse for lower income individuals and for students from underrepresented groups. ${ }^{2}$ In Brazil, students are not often given the opportunity to invest in their skill formation after joining the workforce. There is no two year college system in the country that can provide students the opportunity to further prepare for enrollment in a selective program and schools offering professional and technical degrees

${ }^{1}$ In Brazil, students choose major during the application process.

${ }^{2}$ In 2015 , the average grade of all students who completed the national standardized evaluation for high school students (ENEM) was approximately 509. There is great variation in grade by students' background. Average grade for students previously enrolled in public high schools was 491 against an average of 578 for students enrolled in private schools. Grade is increasing with income. Splitting the sample of test takers by income quintiles, we have an average grade of 470 for students in the lowest quintile against a grade of 576 for students in the highest quintile. Grades also vary by race and gender. Students who identify themselves as black or brown underperformed in comparison with students who identify themselves as white - an average grade of 495 against 529. Female students also underperformed, even though this is likely due to composition bias. They represented the majority of test takers$58 \%$ of the sample - and got an average grade of 506 against an average grade of 514 for male students. 
enroll only a limited number of students. ${ }^{3}$ This framework often leaves high school graduates to choose between pursuing higher education or entering the labor market as a low-skilled worker. Considering the large premiums for higher education in the country ${ }^{4}$, a system that does not provide students the opportunity to access the gains of more education can hinder intergenerational mobility and help perpetuate the country's staggering inequality levels.

Related Literature. This paper contributes to several branches of the literature. First, we contribute to a literature that evaluates the impact of inkind subsidies on human capital investment decisions. According to Peltzman (1973), when in-kind subsidies are available, individuals must forgo entitlement to free education to invest in private education, which can distort decisions. Long (2006) builds on Peltzman's model to discuss how in-kind financial aid affects students' choices between colleges and shows that, when in-kind subsidies are large, students - specially lower income - choose public education even when there are significant differences in resources between public and private institutions. Long (2006) argues that students could benefit from a system that gives them freedom to choose between public and private provision in at least two ways. First, students would have more liberty to choose schools that are a better fit for their needs or preferences. Second, this system would create competition between higher education institutions, motivating public schools to more rapidly adapt to the changing requirements of effective skill formation. There is some research on how in-kind subsidies for public higher education can crowd-out private. Cellini (2009) and Cohodes and Goodman (2014), for instance, show that investment in subsidized lower quality programs grows with increases in the generosity of in-kind subsidies. Nevertheless, the evidence is still scarce. We contribute to this literature showing how students react when they are given the opportunity to choose how to apply subsidies between public and private institutions. In our framework, students are offered the possibility of applying subsidies for enrollment in private higher education. Some of the students eligible for these subsidies are also likely to qualify for public tuition-free higher education, having, thus, the chance to choose between

\footnotetext{
${ }^{3}$ Provision of upper secondary vocational training is limited in Brazil and admission is often selective. In 2017, only about $8 \%$ of students graduating from high school obtained a vocational training - against an average of $40 \%$ in OECD countries. Students from disadvantaged background are significantly less likely to enroll in vocational programs (OECD, 2019). At the post secondary level enrollment is also limited. According to data from the Higher Education Census, in 2017, only 12\% of students enrolled in tertiary education were enrolled in a vocational program.

${ }^{4}$ Even though returns on education have fallen in Brazil in the past decades (Ferreira, Firpo and Messina (2014), Montenegro and Patrinos (2014)), the return to higher education in the country is still considerably large. Ferreyra et al. (2017) estimate that the return to a higher education degree in Brazil is, on average, 125 percent. The average in Latin America is 104 percent
} 
public and private provision.

Our study also contributes to an extensive literature on how subsidies impact investment in higher education. The empirical evidence shows that financial aid has, in general, a positive impact on students' decision to enroll in higher education (Deming and Dynarski (2010) provide a review of this literature). A large share of students that enroll in higher education do not persist until graduation. In the U.S., only $60 \%$ of the students who began seeking a degree in a 4-year institution in 2012 graduated within a 6 years time frame (U.S. Department of Education, 2019). In Brazil, only $33 \%$ of students graduate with a bachelor's degree within the expected duration of the program. Students only fully accrue the benefits of higher education if they graduate. ${ }^{5}$ There are several reasons why students might decide not to persist in higher education. The literature has explored the impact of different factors such as quality enhancing spending (Deming and Walters, 2017) or students' imperfect knowledge of their academic ability or of the returns to higher education (Arcidiacono et al., 2016). If financial hardship is one reason for dropping out, financial aid may impact persistence. In fact, there is a growing body of evidence estimating the causal impact of financial aid on students attainment. ${ }^{6}$ Nguyen, Kramer and Evans (2019) offer a systematic review of this literature. According to this review, additional $\$ 1,000$ of grant aid improves year-to-year persistence by 1.2 percentage points.

In this article, we provide quasi-experimental evidence from two national programs designed to subsidize - partially or fully - the access of low to middle income students to private higher education in Brazil. This article builds on existing work on the impact of financial aid in a number of ways. First, we are able to identify the impact of subsidies for students around a threshold of academic performance not often studied in the literature. In our framework, eligibility for subsidized private higher education is restricted to students that have achieved a minimum level of academic performance on a national standardized evaluation. Contrary to the standard usually set by similar programs ${ }^{7}$,

${ }^{5}$ In Brazil, the average return to incomplete higher education is approximately one third of the return to a higher education degree (Ferreira, Firpo and Messina, 2014)

${ }^{6}$ Using administrative data form Texas and exploring discontinuities in grant generosity for low income students, Denning, Marx and Turner (2019) find that the U.S federal government aid program-Pell Grant-increases degree completion and later earnings. Bettinger (2015) explores variation in the amount of aid offered through Ohio state financial aid program. Other examples include Angrist et al. (2014), Alon (2011), Bettinger (2004), Andrews, Imberman and Lovenheim (2020), Castleman and Long (2016), and Bettinger et al. (2019).

${ }^{7}$ Other papers that evaluate the impact of financial aid exploring discontinuities around a minimum academic requirement threshold, evaluate programs that require at least an above median performance (Bettinger et al. (2019), Scott-Clayton and Zafar (2019), Cohodes and Goodman (2014),Londoño-Vélez, Rodríguez and Sánchez (2020)) 
the minimum requirement is set at the lower end of the national distribution of academic performance. Estimating the impact of subsidies around this threshold informs on how low-achieving students respond to financial aid. There is an extensive literature evaluating how high performing students respond to financial aid. The general conclusion is that aid increases enrollment and persistence for higher ability students (Avery and Hoxby (2003), Barrow et al. (2014), Cohodes and Goodman (2014), Andrews, Imberman and Lovenheim (2020)). Both the costs and returns to higher education vary by students' ability (Belley and Lochner (2007)). Thus, it is not clear if lower ability students increase their enrollment in response to aid in the same way as higher ability students do. More importantly, it is not clear if these students are able to meet minimum academic requirements and persist. There is evidence that even low achieving students can benefit from higher education (Zimmerman, 2014). Much remains unknown about how these students respond to subsidies.

Second, our study design allow us to evaluate other components of students' choice. In our setting, students apply for financial aid at the majorhigher education institution level. Each major-institution pair is expected to distribute financial aid to a given number of students. If there is excess demand, financial aid is distributed to those students with the highest grades in the national standardized evaluation. The application process is handled through an online systems administered by the government. The system informs students on the number of financial aid contracts available for each major-institution and students can apply to only a limited number of majorinstitutions. This system could lead to strategic behavior, with students choosing lower quality programs or less selective majors to increase their likelihood of qualifying for financial aid. The evidence on how financial aid impacts major choice or the choice between programs of different quality is mixed (Cohodes and Goodman (2014), Denning, Marx and Turner (2019)). We contribute to this literature evaluating if eligibility for financial aid impacts students decision to enroll in specific majors or in programs of varying quality.

With our unique data we are able to handle some of the common limitations faced by the literature. First, we have access to a national registry of students enrolled in higher education. This means that we observe every student enrolled in every tertiary education institution in the country - either public, private non profit, or private for profit. Not being able to identify if students decided to enroll in an institution for which data are not available is one common shortcoming in the literature. Additionally, we have access to detailed information on students' characteristics. This gives us the opportunity to explore heterogeneities in response by students characteristics. There are 
a few papers exploring how gender (see Nguyen, Kramer and Evans (2019) for a review), social-economic status (Alon (2011), Angrist et al. (2014) ) or race (Upton, 2016) impact students response to financial aid. The evidence is still inconclusive and more needs to be done to understand how students' background influences choice.

Finally, we provide evidence on the impact of subsidies at an emerging economy with low enrollment rates and profound inequalities in access to higher education. Despite some progress in the past decades ${ }^{8}$, the tertiary education attainment rate among young adults in Brazil is only $19.59 \%$. This is considerably lower than the attainment rate for OECD countries (43\%) and for other Latin American economies. ${ }^{9}$ As of 2013, students from the two lowest income quintiles accounted for only $14.5 \%$ of all enrollment, while students from the highest income quintile accounted for $40 \%$ of all enrollment (Ferreyra et al. (2017), OECD (2018)). The literature is mostly focused on investigating how different federal or state-level subsidies impact higher education in the US. ${ }^{10}$ Investment in higher education is often considered an important driver for productivity and income growth. The institutional framework of a country can influence student's decision to invest in higher education and how they respond to subsidies. Despite a few recent efforts ${ }^{11}$, the evidence on how students respond to subsidies for higher education in emerging economies is still scarce.

This article proceeds as follows. In section 1.2, we develop a simple model of human capital investment to illustrate how ability, social-economic status and subsidies for higher education impact students' choice. In section 1.3 we present the institutional framework of higher education in Brazil and detail the subsidy programs offered by the federal government. In section 1.4, we detail our unique data. Section 1.5 outlines our empirical strategy. In Section 1.6, we present our results and conduct some robustness checks. Section 1.7 presents a discussion of our findings and section 1.8 concludes this paper.

\footnotetext{
${ }^{8}$ Tertiary education attainment rates among young adults-between the ages of 25 and 34 -increased from $10 \%$ in 2010 to $19 \%$ in 2018.

${ }^{9}$ According to OECD data, in 2018,the tertiary education attainment rates among young adults in Argentina was $39.96 \%$, Chile $33.73 \%$, Colombia $28.96 \%$, Costa Rica $27.82 \%$ and Mexico $23.36 \%$.

${ }^{10}$ See Oppedisano (2011), Arendt (2008), Tanzi, Modena and Rettore (2020), Fack and Grenet (2015) for evidence for Europe

${ }^{11}$ See Rau, Rojas and Urzúa (2013), Melguizo, Sanchez and Velasco (2016), Londoño-Vélez, Rodríguez and Sánchez (2020).
} 


\section{2}

\section{Investment in Higher Education Model}

Our empirical exercise evaluates how low-achieving students respond to eligibility for subsidies for higher education. As highlighted in Section 1.1, there is an extensive literature on the effects of subsidizing higher education for higher achieving students. It is less clear what is the impact of offering such subsidies to students in the lower end of the ability distribution. To understand how ability can be related to human capital investment decisions and why governments might opt to subsidize low achieving students, we develop a simple model of higher education investment based on the framework of Belley and Lochner (2007). Assume a population of $i=\{1,2, \ldots, N\}$ individuals that live for two periods and are heterogeneous in ability and parental transfers. In the first period, each individual $i$ must choose between investing in higher education or entering the labor market. We assume that the decision to invest in higher education is indivisible, i.e., individuals choose between obtaining a higher education degree or not. For simplicity, we also assume that there is no relevant heterogeneity in the investment in higher education, i.e., we opt to not consider possible quality or cost heterogeneities across institutions or majors in this paper. ${ }^{12}$ In the second period, individuals earn wages that are a function of their ability and of their first period schooling choice.

Setting. In period $t=0$ each individual $i$ must make a decision, $s_{i}$, of investing or not in higher education

$$
s_{i}= \begin{cases}0 & \text { if } i \text { decides not to invest in H.E. } \\ 1 & \text { if } i \text { invests in H.E. }\end{cases}
$$

Individuals differ in terms of ability and parental transfers. Individual $i$ is endowed with a level $a_{i}$ of ability ${ }^{13}$ and a parental transfer $T_{i}$. If $i$ decides not to invest in higher education, they enter the labor market as a low-skilled worker and receives compensation $w_{l}$. If $i$ decides to enroll in higher education they must pay the costs associated with this investment. While enrolled in higher education, individual $i$ must pay tuition. We also assume that individual $i$ is not allowed to access the labor market while investing in higher education. The cost of investing in higher education is, thus, represented by the sum of tuition and foregone wages. We assume that tuition, $\tau$, is constant across individuals.

\footnotetext{
${ }^{12}$ For a model that considers this type of heterogeneity and studies the effect of financialaid on major choice, see chapter 2 of this dissertation.

${ }^{13}$ Here we define ability as academic ability. For a discussion on the different types of abilities and on how they impact college attendance and earnings see Prada and Urzúa (2017).
} 
In our model, educational credit is available through a government program that offers loans - subsidized or not-to students who meet certain criteria. ${ }^{14}$ In this setting, individuals eligible for the government program can cover at least part of the direct costs of higher education - tuition-borrowing, in the first period, an amount $d_{i}=\gamma_{i} \tau$ with $\gamma \in[0,1]$. Individuals not eligible for the program have no access to credit, i.e., $\gamma_{i}=0$. In the second period, students must repay their loans at an interest rate $R_{i}$. To subsidize access to higher education, the government sets $R_{i}$ at a level lower than the market rate. Rules set by the government determine the size of the student loan $\left(\gamma_{i}\right)$ and the size of the subsidy $\left(R_{i}\right) .{ }^{15}$ The government can offer full scholarship setting $\gamma=1$ and $R=0$. In period $t=0$, consumption is given by

$$
c_{0}=T_{i}+s\left(\gamma_{i} \tau\right)-s \tau+(1-s) w_{l}
$$

In period $t=1$, all individuals access the labor market. As in Belley and Lochner (2007), second period labor market returns depend on ability and on first period decision of investing or not in higher education. The compensation for high skilled workers, i.e., for workers that invested in higher education in the first period, is represented by the sum of the wage for low skilled workers, $w_{l}$, and a college premium $\left(w_{h}\left(a_{i}\right)\right)$. The college premium is increasing in ability. Individuals who borrowed in the first period need to repay their loans $\left(R \times \gamma_{i} \tau\right)$. In period $t=1$, consumption is given by

$$
c_{1}=w_{l}+s w_{h}\left(a_{i}\right)-s R\left(\gamma_{i} \tau\right)
$$

Individuals decide to invest or not in higher education solving the following optimization problem:

$$
\max _{s \in\{0,1\}}\left[U\left(T_{i}+s\left(\gamma_{i} \tau\right)-s \tau+(1-s) w_{l}\right)+\beta U\left(w_{l}+s w_{h}\left(a_{i}\right)-s R\left(\gamma_{i} \tau\right)\right)\right]
$$

$$
\text { s.t. } T_{i}+s\left(\gamma_{i} \tau\right)-s \tau+(1-s) w_{l} \geq 0
$$

As we use the model to get qualitative predictions, we assume for simplicity that utility follows a natural logarithm function and that college premium is a linear function of ability, that is, $w_{h}\left(a_{i}\right)=w_{h} \times a_{i}$, and focus

\footnotetext{
${ }^{14}$ We assume there is no private credit market for higher education. Although this is generally a strong assumption, it is one that is consistent with our empirical setting. Private credit for higher education is growing in Brazil, but still represents a significantly small share of the market. In 2017 - the last year we consider in our analysis - $92 \%$ of the loans for enrolled students in the country were funded through the federal government credit program.

${ }^{15}$ This is a reasonable assumption in our setting. As we detail in section 1.3, the amount of subsidies offered to students from different backgrounds are set by the government and depend on students' income and major-institution profile.
} 
on a pictorial analysis of the model. Define $T_{\min }\left(a_{j}\right)$ as the minimum level of parental transfer that would make an individual of ability $a_{j}$ indifferent between enrolling or not in higher education. It is easy to show that $T_{\min }\left(a_{j}\right)$ is decreasing in ability. Thus, our model establishes that ability and parental transfers act as compensating forces on the decision to enroll in higher education. Given ability, the decision to enroll in higher education is increasing in parental transfers. Alternatively, given parental transfers, the decision to enroll in higher education is increasing in ability. In this framework, high ability individuals might decide to invest in higher education even for low levels of parental transfers. Low ability individuals, alternatively, will only invest in higher education if they receive a high enough transfer from their parents.

We consider, first, a scenario with no transfers from the government $(\gamma=0)$. Figure 1.1 illustrates how ability and parental transfers determine the decision to invest in higher education. In figure 1.1, the x-axis represents ability - variable $a$ - and the y-axis represents parental income-variable $T$. The curve represents the ability-parental transfer pairs indifferent between investing in higher education or not. The point $(1-\gamma) \tau$ in the parental transfer axis represents the model budget constraint. In a framework with no credit, the decision to invest in higher education is only available to individuals with parental transfers high enough to cover tuition costs. Areas A and B of figure 1.1 determine the set of individuals for which investing in higher education is worthwhile. Individuals in area A will invest in higher education. Individuals in area $\mathrm{B}$ will not invest in higher education due to credit constraints. Area $\mathrm{C}$ represents the set of individuals for which investment in higher education is not worthwhile. Individuals in area $\mathrm{C}$ will not invest in higher education.

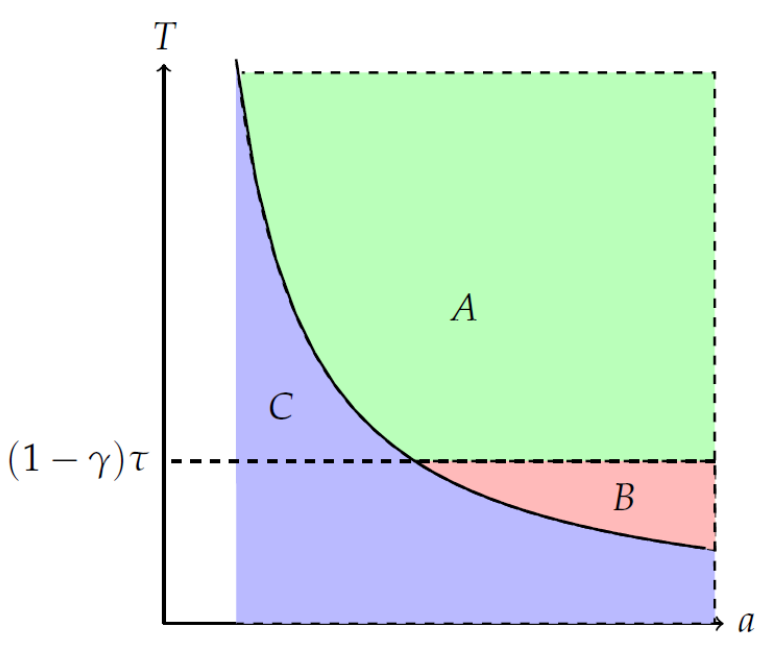

Figure 1.1: Higher Education Enrollment Model 
Our model can be used to illustrate how different policies for higher education impact the decision of students with different characteristics. Consider, first, a pure student credit policy. In our model, a broad student loan program capable of eliminating credit constraints could be implemented by setting the present cost of education to zero $\left(\gamma_{i}=1\right)$, with full repayment in the second period ( $R$ set to a market rate). Figure 1.2 illustrates the impact of a pure credit policy. In this scenario, the set of individuals that find worthwhile to enroll in higher education coincides with the set of individuals that actually enrollrepresented by area A. A student loan program would eliminate income-related constraints to enrollment, allowing high ability-low parental transfers individuals to access higher education (Solis, 2017). This type of policy would not affect lower ability individuals.

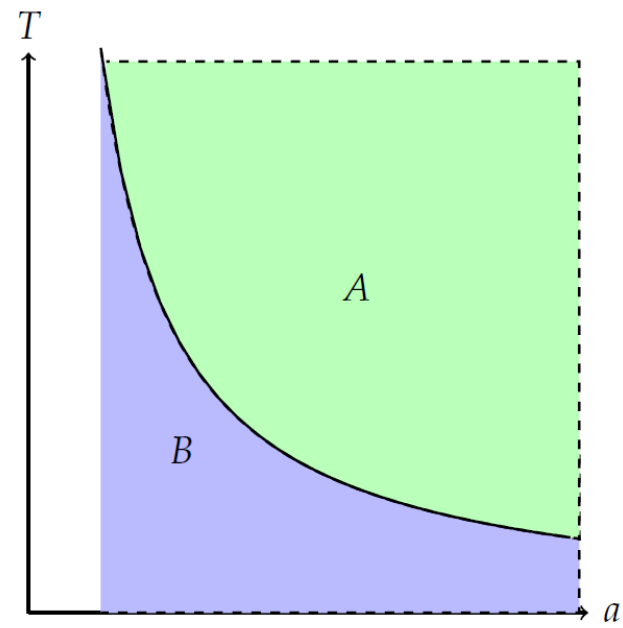

Figure 1.2: Higher Education Enrollment Model - No Credit Constraints

Alternatively, the government could subsidize - fully or partially — access to higher education. In our framework, a subsidy policy could be implemented by reducing the lifetime cost of higher education (setting a positive value for $\gamma_{i}$ and a below market rate value for $R$ ). A subsidy increases the lifetime net returns of higher education, increasing the likelihood of enrollment for individuals of all ability and parental transfer levels. The rate at which the likelihood of enrollment increases with ability and parental transfer depends on the design of the subsidy policy and on modeling assumptions. Figure 1.3 represents one possible scenario. In figure 1.3, we assume a policy that sets $\gamma=1$ and $R$ at a below market rate. This subsidy policy shifts the indifference curve inwards, increasing the likelihood of enrolling at higher education for individuals of all ability and parental transfer levels. Area A represents the set of individuals for which investment in higher education is worthwhile even with no subsidies. Area B represents the set of individuals that will invest in 
higher education in response to the subsidy. Area $\mathrm{C}$ represents individuals that will not invest in higher education.

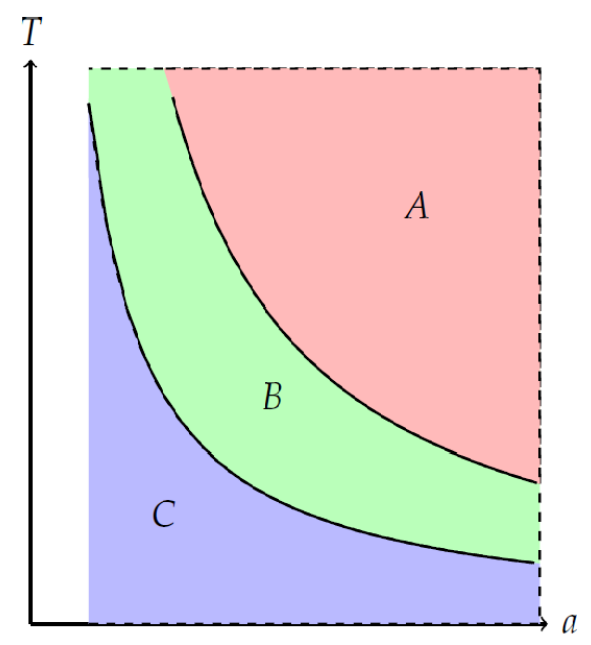

Figure 1.3: Higher Education Enrollment Model - Subsidizing Higher Education

In our framework, students will invest in higher education if they believe this is an investment with net positive return. The decision of students will be made based on their best estimate of the private returns to college education by ability level and on their best estimate of their own ability. If students properly evaluate the returns to higher education, investment will be optimal conditional on the existence of a well functioning market for educational loans. ${ }^{16}$ Thus, if students are estimating returns to higher education properly, an appropriate policy response would be to loosen credit constraints. Eliminating credit constraints impact only the decision of highability low-income students. There are several reasons why students from lower ability levels might be underestimating the returns to higher education.

First, it might be the case that the social return to tertiary education is higher than the private return. For instance, higher education might provide students with skills that can promote innovation and accelerate aggregate productivity and income growth (Hanushek and Woessmann (2008), Gennaioli et al. (2013)). Considering the high premiums for higher education in Brazil and elsewhere, higher education can serve as a powerful tool in reducing income inequality and promoting inter-generational mobility. It can also help reduce racial and gender gaps viewed as socially undesirable.

\footnotetext{
${ }^{16}$ This is valid within our framework. In a more complex setting, students might be debt averse, might not fully observe the costs of higher education, or might not be properly informed of the available credit alternatives.
} 
Second, it is possible that individuals are systematically underestimating even the private returns to higher education. Angel-Urdinola and Gukovas (2018) show that youth in Brazil greatly underestimate current returns to schooling. This becomes even more likely in a scenario in which technological change is expected to increase the relative returns to more complex skills, such as problem solving or critical thinking (Autor, Levy and Murnane (2003), Michaels, Natraj and Van Reenen (2014), Acemoglu and Restrepo (2020)). Further training at the tertiary level can increase individuals' readiness to develop such skills and absorb new technologies.

Finally, it can also be the case that students underestimate their own ability. There is extensive evidence that students - specially first generation, lower income, and minority students - often underestimate their academic potential. If students cannot properly infer their academic ability, their estimates of individual returns to higher education might be imprecise (Bandura et al. (2001), Brown (2002), OECD (2015), Carlana, La Ferrara and Pinotti (2018), Carlana (2019), OECD (2020)).

If policy makers believe that lower ability students are likely to underestimate the returns to education, they might find worthwhile to implement policies that increase their investment in higher education. Our model informs on the need of subsidizing costs to influence the decision of students in the lower end of the ability distribution. It does not provide the information needed to obtain a quantitative estimate of the impact of these subsidies.

Our model also does not inform on the impact of such subsidies on attainment. The decision to persist after initial enrollment may depend not only on the financial, but also on the academic costs of higher education, i.e., the costs of meeting minimum academic requirements (Stinebrickner and Stinebrickner, 2012). It is reasonable to assume that academic effort is a decreasing function of ability. A policy that reduces financial costs of higher education for lower ability students, does not interfere with these academic costs. Thus it is not clear if such policy would have an impact on students' attainment. The impact of the subsidy on enrollment, attainment and other outcomes must be empirically assessed. In the following sections, we explore discontinuities on eligibility for federal subsidies for private higher education in Brazil to evaluate the impact of subsidies on low-ability students.

\section{3}

\section{Institutional Framework}

Higher education in Brazil is provided by both public and private institutions and it is regulated by the federal government. Historically, a large share 
of the federal budget for higher education has been disbursed funding highly selective tuition-free public federal institutions. Spending per student at these institutions is considerably higher than spending per students in countries of similar income and two to three times higher than spending per student at private institutions (World Bank, 2017). Despite the considerable investment, Brazil has performed poorly in international comparisons of performance in research and innovation. ${ }^{17}$

This strategy has also failed to include a large share of the population into higher education, especially students from a less privileged background. The public federal higher education system has been largely criticized for its regressive nature. Historically, public universities conducted need blind application processes. Institutions would admit only students who would place among the top performers in annual or biannual institution-specific examsthe vestibulares. Highly prepared students, who most likely had access to good schools and to the best educational resources, were more likely to get admitted into public institutions and obtain subsidies from the government. Poorer, less prepared students would not enroll in higher education or enroll in private schools and pay in full the cost of their education (World Bank, 2017).

In the past decades, the policies for higher education in the country have changed considerably. First, the government established a national affirmative action policy designed to promote the access of students from underprivileged backgrounds and from underrepresented minorities into public institutions. ${ }^{18}$ The government also established a national centralized admission system, that reduced information asymmetries and application costs (Machado and Szerman, 2016). Finally, with the goal to increase national enrollment rates, the government created two programs designed to subsidize access to private higher education, a subsidized loan program-FIES - and a scholarship programPROUNI.

Created in $1999^{19}$, the federal student credit program - FIES ${ }^{20}$ —was designed to provide subsidized credit for students enrolled in private higher education. Since its creation, the rules and regulations that govern the program have changed considerably. One of the most significant reforms occurred in 2010. The 2010 reform significantly reduced costs of participation for both

${ }^{17}$ In the 2018 Global Innovation Index of the World Intellectual Property Organization (WIPO), Brazil was ranked 64 out of 126 countries, behind countries like Chile, Turkey, Mexico, India, South Africa, Uruguay, and Colombia.

${ }^{18}$ For a more information on affirmative action policies in Brazil see Francis and TannuriPianto (2012), Francis-Tan and Tannuri-Pianto (2018), Estevan, Gall and Morin (forthcoming), and Mello (2019).

${ }^{19}$ Executive Order $n^{o} 1.856-5 / 1999$, later replaced by Law $n^{o} 10.260 / 2001$

${ }^{20}$ Fundo de Financiamento ao Estudante do Ensino Superior 
students and institutions, without establishing a formal limit on the amount of loans to be disbursed through the program. ${ }^{21}$ As a result, the number of loans disbursed through FIES increased considerably. The number of students enrolled in private higher education with FIES financing increased from a little over 130 thousand in 2009 to almost one and a half million in 2015.

The program soon began to face question on its cost-effectiveness and efficiency. FIES was an expensive program. A 2017 report by Brazil's Ministry of Finance ${ }^{22}$ concluded that FIES costed taxpayers more than 21 billion Reais ${ }^{23}$ in 2015 only. This represents approximately $70 \%$ of the costs of Brazil's flagship income redistribution program-Bolsa Família. The program's loose requirements on student's maximum income raised concerns on the regressive nature of the program. ${ }^{24}$ The lack of a strict risk sharing mechanism with institutions raised concerns on incentives created and on the value added by institutions. Within a couple years, it became clear that the 2010 reform had serious shortcomings and that another reform was needed to increase the financial sustainability of the program. This reform began to take shape in the first semester of 2015, after a contentious presidential election. Between 2015 and 2017, the federal government introduced a set of new rules intended to reduce the disbursement of public funds and to target FIES' subsidies on worse-off students. ${ }^{25}$

The reform implemented new rules for the availability and distribution of funding among students. The Ministry of Education would conduct two annual selection processes for FIES, one for enrollment in the first semester and the other for enrollment in the second semester of each year. The selection process was centralized through a national online system. Through this system, students would apply for funding at the major-institution level. The system would inform students on the number of available contracts per major-institution. In case of excess demand, FIES contracts were to be distributed to those students with the highest grade in the national

\footnotetext{
${ }^{21}$ Students benefited from a sharp cut in interest rates, changes in the repayment schedule, a significant increase in the maximum family income limit, the establishment of a rolling basis application process, and the creation of a government backed guarantee fund. Institutions benefited from a more straightforward tuition payment system and from a reduction in their exposure to default risks. For more details on the 2010 reform see chapter 2 of this dissertation or de Mello and Duarte (forthcoming)

${ }^{22}$ Available here: https://www.gov.br/fazenda/pt-br/centrais-de-conteudos/ publicacoes/boletim-de-avaliacao-de-politicas-publicas/arquivos/2017/ diagnostico-fies-junho-2017/view

${ }^{23}$ Approximately $\$ 3.8$ billion.

${ }^{24}$ Before 2015, FIES was restricted only to students with a family income of more than 20 minimum wages.

${ }^{25}$ By the second semester of 2017, the program was, once again, completely reformulated. Considering that our empirical investigation does not cover this period we will not detail the 2017 reform
} 
standardized evaluation (ENEM). The government also imposed more strict limits on the number of contracts available. The total number of loan contracts offered through FIES was to be determined by the availability of public funds. ${ }^{26}$

The government also imposed new requirements for students' eligibility. First, the government imposed a more strict income requirement. The program was redesigned to target lower income students. Only students with per capita family income lower than three times the minimum wage ${ }^{27}$ could apply for a FIES loan. ${ }^{28}$ The government also imposed a minimum academic performance requirement for eligibility. ${ }^{29}$ The minimum academic performance requirement was based on students' performance in the national standardized evaluation for high schools students - ENEM - a large annual evaluation administered by the Ministry of Education. Specifically, only students with an average grade of at least 450 and with essay grade higher than zero in any ENEM exam conducted after 2010 were to be considered eligible for FIES. As it will be detailed in section 1.5 , this minimum performance requirement is central to our identification strategy. Figure 1.4 shows that with the 2015 reform there is a considerable reduction in program's size. Between 2014 and 2017, the number of new loans disbursed through FIES decreased by $60 \%$.

${ }^{26}$ Before the 2015 reform, students could apply for FIES at any point of the academic year and academic performance was not considered a factor for funding distribution. There was no formal limit on the number of available contracts.

${ }^{27}$ Approximately $\$ 450.00$ per capita.

${ }^{28}$ The limit was initially set at one and a half times the minimum wage. In 2016 , the government increased the income limit to two and a half and then three times the minimum wage.

${ }^{29}$ There were a few exceptions to these rules. First, primary teachers employed by public schools were exempt of both the income and the minimum performance requirement. For the 2015 selection processes, students that had not taken any ENEM exam starting 2010 were exempt from the performance requirement. 
Figure 1.4: Enrollment with FIES loans

(1.4(a)) Total

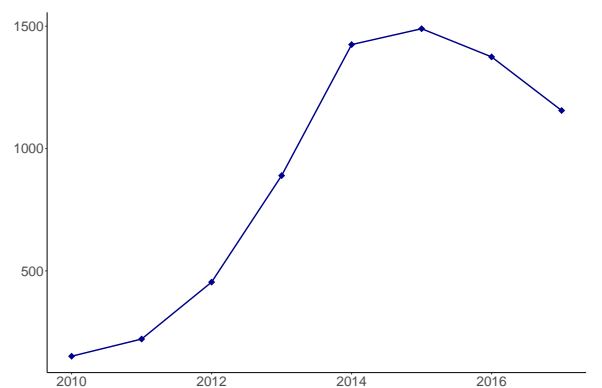

(1.4(b)) New loans

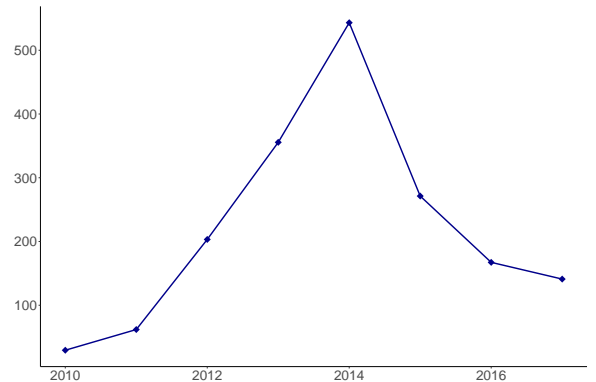

Notes: This figure illustrates the number of students enrolled with FIES loans between the years of 2010 and 2017 in thousands of students. Panel (a) illustrates the total number of students enrolled with FIES and panel (b) illustrates the number of freshman students enrolled with FIES. The data source is the Higer Education Census from INEP and the FIES data from FNDE.

The federal scholarship program-PROUNI ${ }^{30}$ _offers full and partial scholarships to low to middle income students enrolled in private institutions. Higher education institutions that choose to participate in PROUNI are required to enroll a specific number of students with full and partial scholarships in majors deemed of sufficient quality according to the Ministry of Education annual evaluations. ${ }^{31}$ In return, the institutions are considered exempt from a set of taxes and federal contributions. ${ }^{32}$ Figure 1.5 illustrates the number of scholarships distributed through PROUNI between 2010 and 2017. In 2017, approximately 500 thousand students were enrolled in private higher education with a PROUNI scholarship. This represents approximately half the number of students enrolled with FIES in the same period.

${ }^{30}$ Programa Universidade para Todos

${ }^{31}$ Major-institution pairs considered of insufficient quality according to the annual evaluation conducted by the Ministry of Education for two consecutive evaluations are disqualified from the PROUNI program. The scholarships of disqualified majors-institutions are to be redistributed across majors within the institutions.

${ }^{32}$ Institutions are exempt of paying taxes on income-Imposto de Renda das Pessoas Jurídicas (IRPJ) - a tax on profit - Constribuição Social sobre o Lucro Líquido - and two special contributions - Contribuição Social para o Financiamento da Seguridade Social and Contribução para o Programa de Integração Social. 
Figure 1.5: Enrollment with PROUNI scholarships (thousand)

$$
\text { (1.5(a)) Total }
$$

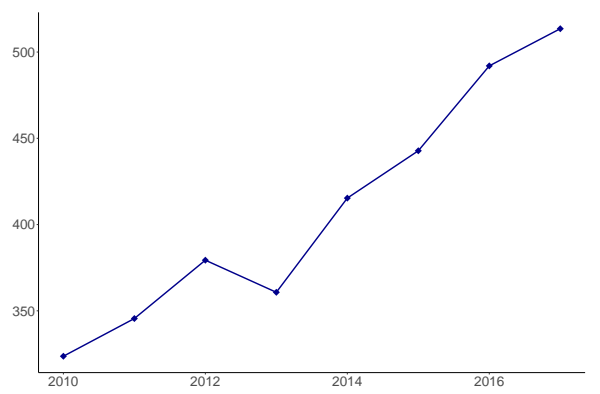

(1.5(b)) New Scholarships

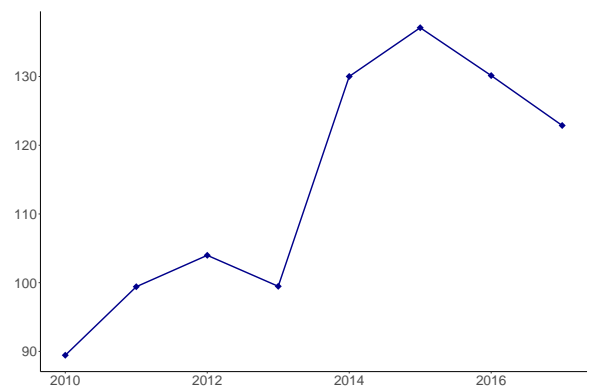

Notes: This figure illustrates the number of students enrolled with PROUNI scholarship between the years of 2010 and 2017 in thousands of students. Panel (a) illustrates the total number of students enrolled with PROUNI and panel (b) illustrates the number of freshman students enrolled with PROUNI. The data source is the Higer Education Census from INEP.

Students must meet a set of requirements to be considered eligible for PROUNI. First, the program is only available to students that meet a maximum income requirement. Full PROUNI scholarships are available to students whose per capita family income is less than one and a half minimum wage. Partial scholarships - that cover $50 \%$ or $25 \%$ of tuition - are available for students with slightly higher income levels. Second, scholarships are only available to students who completed high school in a public school or in a private school with full scholarship. ${ }^{33}$ To apply for a scholarships in any given year, students are required to have participated in the previous year national standardized evaluation (ENEM). Starting 2013, the program imposed a minimum academic ability requirement for eligibility. Only students with an average ENEM grade of 450 points or higher and with an essay grade higher than zero were to be considered eligible for the program. As with FIES, the application process for PROUNI is conducted through an online national system. In the application process, students choose to apply for a given set of major-institution pairs. Available scholarships are distributed to applying students according to their average grade in ENEM, with priority given to students who get higher grades. ${ }^{34}$

\footnotetext{
${ }^{33}$ There are two exceptions to this rules. Students with disability or students who are currently teachers at a public school and that intend to use the scholarship to enroll in a education major.

${ }^{34} \mathrm{In}$ case there is a shortage of demand for a particular major-institutions the remaining slots available for PROUNI will be redistributed through a second stage application process. In this stage, students that meet the income requirements and that have taken any ENEM test since 2010 can apply.
} 
There are a few similarities between FIES and PROUNI. Both programs have in common the fact that they offer federally funded subsidies for enrollment in private higher education to students that meet a common minimum academic requirement - obtain a grade of at least 450 on the country's evaluation of high school students (ENEM). They also use a similar system to allocate subsidies. For the period that we consider in our analysis, both programs allocated subsidies trough an online system that allowed students to apply for subsidies at the major-institution level and that selected students based on their performance on the ENEM evaluation. Nevertheless, it is important to highlight some of the significant differences between these two programs.

From the students' perspective, the main difference between FIES and PROUNI is the size of the subsidy. PROUNI works as an unconditional grant. Students who are admitted into private higher education with a PROUNI scholarship are exempt from paying tuition costs for the full duration of the course. ${ }^{35}$ FIES, on the other hand, is a subsidized credit program. Students admitted with FIES funding must repay the cost of their education after graduation at a subsidized interest rate. From the students' perspective, PROUNI is a much more generous program. One would expect the demand for PROUNI scholarships to be stronger than the demand for FIES funding among students eligible for both programs. Given that subsidies are distributed according to academic performance, the difference in subsidy size could result in differences in academic readiness of students enrolled with both programs. The available data reveals that students enrolling with PROUNI are, on average, more academically prepared than students enrolling with FIES both at the moment of application and while enrolled. Between 2015 and 2016, the average minimum ENEM grade required to obtain a PROUNI scholarship588.4 - was much higher than the average minimum ENEM grade required to obtain FIES funding - 536.7. Using data from the 2015 ENADE exam-an annual evaluation of students enrolled in higher education in Brazil - we find that students enrolled in higher education with PROUNI have much higher average grade - 50.28 - than students enrolled with FIES — 41.92.

The second significant difference between the two programs is the socioeconomic profile of targeted students. PROUNI was designed from the start as a program that would benefit students from underprivileged backgrounds. The program is restricted to students whose families have per capita income lower than 1.5 minimum wages and that graduated from a public high school or a private high school with full scholarship. PROUNI also has an affirma-

\footnotetext{
${ }^{35}$ Students who do not meet minimum academic performance requirements-fail more than $25 \%$ of their credits - while enrolled can loose their scholarship.
} 
tive action arm. Institutions participating in PROUNI are required to reserve a share of their scholarships to students from underrepresented minoritiesblack, brown, indigenous, and students with disabilities. ${ }^{36}$ FIES, on the other hand, was designed as a policy intended to increase enrollment rates in private higher education. Between 2010 and 2015, FIES was only unavailable for students with a family income of more than 20 minimum wages, a requirement that would only restrict access to funding for students at the very top of the country's income distribution. In the 2015 reform, the government established a more strict income requirement. Specifically, FIES was restricted to students with per capita family income lower than three times the minimum wagethis represents approximately the percentile 90 of the country's household per capita income distribution and is two times higher than PROUNI maximum income level. Even after the 2015 reform, other socioeconomic factors would not be considered relevant for funding allocation.

The method through which the government compensates higher education institutions that participate in PROUNI and FIES is another important difference. According to PROUNI rules, higher education institutions are considered exempt from some taxes and federal contributions if they admit a minimum number of students with full or partial scholarships every year. According to this scheme, higher education institutions do not financially benefit from increasing the number - or the persistence - of students with PROUNI scholarships. The compensation for students enrolled with FIES is very different. For every student currently enrolled with FIES the government transfers to the institution treasury bonds with face value corresponding to the financed tuition. The bonds are tradable for Social Security obligations and the government holds regular repurchase auctions. Government transfers are, thus, a direct function of the number of students currently enrolled with FIES. The differences in compensation schemes create differences in expected revenue per student for each program. The evidence suggests that, even though different types of higher education institutions enroll at least some students with both FIES and PROUNI, for profit institutions are more likely to admit large numbers of students with FIES funding. In 2015, around $7 \%$ of students enrolled in private higher education were enrolled with a PROUNI scholarship at both for profit and non profit institutions. Students with FIES, on the other, comprised $29 \%$ of students enrolled in for profit institution against $19 \%$ of students enrolled in non profit institutions. Students with FIES are also less likely to enroll in Brazil's universities - institutions that have regulatory autonomy and

\footnotetext{
${ }^{36}$ The share of scholarships reserved to minority students depends on the share of minority population within each state.
} 
conduct research. In 2015, only 31.6\%. of the students with FIES funding were enrolled in universities while $42.6 \%$ of students with PROUNI were enrolled in universities.

Finally, there are significant differences in how the government allocates funding through FIES and PROUNI. The general rule for PROUNI allocation is that higher education institutions must admit at least one student with full scholarship for every ten students enrolled in each major. ${ }^{37}$ The number of scholarships available are then a function of number of enrolled students at the major level. The number of student loan contracts offered through FIES, on the other hand, are determined through negotiations between the government and higher education institutions. Every semester, the government presents a plan for funding allocation giving priority to regional development concerns, higher quality majors, and majors considered strategic. Higher education institutions can then present a proposal on how they would like to allocate funding across majors, based on their specific needs and government defined criteria. Higher education institution thus have some flexibility to allocate available subsidies to higher demand majors. The government must approve each institution's proposal.

In 2017, approximately $26 \%$ of the students enrolled in private higher education in Brazil received subsidies from either PROUNI or FIES. Despite the size and relevance of these programs, there are few systematic evaluations of their impact. ${ }^{38}$ In this paper, we explore the fact that both PROUNI and FIES established the same minimum academic requirement for eligibilitya minimum grade of 450 on the national exam for high school students (ENEM) - to investigate how subsidies for higher education impact the choice of academically marginal students.

\section{4 \\ Data}

In this paper, we investigate if students change their behavior in response to being considered eligible for private higher education subsidies. As we detailed in section 1.3, Brazil's federal government subsidize access to private higher education through two national programs: a scholarship programPROUNI - and a subsidized lending program-FIES. To apply for any of these two programs, students must meet a few requirements. In particular, students

\footnotetext{
${ }^{37}$ Institutions can choose to offer some partial scholarships instead of full scholarships. There is a rule determining how many partial scholarships must be offered by number of enrolled students. If a major is considered of insufficient quality by the Ministry of Education, the scholarships that should have been offered for this major must be redistributed across the other majors offered by the higher education institution.

${ }^{38}$ Dearden and Nascimento (2019) are an exception.
} 
must obtain a minimum average grade of 450 in the national standardized evaluation for high school students (ENEM). We estimate the causal impact of subsidy availability on students' human capital investment decisions exploring the discontinuity in eligibility around this minimum academic performance threshold. To implement this empirical strategy, we need two sets of information. First, we need information on students performance at the national standardized evaluation (ENEM). Second, we need to link this information to information on students' educational decisions in the years following the exam. We obtain these data by merging two data sets with information at the student level: the ENEM exam individual data and the Higher Education Census. ${ }^{39}$

Brazil's national standardized evaluation for high school students$\mathrm{ENEM}^{40}$ - is administered by the Ministry of Education and takes place once every year. Participation in the exam is voluntary and it is open to students that are expected to graduate from high school in the year of the exam and students that have graduated from high school in previous years. ${ }^{41}$ Approximately 5 million students take the ENEM exam every year, making it one of the largest high school exams in the world (Travitzki, Calero and Boto, 2014). ENEM is considered an important part of the college admission process in Brazil. Several higher education institutions in the country - both public and private - consider grades from ENEM in their admission processes. ${ }^{42}$ During the exam, students must answer 180 multiple choice questions equally divided into four different areas: language, human sciences, natural sciences and math. Students must also write an essay on a given topic. In each of these areas, students are assigned a grade from 0 to 1000. The average ENEM grade is given by the simple average of students' grade at each area, including the essay grade. As detailed in section 1.3, students are required to obtain a minimum average grade of 450 to qualify for subsidies for private higher education.

Information on students' individual performance on each ENEM area is available through the ENEM exam individual data. This data set also

${ }^{39}$ The ENEM student data and the Higher Education Census are administered by INEPan independent government agency linked to Brazil's Ministry of Education - and are publicly available (http://inep.gov.br/microdados). Personal identifiers required to merge these two data sets are not included in the public version. INEP authorizes researchers with an approved research project to access a merged version of the data. Access is only available through hardware located at a room for access to sensitive information at INEP's headquarter in Brasília (more information here: http://inep.gov.br/dados/sedap).

${ }^{40}$ Exame Nacional do Ensino Médio

${ }^{41}$ Between 2009 and 2016, students that had not graduated from high school could take the ENEM exam and use their grade to obtain a high school certificate. Students that are not expected to graduate from high school in the year of the exam can also take it for training purposes.

${ }^{42}$ in 2017, $21 \%$ of new students enrolled in higher education in Brazil were admitted through a process that used ENEM grades as reference. 
contains basic administrative information on students' background such as age, gender, race and information on a student-level survey. The ENEM survey includes information on a categorical measure of family income. ENEM data are available from 1998 to 2019. As detailed in section 1.3, the minimum performance requirement for eligibility for the subsidized credit program was established in the second semester of 2015 and, in 2017, the credit program underwent another major reform. For this reason, we restrict our analysis to the cohorts making the decision to enroll in higher education between 2015 and 2016, i.e, the cohorts taking the ENEM exam between 2014 and 2015.

The minimum ENEM grade is not the only requirement for eligibility for subsidies. In order to be considered eligible, students need to obtain a grade higher than zero on ENEM's essay. We restrict our sample to students that meet this requirement. Students also need to satisfy a maximum family income requirement. We do not have access to detailed income information and, for this reason, we do not restrict our sample on income basis. Finally, we restrict our analysis to students that graduated from high school in the same year they took the exam. We focus on high school seniors for mainly two reasons. First, this allow us to exclude from our analysis students that might be retaking the exam with the sole purpose of obtaining the minimum grade required for eligibility (Solis, 2017). Second, the rules that determine eligibility for subsidies are slightly different for the credit and the scholarship programs. To be eligible for the credit program, students must obtain the minimum grade of 450 in any ENEM exam starting from 2010. To be eligible for the scholarship program, students must obtain the minimum grade in the previous year exam. For seniors that are choosing to enroll in higher education right after high school, the minimum academic requirement rule is the same for both the loan and the scholarship programs.

Our final sample contains nearly 3 million observations. Table 1.1 details the distribution of ENEM grade for the students in our final sample. The average ENEM grade is 509.09. Students, on average, perform better on the human sciences and language exams. The math exam seems to be the most challenging for students. It is the exam with the lowest average grade and the highest variance. The minimum grade for eligibility - 450-represents approximately the 23rd percentile of the distribution of ENEM grade. Thus, the minimum academic performance requirement impacts the decision of students in the lower end of the distribution of academic ability. 
Students within this interval are more likely to be female (61\%), black (12\%), and to be expected to graduate from a public high school (90\%). Students within this interval are also less privileged than students from the full sample according to all socioeconomic variables available.

Table 1.2: Descriptive Statistics - Students' Characteristics

\begin{tabular}{|c|c|c|c|c|}
\hline & (1) & (2) & (3) & (4) \\
\hline Variables & Mean & $\mathrm{N}$ & Mean $[-50,50]$ & $\mathrm{N}[-50,50]$ \\
\hline Female Student & $\begin{array}{c}0.583 \\
(0.493)\end{array}$ & $2,876,864$ & $\begin{array}{c}0.614 \\
(0.487)\end{array}$ & $1,276,294$ \\
\hline Black Student & $\begin{array}{c}0.107 \\
(0.310)\end{array}$ & $2,836,669$ & $\begin{array}{c}0.126 \\
(0.331)\end{array}$ & $1,258,667$ \\
\hline Graduating from Public High School & $\begin{array}{c}0.770 \\
(0.421)\end{array}$ & $2,874,649$ & $\begin{array}{c}0.901 \\
(0.299)\end{array}$ & $1,275,222$ \\
\hline Student Age & $\begin{array}{c}18.208 \\
(3.741)\end{array}$ & $2,876,795$ & $\begin{array}{c}18.707 \\
(4.453)\end{array}$ & $1,276,271$ \\
\hline Has a Car at Home & $\begin{array}{c}0.533 \\
(0.499)\end{array}$ & $2,875,091$ & $\begin{array}{c}0.424 \\
(0.494)\end{array}$ & $1,275,285$ \\
\hline Has Internet Access & $\begin{array}{c}0.703 \\
(0.457)\end{array}$ & $2,875,077$ & $\begin{array}{c}0.598 \\
(0.490)\end{array}$ & $1,275,281$ \\
\hline Father Education & $\begin{array}{c}1.590 \\
(0.728)\end{array}$ & $2,599,397$ & $\begin{array}{c}1.371 \\
(0.591)\end{array}$ & $1,122,647$ \\
\hline Mother Education & $\begin{array}{c}1.720 \\
(0.764)\end{array}$ & $2,757,266$ & $\begin{array}{c}1.501 \\
(0.666)\end{array}$ & $1,205,852$ \\
\hline Family Income & $\begin{array}{c}4.543 \\
(12.542)\end{array}$ & $2,875,097$ & $\begin{array}{c}2.220 \\
(4.499)\end{array}$ & $1,275,287$ \\
\hline Household Size & $\begin{array}{c}4.148 \\
(1.405)\end{array}$ & $2,875,097$ & $\begin{array}{c}4.268 \\
(1.514)\end{array}$ & $1,275,287$ \\
\hline Per Capita Family Income & $\begin{array}{c}1.215 \\
(3.526)\end{array}$ & $2,875,097$ & $\begin{array}{c}0.582 \\
(1.257)\end{array}$ & $1,275,287$ \\
\hline
\end{tabular}

Notes: This table presents descriptive statistics for the final sample. Columns (1) and (2) present descriptive statistics for the full sample. Columns (3) and (4) present descriptive statistics for students with average grades between 400 and 500 - an 100 points interval around the minimum performance threshold. Columns (1) and (3) present the variable mean and standard deviation (in parenthesis). Columns (2) and (4) presents sample size. Variables Female Student, Black Student, Graduating from Public High School, Has a Car at Home, and Has Internet Access are binary variables. Mother Education and Father Education are categorical variables that take the value of 1 if the parent has less than secondary education education, 2 if the parent has secondary education and 3 if the parent has a college degree or higher. Family Income is a categorical variable representing different income intervals as multiples of the national minimum wage. We use the median value in each of these intervals and the reported household size to calculate Per Capita Family Income. 
From the Higher Education Census, we obtain information on students' decision to enroll in higher education after graduating from high school. Every year, the Higher Education Census collects information from all higher education institutions in the country-public and private. The Census contains information at the institution, major, instructor and student level. At the institution level, the Census collects information on academic and administrative personnel, financial information, and information on the different majors offered by each institution. At the major-institution level, the Census collect information on number of credits required for graduation, minimum length of program, number of applicants per type of application process, number of enrolled students, number of dropouts, and number of graduates. Students' data include demographics and information on financial aid by source and type. For instructors, we have data on demographics, education, and employment type.

The Census contain information on students enrolled in every higher education institution in the country. Thus, we can use it to identify if students decided to enroll in higher education after taking the ENEM exam between 2014 and 2015. Due to restrictions in data access, the latest information available is from the 2017 Census. We use information from the 2015, 2016, and 2017 Census to learn about students' decisions up to three years after taking the ENEM exam. Table 1.3 presents this information for students in our final sample. Approximately $21 \%$ of the students in our sample enroll in higher education, $14 \%$ in private institutions and $7 \%$ in public institutions. Table 1.3 also indicates the percentage of students that persist after initial enrollment. Considering public and private institutions, $17 \%$ of the students in our sample persist after one year and $13 \%$ persist after two years of initial enrollment. That means that of the students that actually enroll, roughly $83 \%$ persist after one year and only $65 \%$ persist after two years. Persistence rates are higher for public institutions - $88 \%$ after one year and $72 \%$ after two years against $81 \%$ after one year and $62 \%$ after two years for private institutions. Considering our full sample, $4.5 \%$ of students persist after three years. Since we only have information on persistence after three years for about half of our sample - students who took the ENEM exam in 2014-this is an imperfect measure of persistence.

Table 1.3 indicates that the private sector enrolls a large share of the higher education students in our sample. Approximately $67 \%$ of the students in our sample that enroll in higher education, enroll in a private institution. It also shows that publicly provided financial aid is an important feature of private higher education. Approximately $6.4 \%$ of the students in our sample fund at least part of their enrollment in private higher education with some 
form of state subsidy - 3.4\% from the credit program (FIES) and 3\% from the scholarship program (PROUNI). Thus, almost half of the students in our sample that enroll in private higher education have access to some form of financial aid from the government. In the next sections, we explore the role financial aid play in students' decision to invest in higher education.

Table 1.3: Descriptive Statistics - Students' Decision to Enroll in Higher Education

\begin{tabular}{ccc}
\hline \hline Variable & Mean & Std. Dev. \\
& & \\
\hline Enroll in Higher Education - Total & 0.212 & 0.409 \\
Persist after one year - Total & 0.178 & 0.382 \\
Persist after two years - Total & 0.139 & 0.346 \\
Persist after three years - Total* & 0.045 & 0.207 \\
Enroll in Higher Education - Private & 0.144 & 0.351 \\
Persist after one year - Private & 0.117 & 0.322 \\
Persist after two years - Private & 0.09 & 0.287 \\
Persist after three years - Private* & 0.026 & 0.16 \\
Enroll in Higher Education - Public & 0.068 & 0.251 \\
Persist after one year - Public & 0.060 & 0.238 \\
Persist after two years - Public & 0.049 & 0.216 \\
Persist after three years - Public* & 0.018 & 0.135 \\
Enrolled with FIES & 0.034 & 0.180 \\
Enrolled with PROUNI & 0.030 & 0.170 \\
Enrolled with PROUNI (Partial scholarship) & 0.009 & 0.093 \\
Enrolled with PROUNI (Full scholarship) & 0.021 & 0.143 \\
Obs. & $2,876,864$ & \\
\hline
\end{tabular}

Notes: This table presents enrollment and persistence information for the final sample. Information is obtained from the Higher Education Census from 2015 to 2017. It presents information on the proportion of students deciding to enroll and persist in public and private higher education up to three years after initial enrollment. It also contains information on the proportion of students enrolling in private higher education with some form of government funded subsidy. Due to data limitation, We do not observe the value of variables market with $*$ for students from who took the ENEM exam in 2015.

\section{5}

\section{Empirical Strategy}

In this paper, we estimate the impact of eligibility for subsidized private higher education on the human capital investment decisions of low-ability 
students in Brazil. As detailed in section 1.3, to be considered eligible for public subsidies for private higher education, students must obtain a minimum grade of 450 in the national standardized evaluation for high school students (ENEM). We explore this eligibility requirement - through a Regression Discontinuity Design - to estimate the causal impact of eligibility on students' choices.

A Regression Discontinuity Design (RDD) can be used when treatment assignment is determined as a function of an observed variable. In our case, treatment - eligibility for financial aid - is a function of students performance on an standardized evaluation. Only students that cross a given performance threshold - students who obtain an ENEM grade higher than 450 - can be considered eligible for financial aid. If individuals are unable to manipulate the assignment variable, variation in treatment near the threshold is as good as random. If no other relevant factor varies discontinuously around the threshold, differences in outcome around the threshold are caused by the treatment. In this framework, we can estimate treatment effect by comparing the choices of individuals just above and just below the established threshold.

To estimate the treatment effect, we implement a data driven non parametric version of the RDD. The non parametric version reduces the risks associated with model specification. ${ }^{43}$ We compute treatment effects estimating a local polynomial non-parametric regression for observations within a bandwidth defined according to the optimal bandwidth selection procedure proposed by Calonico, Cattaneo and Titiunik (2015). Specifically, we estimate the parameters of the following model on a subset of the data within a chosen bandwidth to the left and right to the eligibility threshold:

$$
Y_{i}=\alpha+\beta_{0} T_{i}+\beta_{1} r_{i}+\beta_{2} r_{i} T_{i}+\epsilon_{i}
$$

Here $Y_{i}$ represents the outcome variable, $T_{i}$ a binary variable indicating students who are eligible and ineligible for aid - i.e., students who crossed the eligibility threshold - and $r_{i}$ represents the assignment variable - the ENEM grade.

We are able to obtain precise estimates even for small neighborhoods around the eligibility threshold. ${ }^{44}$ We assess the robustness of our results replicating the analysis considering local polynomial estimators of various orders and implementing a bias-corrected robust inference procedure (Calonico, Cattaneo and Titiunik, 2014).

\footnotetext{
${ }^{43}$ Results for the parametric version are similar and available upon request.

${ }^{44} \mathrm{We}$ also estimated our results considering alternative methods for optimal bandwidth selection. Results are similar and available upon request.
} 
The validity of an RD approach depends on two basic assumptions. The first assumption states that individuals are not able to precisely control the assignment variable around the treatment assignment threshold. In our framework, eligibility is determined according to students' average grade in the national standardized evaluation for high school students (ENEM). Only students who obtain a grade of 450 or higher are considered eligible for financial aid. If students could manipulate ENEM grade, students interested in enrolling in higher education with financial aid could improve their grades and increase their chances of participating in the program. Thus, our identification strategy relies on the assumption that students are unable to control their grade around the eligibility threshold. In our framework, this is likely the case. ENEM plays a central role in the admission process for higher education in Brazil and several safety measures are taken by the government to guarantee that students are not manipulating their results. Every student in the country takes the same exam in the exact same day under strict anti-cheating measures. The exam's answer are publicized right after the test and multiple choice questions are graded with the use of a computer program. ENEM's essays are evaluated through blind grading.

Given our institutional framework, it is unlikely that students are able to manipulate their ENEM grade. Either way, we can use our data to assess the robustness of this assumption. In figure 1.6, we plot the histogram of ENEM's average grade, standardizing the average grade around the eligibility threshold. The histogram can be used to evaluate if there is any discontinuity in ENEM grade around the minimum performance threshold. If students could manipulate their grade, we would expect to see some bunching around zero. Figure 1.6 shows no visible discontinuities in the distribution of ENEM's grade. We also implement a formal manipulation testing procedure using the local polynomial density estimators proposed in Cattaneo, Jansson and Ma (2018). ${ }^{45}$ Figure 1.7 illustrates the result of this test. Again we find no evidence of manipulation around the eligibility threshold.

\footnotetext{
${ }^{45}$ For more information on manipulation testing see McCrary (2008).
} 
Figure 1.6: Histogram - ENEM Average Grade

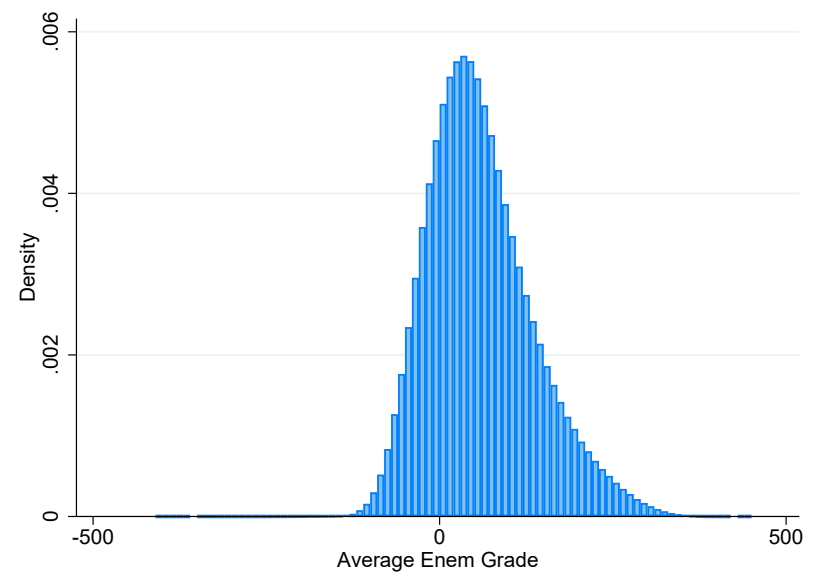

Notes: This figure presents a histogram of ENEM grade for students in the final sample. The final sample includes all students taking the ENEM exam between 2014 and 2015 who are expected to graduate from high school in that same year and who obtained a grade higher than zero on ENEM's essay - 2,876,864 students total. In this figure, we standardize ENEM grade around the minimum threshold requirement. Thus, the grade zero represents the minimum threshold for eligibility — originally 450 points. The histogram starts at grade -500 and bins width is specified at 10 points. 
Figure 1.7: Manipulation Test - ENEM Average Grade

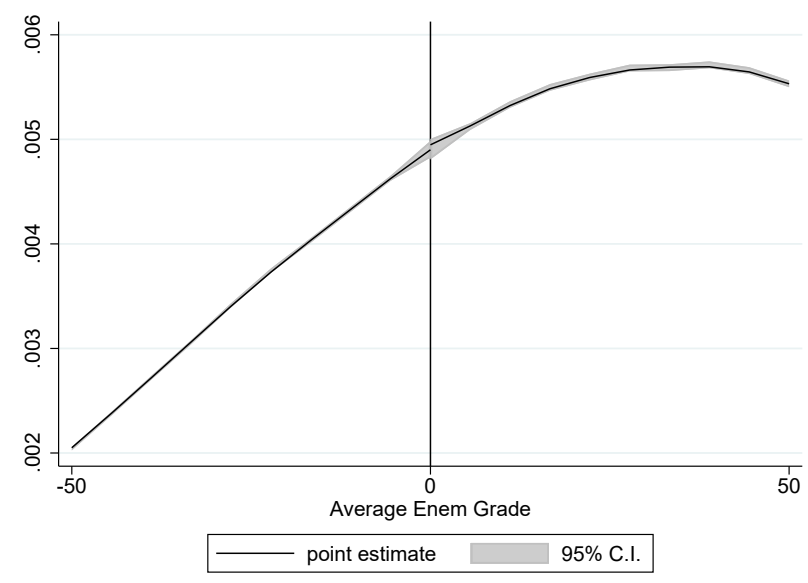

Notes: This figure presents the results a manipulation test for ENEM grade considering the students in our final sample. The final sample includes all students taking the ENEM exam between 2014 and 2015 who are expected to graduate from high school in that same year and who obtained a grade higher than zero on ENEM's essay - 2,876,864 students total. In this figure, we standardize ENEM grade around the minimum threshold requirement. Thus, the grade zero represents the minimum threshold for eligibility — originally 450 points. We implement a manipulation test based on a local polynomial density estimator technique as proposed by Cattaneo, Jansson and Ma (2018). Results show no evidence of manipulation around the minimum eligibility threshold at a $95 \%$ confidence interval.

For identification, we need variables unrelated to treatment to vary smoothly with respect to the assignment variable around the minimum eligibility cutoff. If the distribution of individual characteristics jump around the treatment threshold we are not able to identify treatment effect. To evaluate if other factors - besides treatment - vary discontinuously around the minimum threshold we evaluate how variables determined at the baseline period vary with the assignment variable. If all other relevant factor vary continuously around the threshold, the value of individual characteristics determined before treatment should not be affected by treatment. We test this assumption implementing a non-parametric Regression Discontinuity for all of the observed covariates in our sample. Table 1.4 presents the results of this exercise. For all baseline variables, there is no significant discontinuity around the minimum performance threshold. 
Table 1.4: Test for Discontinuity in Covariates

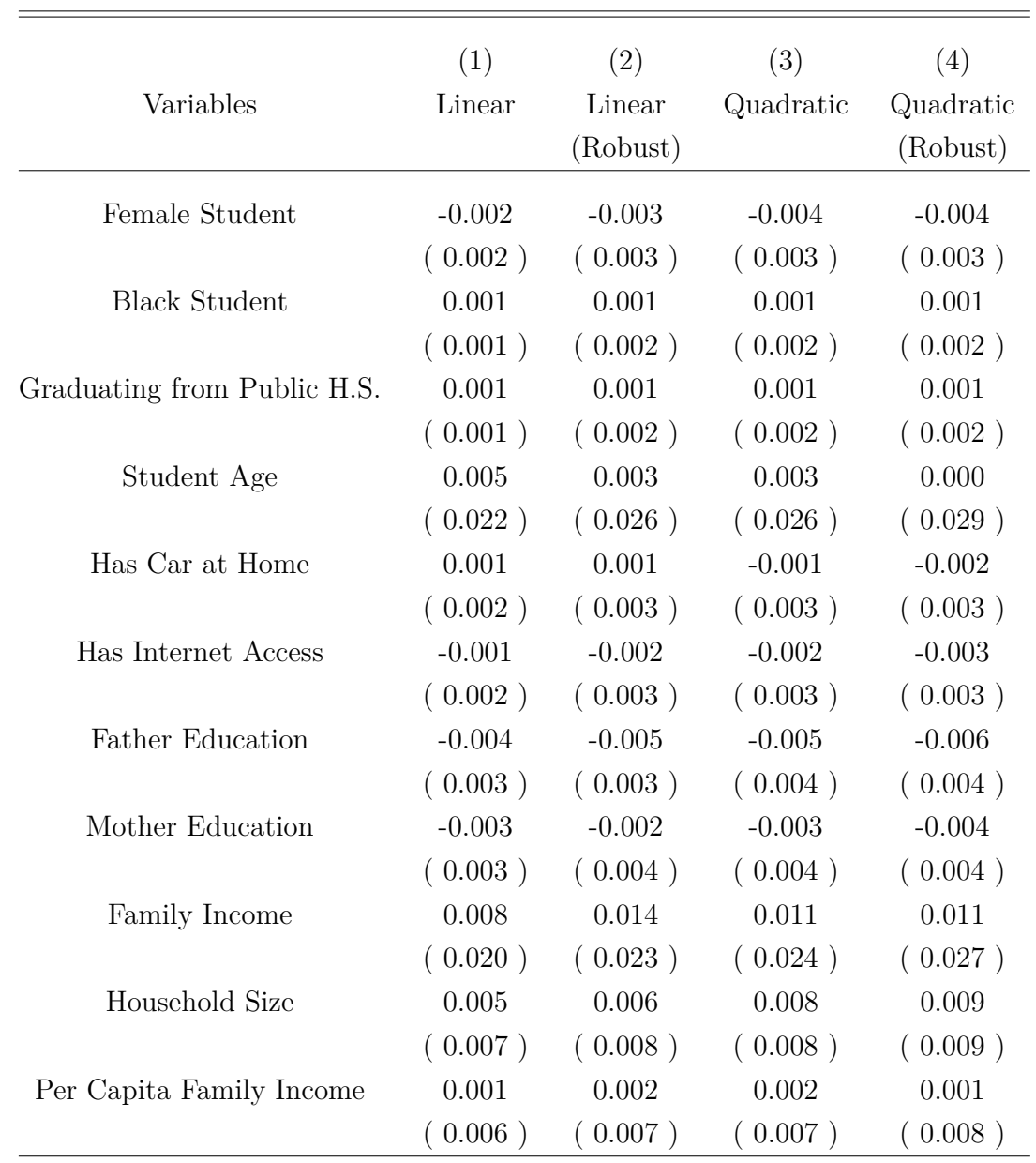

Notes: This table presents the results of a regression discontinuity design on the baseline characteristics of students in our final sample. The final sample includes all students taking the ENEM exam between 2014 and 2015 who are expected to graduate from high school in that same year and who obtained a grade higher than zero on ENEM's essay - 2,876,864 students total. In each row, we test whether crossing the eligibility threshold has a significant impact on a given baseline characteristic. Variables names are given in the first column. We implement a data driven non parametric version of the RD design (Calonico, Cattaneo and Titiunik, 2015). Across columns we assess the robustness of our results using local polynomial estimators of various orders - columns (1) and (2) linear and columns (3) and (4) quadratic - and implementing a bias-corrected robust inference procedure (Calonico, Cattaneo and Titiunik, 2014) —columns (2) and (4). For all baseline variables, there is no significant discontinuity around the minimum performance threshold. 


\section{6 \\ Results}

In this paper, we explore discontinuities in eligibility for subsidies for private higher education to assess how financial aid impact the decisions of low-ability students. As detailed in section 1.3, Brazil's federal government subsidize access to private higher education through two national programs: a student loan program - FIES — and a scholarship program - PROUNI. Both FIES and PROUNI require students to meet a minimum academic performance eligibility requirements. Specifically, students are required to obtain a minimum grade of 450 on the national evaluation for high schools students exam.

Ideally, we would like to estimate how the availability of financial aid impact students' behavior. With the available data, we observe the students who meet the minimum academic performance eligibility requirement. We are not able to identify which students were actually given the opportunity to obtain financial aid. Not every student that reaches the minimum academic performance threshold meets the other requirements for eligibility. First, financial aid is not available for students whose family income crosses a given maximum income threshold. We do not have precise information on students' family income and are, thus, unable to restrict our analysis to students who meet the income eligibility requirement. Second, the supply of financial aid is constrained. Subsidies are distributed at the major-institution level. Students apply for financial aid through an online system that details the number of contracts available at each major-institution. If the number of applicants is higher than the number of available contracts, financial aid is distributed according to students' performance in the national standardized evaluation. Our data provides information on final matches - i.e. we observe if a student enrolled in a given major-institution. We do not have information on students' application process. Thus, we are not able to identify students who did not have access to financial aid due to excess demand in their major-institution of choice.

Given the limitations of our data, we are not able to directly estimate the impact of financial aid availability on students' behavior. Nevertheless, we can uncover the impact of crossing the minimum academic requirement for eligibility. For this reason, we focus on evaluating the impact of eligibility on students' choice. We adopt a very conservative approach and assume that all students who meet the minimum academic performance requirement could be eligible for financial aid. All estimates obtained under this assumption should be considered a lower bound of the actual impact of aid availability. 
Financial Aid. To assure that the eligibility effect we are estimating on students' behavior is related to availability of financial aid, we need to verify if students who do not meet the eligibility requirement are actually constrained in their ability to obtain subsididies from the government. To investigate if this is the case, we analyze how access to financial aid varies around the minimum academic performance threshold for eligibility. We estimate the impact of eligibility - as detailed in section 1.5 - on a variable that indicates if the student enrolled in private higher education with financial aid. Table 1.5 details the results of this test. Crossing the minimum academic performance threshold required for eligibility increases the likelihood of obtaining government sponsored financial aid by 1 percentage point. Considering that only $6.4 \%$ of the students in our sample enroll in higher education with financial aid, this value represents a $15.6 \%$ increase from the sample average. Table 1.5 also reveals that the impact is positive and significant for all forms of financial aid, although stronger for the student loan program-FIES.

To further evaluate if the eligibility requirement is an actually binding constraint, we need to verify if students with grades below the eligibility threshold are able to obtain financial aid. In figure 1.8 we illustrate how access to financial aid varies with ENEM grade. Figure 1.8 reveals that students below the eligibility threshold are highly unlikely to obtain any type of financial aid. ${ }^{46}$ It also shows a clear discontinuity in access to financial aid for students that cross the eligibility threshold.

\footnotetext{
${ }^{46}$ As detailed is section 1.3, FIES applies a few exceptions to the minimum academic performance requirement.
} 
Table 1.5: Eligibility Effect: Financial Aid

\begin{tabular}{cccccc}
\hline \hline Variables & Financial Aid & FIES & PROUNI & $\begin{array}{c}\text { PROUNI } \\
(\text { Full })\end{array}$ & $\begin{array}{c}\text { PROUNI } \\
\text { (Partial) }\end{array}$ \\
\hline Coeff & $0.010 * * *$ & $0.007 * * *$ & $0.003 * * *$ & $0.002 * * *$ & $0.001 * * *$ \\
SE & $(0.000)$ & $(0.000)$ & $(0.000)$ & $(0.000)$ & $(0.000)$ \\
BW & 26.953 & 32.565 & 45.675 & 39.067 & 56.684 \\
Local-Poly. & 1 & 1 & 1 & 1 & 1 \\
N & 727994 & 870383 & 1181442 & 1028368 & 1414984 \\
& & & & & $0.002 * * *$ \\
Coeff & $0.011 * * *$ & $0.007 * * *$ & $0.003 * * *$ & $0.002 * * *$ \\
SE & $(0.000)$ & $(0.000)$ & $(0.000)$ & $(0.000)$ & $(0.000)$ \\
BW & 53.975 & 62.031 & 45.803 & 50.912 & 50.102 \\
Local-Poly. & 2 & 2 & 2 & 2 & 2 \\
N & 1359950 & 1518814 & 1184556 & 1296095 & 1278944 \\
& & & & & \\
Coeff & $0.010 * * *$ & $0.007 * * *$ & $0.003 * * *$ & $0.002 * * *$ & $0.002 * * *$ \\
SE & $(0.001)$ & $(0.000)$ & $(0.000)$ & $(0.000)$ & $(0.000)$ \\
BW & 78.091 & 114.356 & 70.159 & 69.724 & 86.916 \\
Local-Poly. & 3 & 3 & 3 & 3 & 3 \\
$\mathrm{~N}$ & 1790839 & 2223755 & 1663738 & 1656640 & 1916570 \\
\hline
\end{tabular}

Notes: This table presents the results of a regression discontinuity design on variables indicating access to publicly funded subsidies to private higher education. The final sample includes all students taking the ENEM exam between 2014 and 2015 who are expected to graduate from high school in that same year and who obtained a grade higher than zero on ENEM's essay - 2,876,864 students total. In each column, we test whether crossing the eligibility threshold has a significant impact for a given type of subsidy. In column (1) we test the impact on all subsidies available, in column (2) on subsidized credit (FIES), in column (3) on any scholarship (PROUNI), in column (4) on full scholarship and in column (5) on partial scholarship. We implement a data driven non parametric version of the RD design and select optimal bandwidths according to a MSE selection procedure (Calonico, Cattaneo and Titiunik, 2015). We assess the robustness of our results using local polynomial estimators of various orders. Row Coeff. presents the estimate of treatment effect, row S.E. presents standard errors, row B.W. presents the optimal bandwidth, row Local-Poly. presents the order of the local polynomial estimator and row $N$ presents the number of effective observations. $* * *$ represents p-value $<0.01,{ }^{* *}$ p-value $<0.05$, and ${ }^{*}$ p-value $<0.1$. 
Figure 1.8: Eligibility Effect: Access to Subsidies to Private Higher Education (1.8(a)) Subsidized Credit (FIES) (1.8(b)) Scholarsips (PROUNI)
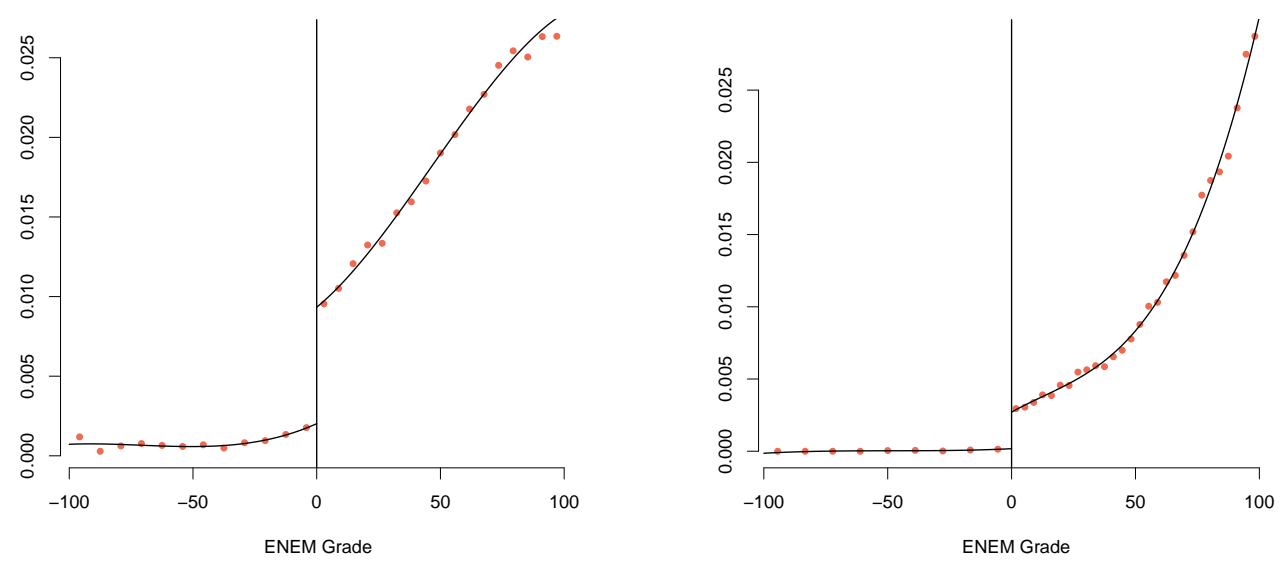

Notes: This figure presents the results of a regression discontinuity design on access to subsidized credit (FIES) - panel (a) — or publicly funded scholarship (PROUNI) panel (b). The final sample includes all students taking the ENEM exam between 2014 and 2015 who are expected to graduate from high school in that same year and who obtained a grade higher than zero on ENEM's essay - 2,876,864 students total. The $\mathrm{x}$-axis represents grade on the national standardized evaluation (ENEM). In this figure, we standardize ENEM grade around the minimum threshold requirement. Thus, the grade zero represents the minimum threshold for eligibility — originally 450 points. The $\mathrm{y}$-axis represents likelihood of obtaining financial aid. We implement a data driven non parametric version of the RD design and select optimal bandwidths according to a MSE optimal selection procedure (Calonico, Cattaneo and Titiunik, 2015). For this figure, we use a linear local polynomial estimator.

Enrollment and Persistence. Next, we estimate the impact of crossing the eligibility threshold on students' decision to enroll and persist in higher education. We implement our regression discontinuity design - as detailed in section 1.5 - on variables indicating if the student enrolled in higher education the year after taking the ENEM exam and if the student remained enrolled one, two, and three years after initial enrollment. We have students' enrollment information for every higher education institution in the country. Thus, we are able to identify the educational decisions of every student who is part of our final sample. In our preferred specification, we implement a data driven regression discontinuity design estimating a local linear regression around the eligibility threshold and selecting optimal bandwidths according to a mean square error (MSE) optimal selection procedure (Calonico, Cattaneo and Titiunik, 2015). Later in this section, we show that our results are not sensitive 
to our choice of specification. Figure 1.9 presents the results of our analysis. Obtaining the minimum grade required for eligibility for financial aid has a positive and significant impact on students' likelihood of enrolling in higher education. Students who cross the eligibility threshold are one percentage point more likely to enroll in higher education. Considering that students just below the eligibility threshold have a $10 \%$ probability of enrolling in higher education eligibility increases enrollment by approximately 10\%. Figure 1.9 also shows that the impact of eligibility on the likelihood of persisting up to three years after initial enrollment is positive and significant. The likelihood of persisting after one, two, and three ${ }^{47}$ years after initial enrollment increases by $0.8,0.6$ and 0.2 percentage points. This decreasing impact with time is consistent with the high dropout rates in the country. ${ }^{48}$ Comparing our results with the average persistence for students just below the threshold reveals that eligibility for financial aid increases persistence by almost $10 \%$ for every year after initial enrollment - $8 \%$ after the first year, $10 \%$ after the second year, and $11 \%$ after the third year. One concern with a policy that subsidizes access to higher education through tuition payments is that students may lack the academic readiness or the financial means for non-tuition costs required to persist. Our result suggests that low-ability students who enroll in higher education due to being eligible to financial aid present the same likelihood of persisting after enrollment as students in the full sample.

${ }^{47}$ As detailed in section 1.4, we only have information on students persistence at the end of the third year for the students who took the ENEM exam in 2014-roughly half of our sample.

${ }^{48}$ In Brazil, only $33 \%$ of students graduate with a bachelor's degree within the expected duration of the program (OECD, 2019). 
Figure 1.9: Eligibility Effect: Persistence by end of year $\mathrm{x}$

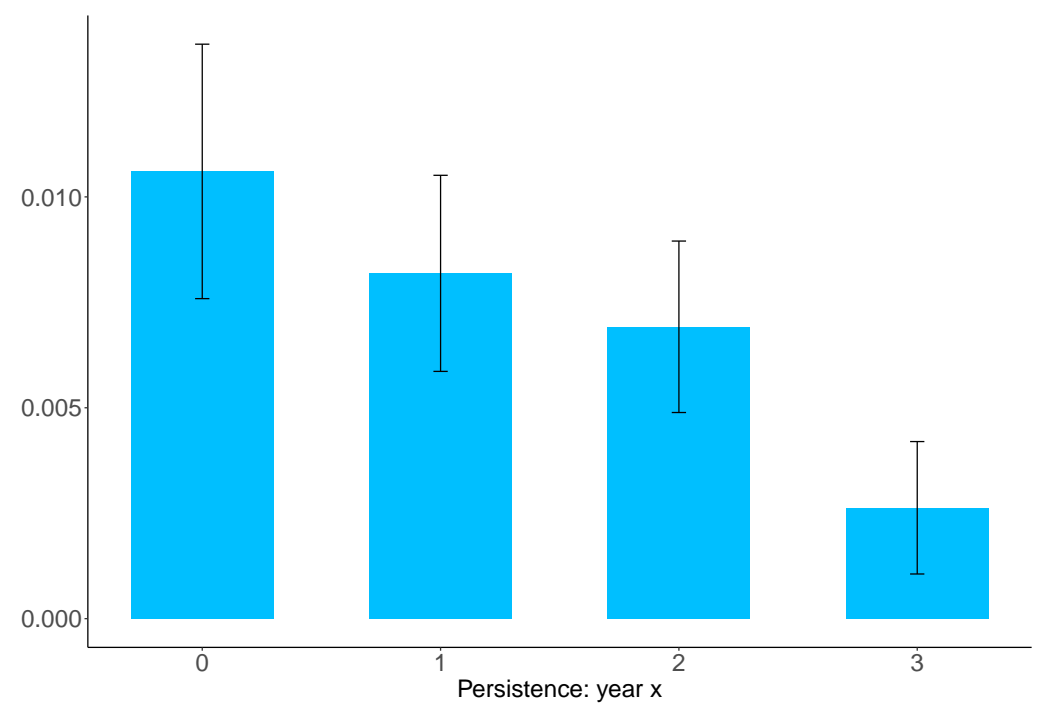

Notes: This figure presents the results of a regression discontinuity design on enrollment after $\mathrm{x}$ years. The final sample includes all students taking the ENEM exam between 2014 and 2015 who are expected to graduate from high school in that same year and who obtained a grade higher than zero on ENEM's essay$2,876,864$ students total. The $\mathrm{x}$-axis represents years after initial enrollment. The $y$-axis represents treatment effect $x$ years after initial enrollment. We implement a data driven non parametric version of the RD design and select optimal bandwidths according to a MSE optimal selection procedure (Calonico, Cattaneo and Titiunik, 2015). For this figure, we use a linear local polynomial estimator.

Figure 1.10 illustrates the relation between ENEM grade and enrollment and attainment around the eligibility threshold. As expected, both enrollment and persistence are increasing with ENEM grade, i.e. higher ability studentsas measured by grade in the national standardized evaluation for high school students - are more likely to enroll and persist in higher education. Figure 1.10 also illustrates the impact of crossing the eligibility threshold on students' behavior, i.e., the positive impact of crossing the eligibility threshold on enrollment and attainment by the end of the first, second, and third year of enrollment. 
Figure 1.10: Eligibility Effect: Enrollment and Persistence

(1.10(a)) Enrollment

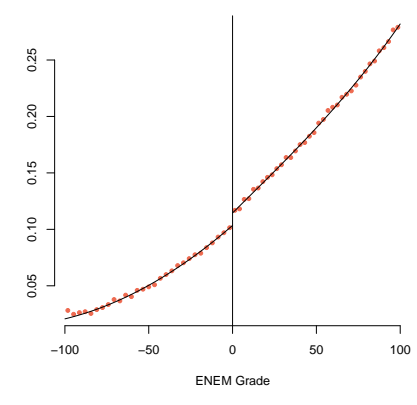

$(1.10(\mathrm{c}))$ Attainment by end of 2nd year

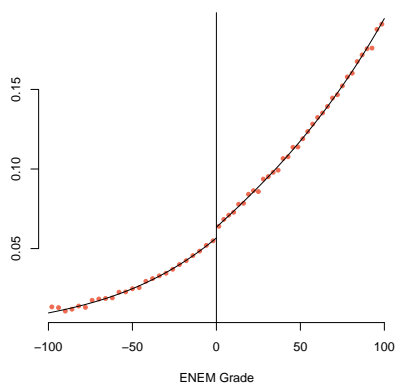

(1.10(b)) Attainment by end of 1st year

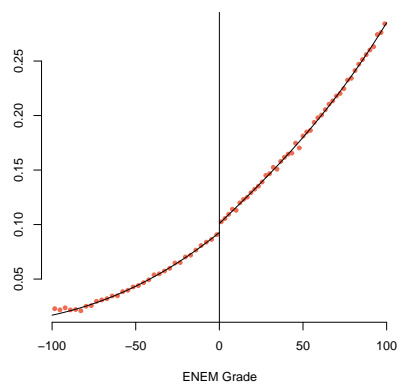

(1.10(d)) Attainment by end of 3rd year

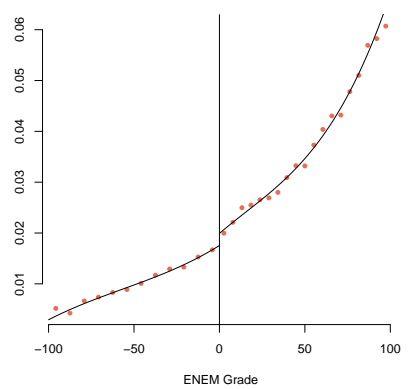

Notes: This figure presents the results of a regression discontinuity design on enrollment and persistence in higher education - including public and private institutions. The final sample includes all students taking the ENEM exam between 2014 and 2015 who are expected to graduate from high school in that same year and who obtained a grade higher than zero on ENEM's essay - 2,876,864 students total. The x-axis represents grade on the national standardized evaluation used to determine eligibility for subsidies to higher education (ENEM). In this figure, we standardize ENEM grade around the minimum threshold requirement. Thus, the grade zero represents the minimum threshold for eligibility - originally 450 points. The y-axis represents likelihood of enrollment (panel (a)) or persistence at the end of the first (panel (b)), second (panel (c)) or third (panel (d)) year. We implement a data driven non parametric version of the RD design and select optimal bandwidths according to a MSE optimal selection procedure (Calonico, Cattaneo and Titiunik, 2015). For this figure, we use a linear local polynomial estimator.

Type of Institution (Public versus Private). Our data contains information on all higher education institutions in the country, including public institutions. We explore these data to evaluate how eligibility for subsidized funding 
for private education affects students' decision to enroll in public higher education. In Brazil, public institutions are tuition-free. In general, public schools are highly selective and deemed as of higher quality and prestige. Nevertheless, there are a few reasons why students might prefer a private institution even when given the opportunity to enroll in a public one. First, admission to higher education in Brazil is determined at the major level. There is high variance on acceptance rates by major, with majors considered of high return or high prestige - such as medicine or engineering - conducting highly selective admission processes. Students - specially lower ability students - often must choose less selective majors if they want to access the subsidies offered to students enrolled in public education. Second, public institutions in the country often do not offer students the same flexibility as private schools. Full time schedules and isolated campuses restrict students' opportunities for professional training while in college. ${ }^{49}$ Faculty and staff strikes are common and students sometimes are not able to precisely predict graduation dates. Public institutions are also often criticized for their inability to adapt to the changing needs of the labor market (World Bank, 2017).

There is a literature exploring how in-kind subsidies can crowd out private spending in education and distort decisions. To access in-kind subsidiesin our framework, tuition-free public institutions - individuals must forgo investment in private education. According to Peltzman (1973), the in-kind nature of this type of subsidy can encourage students to reduce their total investment in education - in terms of quantity or quality. According to this literature, even students who believe private schools are a better fit for them, would be discourage from applying to private schools given the in-kind nature of subsidies for public schools. Students could benefit from a system that gives them the opportunity to choose how to apply subsidies for education by choosing a program that is a better match for their needs or preferences. This system could also encourage competition between higher education institutions increasing the quality of public provision (Long, 2006).

Our setting gives us the opportunity to explore how students react when they are given the opportunity to choose how to apply subsidies between public or private institutions. Students in our sample who obtain the minimum academic performance required for access to financial aid are eligible for subsidies to private higher education. Some of these students may also qualify for public tuition-free higher education. Exploring the impact of crossing the eligibility threshold on the decision to enroll and persist in public and

\footnotetext{
${ }^{49}$ Most internship opportunities in Brazil are year round, with students usually taking a period of the day off from school for professional training.
} 
private institutions shed a light on how in-kind subsidies can impact behavior. Figure 1.11 presents the results of this exercise. Figure 1.11 shows that there is a positive and significant impact of crossing the eligibility threshold on enrollment and persistence in private higher education and a negative and significant impact on enrollment and persistence in public higher education. For students that cross the eligibility threshold, the likelihood of enrolling in private higher education increases $8.5 \%$ from the sample average and the likelihood of enrolling in public higher education decrease $3 \%$ from the sample average. Our results show that students reduce their demand for public tuitionfree institutions when given the opportunity to apply at least part of the subsidies they would obtain from public education into private schools, an outcome consistent with the predictions of the Peltzman's model.

Figure 1.11: Eligibility Effect: Persistence year $\mathrm{x}$

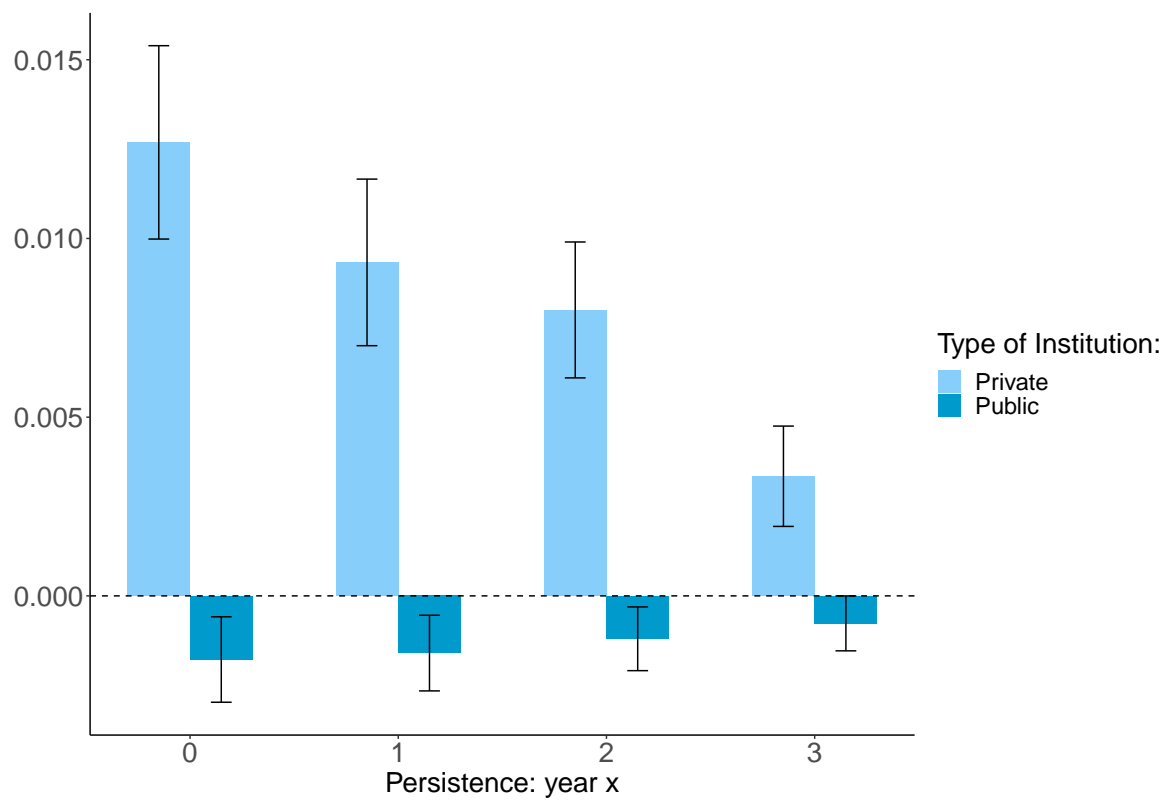

Notes: This figure presents the results of a regression discontinuity design on enrollment after x years on public and private institutions. The final sample includes all students taking the ENEM exam between 2014 and 2015 who are expected to graduate from high school in that same year and who obtained a grade higher than zero on ENEM's essay - 2,876,864 students total. The $\mathrm{x}$-axis represents years after initial enrollment. The y-axis represents treatment effect $\mathrm{x}$ years after initial enrollment. We implement a data driven non parametric version of the RD design and select optimal bandwidths according to a MSE optimal selection procedure (Calonico, Cattaneo and Titiunik, 2015). For this figure, we use a linear local polynomial estimator.

Heterogeneity by Students' Income. Our detailed data and large sample 
size gives us the opportunity to explore how income impact students' response to subsidy eligibility. As detailed in section 1.4, we have access to a self reported categorical variable that indicates the students' family income in terms of different ranges of minimum wages. We use this variable to build an approximate measure of per capita family income. We then use the per capita family income variable to split the sample into different income quintiles. Estimating the eligibility impact for students in different quintiles shows how response to subsidies for private higher education varies with students' income. Figure 1.12 illustrates the likelihood of enrolling in higher education for students from different income quintiles - the gray line - and the differential eligibility impact - the black line. We find that the likelihood of enrolling in higher education is increasing with income. In our sample, students from the highest income quintile are 3.7 times more likely to enroll in higher educationat a $35 \%$ rate - than students in the lowest income quintile. Figure 1.12 also illustrates the eligibility impact for students in different income quintiles. Table 1.6 further details these results. The eligibility effect is positive and significant for all income quintiles except for the highest one. This is expected given that program design restricts access of high income students to subsidies.

A policy that reduces or eliminates credit constraints is expected to have a stronger impact on students more likely to be constrained, i.e., lower income students (Solis, 2017). In our case, the relation between income and eligibility effect is more complex for at least two reasons. First, the government is not only relaxing income constraints, but also subsidizing access to higher education. As our model illustrates, subsidies alter relative prices and the expected net returns from education. If higher income individuals are more likely to be closer to the indifference curve between enrolling or not in higher education, they will be more strongly affected by subsidy eligibility. Second, subsidies are distributed according to students performance in the national evaluation of high school students. If performance is positively correlated with incomewhich is true in our framework - distributing subsidies according to academic performance tends to benefit higher income students.

Our results highlight how the design of the subsidy distribution policy can determine its impact for students from different income levels. Both FIES and PROUNI are not available for students whose family income crosses a given threshold. This design restricts access to subsidies for students at the higher end of the national income distribution. But there is still an income distribution of potential beneficiaries - students whose family income sits below the threshold. A policy that determines subsidy allocation based on academic performance and it is blind to other socioeconomic characteristics is likely to 
distribute larger subsidies to students in the top of the income distribution of potential beneficiaries. Our empirical exercise suggests that this is the case. According to our results, policies that intend to prioritize students in the very lower end of the income distribution must consider income as a relevant factor for the allocation of benefits.

Figure 1.12: Eligibility Effect: Enrollment by Income Quintile

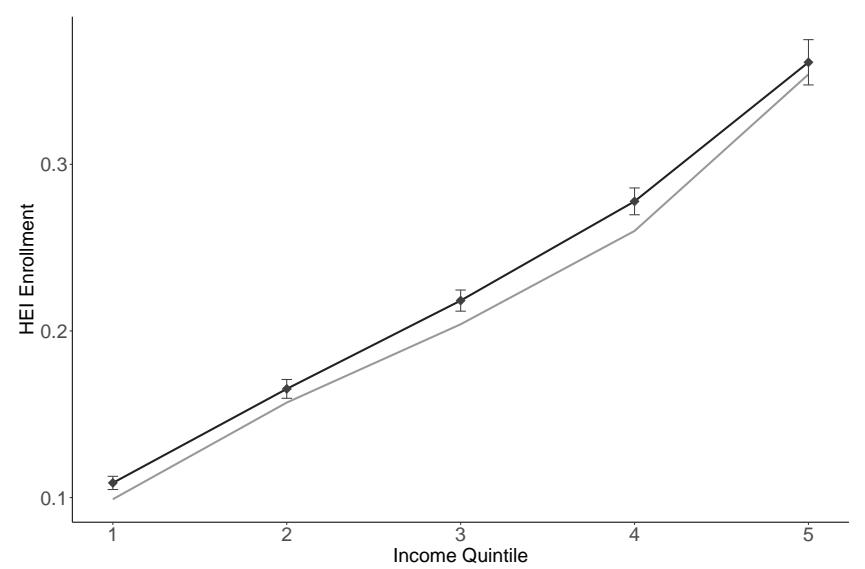

Notes: This figure presents the results of a regression discontinuity design on the enrollment of students with different income levels. We use the per capita income variable - generated as detailed in section 1.4- to split the final sample into different income quintiles. We then estimate a regression discontinuity for each income quintile. The $\mathrm{x}$-axis represents income quintiles, with 1 representing the lowest and 5 the highest. The $y$-axis represents likelihood of enrollment. The gray line represents the average likelihood of enrollment for students in each income quintile. The black line represents the treatment effect - the impact of eligibility for financial aid on enrollment. Confidence intervals are given by the vertical lines. We implement a data driven non parametric version of the RD design and select optimal bandwidths according to a MSE optimal selection procedure (Calonico, Cattaneo and Titiunik, 2015). For this figure, we use a linear local polynomial estimator. 
Table 1.6: Eligibility Effect: Enrollment by Income Quintile

\begin{tabular}{cc}
\hline \hline & $(1)$ \\
Income Quintile & Higher Education \\
\hline Lowest & $0.0098 * * *$ \\
& $(0.002018)$ \\
Second & $0.008224 * * *$ \\
& $(0.002877)$ \\
Third & $0.014217 * * *$ \\
& $(0.003239)$ \\
Fourth & $0.017762 * * *$ \\
& $(0.004105)$ \\
Highest Fifth & 0.007224 \\
& $(0.006933)$ \\
\hline
\end{tabular}

Notes: This table presents the results of a regression discontinuity design on variables indicating enrollment of students from different income levels. We use the per capita income variable - generated as detailed in section 1.4 - to split the final sample into different income quintiles. We then estimate a regression discontinuity for each income quintile. Each row presents results for a different income quintile, as given by first column labels. In each column, we test whether crossing the eligibility threshold has a significant impact on enrollment. Standard errors are presented in parenthesis. We implement a data driven non parametric version of the $\mathrm{RD}$ design and select optimal bandwidths according to a MSE selection procedure (Calonico, Cattaneo and Titiunik, 2015). For this table, we use a linear local polynomial estimator. ${ }^{* * *}$ represents p-value $<0.01,{ }^{* *}$ p-value $<0.05$, and $*$ p-value $<0.1$.

Heterogeneity by Students' Race. Racial disparities in socioeconomic status and access to higher education are widespread in Brazil. Even though blacks comprise almost $10 \%$ of the country's population ${ }^{50}$, they represented only $7.8 \%$ of students newly enrolled in public higher education and 5.02\% of students newly enrolled in private higher education in $2015 .{ }^{51}$ An analysis of the socioeconomic background of students enrolling in higher education with FIES and PROUNI shows that the share of black students enrolled with both programs is similar-around 7 percent - and higher than the average share of black students enrolled in private higher education as a whole. For

\footnotetext{
${ }^{50}$ PNAD Contínua 2019

${ }^{51}$ For information on recent progress and the country's affirmative action policies see Francis and Tannuri-Pianto (2012), Francis-Tan and Tannuri-Pianto (2018), Estevan, Gall and Morin (forthcoming), and Mello (2019)
} 
PROUNI, this result is not surprising. PROUNI explicitly reserves a share of its scholarships to students from underrepresented minorities. FIES, on the other hand, does not consider race as a relevant factor for the distribution of funding. The high number of black students enrolling in higher education with FIES suggests that these students might be more sensitive to the availability of subsidies when deciding to enroll in higher education. We can use our detailed data set to explore if black students react differently to being considered eligible for subsidies.

To evaluate the impact of eligibility for subsidies on black students, we replicate our previous empirical analysis splitting the sample between black and non black students. Table 1.7 presents the results of this exercise. We find that the impact of subsidy eligibility on black students is much stronger than the impact on non black students. Specifically, we find that black students are more than two times more likely to enroll in higher education is response to subsidy eligibility than non black students. We also find no impact on enrollment in public higher education, suggesting that the negative impact on enrollment in public higher education we find for the full sample is driven by the behavior of non white students.

We cannot affirm with certainty if this result reflects the impact of PROUNI's affirmative action arm. Nevertheless, as we will argue later in this section, we have reason to believe that the impact of eligibility on students' decision to enroll in private higher education is driven mainly by FIES. In this case, our result is evidence of a higher sensitivity of black students to subsidy availability. 
Table 1.7: Eligibility Effect: Enrollment of Black Students

\begin{tabular}{cccc}
\hline \hline & $(1)$ & $(2)$ & $(3)$ \\
Student Char & Higher Education & Private H.E. & Public H.E. \\
\hline Non Black Students & $0.009 * * *$ & $0.011 * * *$ & $-0.002 * * *$ \\
& $(0.002)$ & $(0.001)$ & $(0.0006)$ \\
Black Students & $0.020 * * *$ & $0.020 * * *$ & -0.0007 \\
& $(0.004)$ & $(0.003)$ & $(0.001)$ \\
\hline
\end{tabular}

Notes: This table presents the results of a regression discontinuity design on variables indicating enrollment of black and non black students. We use information from the ENEM survey to split the final sample into black and non black students. We then estimate a regression discontinuity for each different set of students. The first two rows present results for non black students. The final two rows present results for black students. In each column, we test whether crossing the eligibility threshold has a significant impact on enrollment. Standard errors are presented in parenthesis. We implement a data driven non parametric version of the RD design and select optimal bandwidths according to a MSE selection procedure (Calonico, Cattaneo and Titiunik, 2015). For this table, we use a linear local polynomial estimator. ${ }^{* * *}$ represents pvalue $<0.01,{ }^{* *} \mathrm{p}$-value $<0.05$, and ${ }^{*} \mathrm{p}$-value $<0.1$.

Our previous analysis on the presence of income heterogeneities in treatment effect reveals that the eligibility impact is increasing with income up to the income level in which students are no longer eligible for subsidies. We argue that this result suggests that a policy that distributes subsidies according to students' academic performance in a framework in which family income and academic readiness are positively correlated is likely to have a stronger impact on students in the higher end of the income distribution of potential participants. We then suggest that a policy intending to prioritize lower income individuals must consider income in their benefit allocation rule. One might wonder what would be the impact of explicitly considering a socioeconomic characteristic highly correlated with income. In our framework, one such characteristics is students' race. In our sample of ENEM takers, black students are over-represented among lower income students $-27 \%$ of black students are in the lowest income quintile and $25 \%$ of black students are in the second lowest income quintile. To explore what would be the impact of targeting black students, we evaluate whether the impact of subsidy eligibility is heterogeneous across income levels when we consider only the sample of black students. Table 1.8 presents the results of this exercise. Our results show 
that the eligibility impact is also increasing with income for the sample of only black students. This result further highlights the importance of policy design for the allocation of subsidies. Not considering income as a factor in the distribution of subsidies to students benefits students in the higher end of the income distribution of eligible students even when we target a population that is over represented among lower income students.

Table 1.8: Eligibility Effect: Enrollment by Income Quintile and Race

\begin{tabular}{ccc} 
Income Quintile & Non-Black Students & Black Students \\
\hline Lowest & $0.0087 * * *$ & $0.0166 * * *$ \\
\multirow{2}{*}{ Second } & $(0.0022)$ & $(0.0059)$ \\
& $0.0062 *$ & $0.0223 * * *$ \\
Third & $(0.0032)$ & $(0.0064)$ \\
& $0.0135 * * *$ & $0.0208 * *$ \\
Fourth & $(0.0034)$ & $(0.0086)$ \\
& $0.0153 * * *$ & $0.0361 * * *$ \\
Highest Fifth & $(0.0045)$ & $(0.0118)$ \\
& 0.0068 & 0.0191 \\
& $(0.0072)$ & $(0.0216)$ \\
\hline
\end{tabular}

Notes: This table presents the results of a regression discontinuity design on variables indicating enrollment of black and non black students from different income levels. We use the per capita income variable - generated as detailed in section 1.4- to split the final sample into different income quintiles and split this sample among black and non black students. We then estimate a regression discontinuity for each income quintile and race. Each row presents results for a different income quintile, as given by first column labels. In each column, we test whether crossing the eligibility threshold has a significant impact on enrollment. Standard errors are presented in parenthesis. I column (1), we estimate the impact on non black students and in column (2) the impact on black students. We implement a data driven non parametric version of the RD design and select optimal bandwidths according to a MSE selection procedure (Calonico, Cattaneo and Titiunik, 2015). For this table, we use a linear local polynomial estimator. ${ }^{* * *}$ represents p-value $<0.01,{ }^{* *}$ p-value $<0.05$, and* $\mathrm{p}$-value $<0.1$.

Quality at the Major-Institution Level. Enrollment and persistence are just one attribute of choice. When deciding how much to invest in higher edu- 
cation, students also choose quality. Our framework allows us to explore how eligibility for financial aid impact students' choice between programs of different quality. As in Londoño-Vélez, Rodríguez and Sánchez (2020), we restrict this analysis to the students who actually enrolled in higher education. The availability of financial aid can impact students investment in quality in nontrivial ways. On one hand, subsidies can reduce the costs associated with higher quality programs allowing students from an underprivileged background to access these programs. On the other, when the supply of aid is constrained - as in our case - students can strategically alter their quality investment decisions to increase their likelihood of obtaining subsidies. We explore how eligibility for financial aid impact students' decision to invest in quality both at the major-institution and at the institution level.

We measure quality through variables that indicate the academic readiness of previous cohorts ${ }^{52}$, the selectivity of the program, the proportion of students who do not persist, the qualifications of the teaching staff, and the proportion of online classes. Table 1.9 presents the impact of being considered eligible for subsidies on quality at the major-institution level. We find that eligibility impacts only two quality variables at the program level, the proportion of full time faculty and the number of applicants per maximum cohort size. Given that eligibility has a negative impact on enrollment in public institutions, the negative impact on full time faculty is not surprising. Public institutions in Brazil are significantly more likely to hire teaching staff as full time faculty. The fact that we explore the impact of aid on students around the eligibility threshold helps explain the negative impact on number of applicants per cohort size. As detailed in section 1.3, for both FIES and PROUNI aid is distributed according to students' ENEM performance. As such, students who just crossed the eligibility are unlikely to qualify for aid on programs with low admission rates. The fact that this impact on selectivity is not consistent with the impact on other quality indicators suggests that eligibility for aid does not consistently impact students investment in quality at the program level.

\footnotetext{
${ }^{52}$ The variable Average ENEM Grade and Minimum ENEM Grade measure the average and minimum ENEM grade of freshman students from the previous cohorts
} 
Table 1.9: Eligibility Effect: Major-Institution Level Characteristics

\begin{tabular}{ccccc}
\hline \hline Variables & $(1)$ & $(2)$ & $(3)$ & $(4)$ \\
& Linear & Linear & Quadratic & Quadratic \\
(Robust) & & 0.366 & 0.396 & 0.539 \\
(Robust)
\end{tabular}

Notes: This table presents the results of a regression discontinuity design on quality at the major-institution level. The sample includes all students in the original sample that enrolled in higher educatio after taking the ENEM exam-610,137 students total. In each row, we test whether crossing the eligibility threshold has a significant impact on a given major-institution characteristic. Variables names are presented in the first column. We implement a data driven non parametric version of the RD design (Calonico, Cattaneo and Titiunik, 2015). Across columns we assess the robustness of our results using local polynomial estimators of various orders - columns (1) and (2) linear and columns (3) and (4) quadratic - and implementing a bias-corrected robust inference procedure (Calonico, Cattaneo and Titiunik, 2014)—columns (2) and (4). *** represents p-value $<0.01,{ }^{* *}$ p-value $<0.05$, and $*$ p-value $<0.1$.

Quality at the Institution Level. Table 1.10 presents the impact of crossing the eligibility threshold on quality at the institution level and tells a different story. According to table 1.10, students eligible for financial aid are more likely to enroll in institutions with lower academic readiness from the previous cohort, lower number of applicants per maximum cohort size and higher dropout rates. Results, thus, suggest that, even though eligibility for financial aid does not affect quality investment at the program level, it has a negative impact on quality at the institution level. This result is consistent with a framework in which students choose less selective institutions - for instance private over 
public schools - to qualify for financial aid to programs they believe are a better fit for their needs.

Table 1.10: Eligibility Effect: Institution Level Characteristics

\begin{tabular}{|c|c|c|c|c|}
\hline & $(1)$ & $(2)$ & $(3)$ & $(4)$ \\
\hline Variables & Linear & $\begin{array}{c}\text { Linear } \\
\text { (Robust) }\end{array}$ & Quadratic & $\begin{array}{l}\text { Quadratic } \\
\text { (Robust) }\end{array}$ \\
\hline Revenue per Student & $\begin{array}{c}6397.640 * \\
(3616.159)\end{array}$ & $\begin{array}{c}7047.910 * \\
(4283.509)\end{array}$ & $\begin{array}{c}6769.186 \\
(4415.925)\end{array}$ & $\begin{array}{c}6737.135 \\
(4799.308)\end{array}$ \\
\hline Tuition Revenue - per Student & $\begin{array}{c}5875.427 * \\
(3415.614)\end{array}$ & $\begin{array}{c}6550.148 \\
(4078.344)\end{array}$ & $\begin{array}{c}6623.224 * \\
(3895.996)\end{array}$ & $\begin{array}{c}6689.125 \\
(4246.479)\end{array}$ \\
\hline Average ENEM Grade & $\begin{array}{c}-1.479 * * * \\
(0.574)\end{array}$ & $\begin{array}{c}-1.597 * * \\
(0.671)\end{array}$ & $\begin{array}{c}-1.634 * * \\
(0.662)\end{array}$ & $\begin{array}{r}-1.724 * * \\
(0.737)\end{array}$ \\
\hline Minimum ENEM Grade & $\begin{array}{c}-1.057 * * * \\
(0.346)\end{array}$ & $\begin{array}{c}-1.072 * * * \\
(0.406)\end{array}$ & $\begin{array}{c}-1.169 * * \\
(0.462)\end{array}$ & $\begin{array}{c}-1.251 * * \\
(0.517)\end{array}$ \\
\hline Applicants per Max. Cohort Size & $\begin{array}{c}-0.290 * * * \\
(0.059)\end{array}$ & $\begin{array}{c}-0.306 * * * \\
(0.068)\end{array}$ & $\begin{array}{c}-0.305 * * * \\
(0.067)\end{array}$ & $\begin{array}{c}-0.317 * * * \\
(0.074)\end{array}$ \\
\hline Dropout Rate & $\begin{array}{c}0.003 * \\
(0.002)\end{array}$ & $\begin{array}{c}0.004 * \\
(0.002)\end{array}$ & $\begin{array}{l}0.004 * * \\
(0.002)\end{array}$ & $\begin{array}{l}0.005 * * \\
(0.002)\end{array}$ \\
\hline On leave Rate & $\begin{array}{c}0.003 \\
(0.002)\end{array}$ & $\begin{array}{c}0.003 \\
(0.003)\end{array}$ & $\begin{array}{c}0.003 \\
(0.003)\end{array}$ & $\begin{array}{c}0.003 \\
(0.003)\end{array}$ \\
\hline
\end{tabular}

Notes: This table presents the results of a regression discontinuity design on quality at the institution level. The sample includes all students in the original sample that enrolled in higher education after taking the ENEM exam-610,137 students total. In each row, we test whether crossing the eligibility threshold has a significant impact on a given institution characteristic. Variables names are presented in the first column. We implement a data driven non parametric version of the RD design (Calonico, Cattaneo and Titiunik, 2015). Across columns we assess the robustness of our results using local polynomial estimators of various orders - columns (1) and (2) linear and columns (3) and (4) quadratic - and implementing a bias-corrected robust inference procedure (Calonico, Cattaneo and Titiunik, 2014) — columns (2) and (4). ${ }^{* * *}$ represents p-value $<0.01,{ }^{* *}$ p-value $<0.05$, and* p-value $<0.1$.

Major Choice. It is not clear how the decision to enroll in programs of equivalent quality offered by lower quality institutions impacts students' skill formation while in college and their expected outcomes in the labor market. The literature shows that prestige at the institution level impacts labor market outcomes (MacLeod and Urquiola (2015), MacLeod et al. (2017)). It also shows that investment decisions at the program level, for instance, choice of major impacts returns to education (Arcidiacono (2004), Hastings, Neilson and Zimmerman (2013)). To investigate if eligibility for aid impacts students' choice 
between different majors, we replicate our regression discontinuity designas detailed in section 1.5- on variables indicating if the student enrolled in a particular major. Table 1.11 presents the results of this exercise. For all specifications considered, eligibility for aid has a positive and significant impact on the likelihood of students choosing three majors: Engineering, Agricultural Sciences and General Health. ${ }^{53}$ As we detail in chapter 2 of this dissertation, the tuition costs of these majors are higher than average with Engineering and Agricultural Sciences majors offering higher than average labor market returns for both young and older professionals. These three majors also offer specific market-oriented training and a more straightforward path for a profession. Results, thus, suggests that, in a framework in which students choose major during the application process, students eligible for financial aid tend to prioritize technical majors with higher costs and return over institution's prestige.

${ }^{53}$ General Health includes all health majors except for Medicine and Odontology. 
Table 1.11: Eligibility Effect: Major Choice

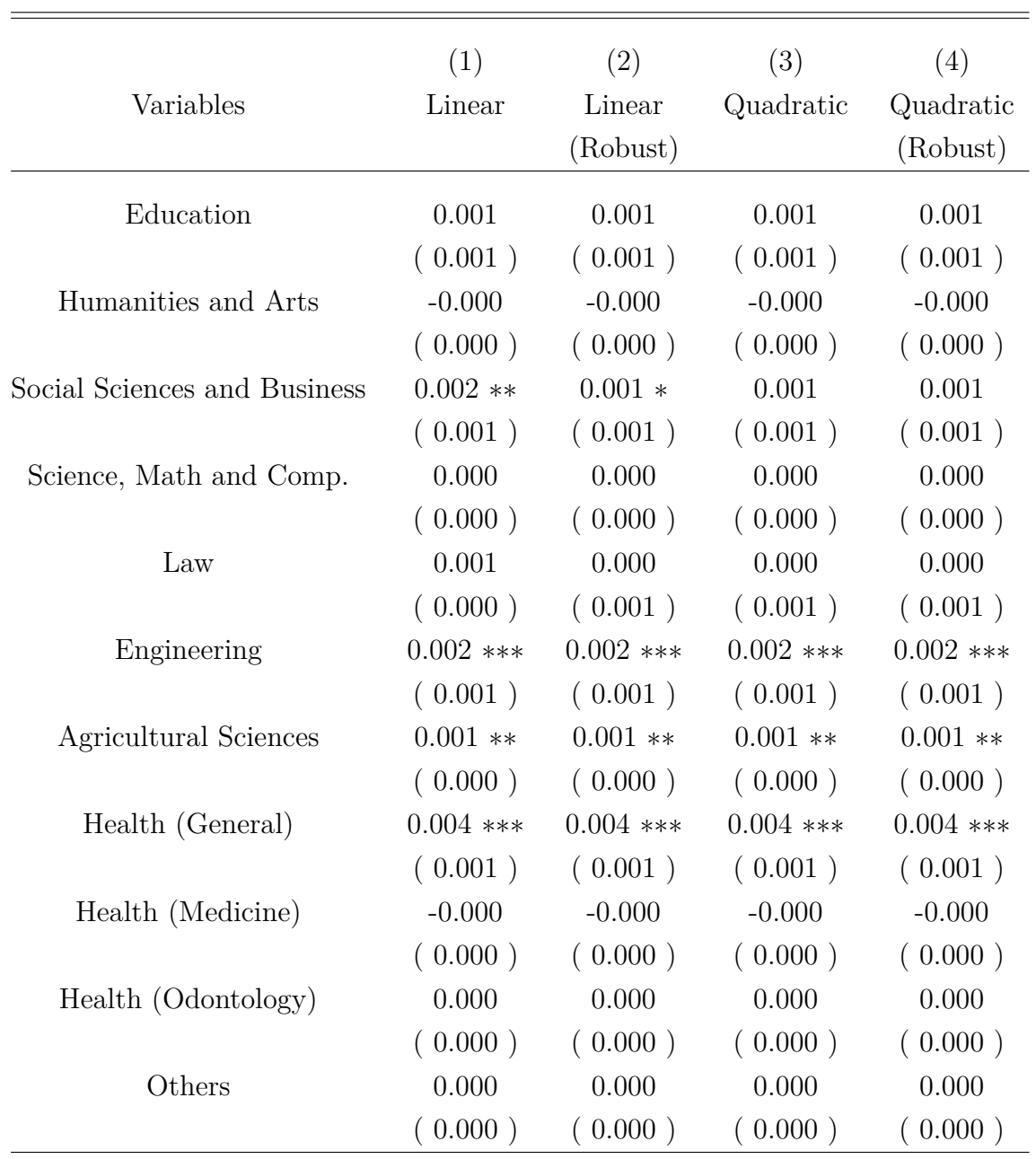

Notes: This table presents the results of a regression discontinuity design on students choice of major. The final sample includes all students taking the ENEM exam between 2014 and 2015 who are expected to graduate from high school in that same year and who obtained a grade higher than zero on ENEM's essay—2,876,864 students total. In each row, we test whether crossing the eligibility threshold has a significant impact on the choice of enrolling in a given major. Major names are presented in the first column. We implement a data driven non parametric version of the RD design (Calonico, Cattaneo and Titiunik, 2015). Across columns we assess the robustness of our results using local polynomial estimators of various orders - columns (1) and (2) linear and columns (3) and (4) quadratic - and implementing a bias-corrected robust inference procedure (Calonico, Cattaneo and Titiunik, 2014) — columns (2) and (4). *** represents p-value $<0.01,{ }^{* *}$ p-value $<0.05$, and* p-value $<0.1$.

Discussion: FIES or PROUNI. In all the results presented so far, we evaluated the impact of eligibility for subsidies for higher education making no distinction between the federal credit - FIES - and the federal scholarship 
program-PROUNI. We adopt this strategy, because both programs consider the same academic readiness threshold for eligibility and we are not able to separately identify the impact of each program around the eligibility threshold. As we detail in section 1.3, there are significant differences between the two programs and it is important to understand by how much each program drives our results. Our empirical design does not allow us to answer this question with certainty, but we can explore the available data and the differences in design between the two programs to shed some clarity on this point.

We start by evaluating the likelihood of obtaining subsidies from both PROUNI and FIES for those students most likely to be affected by the minimum academic ability requirement, i.e. students with academic performance within a certain range of the eligibility threshold. We use our data to identify the share of students around the eligibility threshold that enroll in higher education with PROUNI or FIES. Table 1.12 presents the proportion of students within a given range of the eligibility threshold that enroll in private higher education and the proportion that enroll with FIES or PROUNI. Results reveal that for the sample of students most likely to be affected by the eligibility threshold, FIES is a much more relevant source of subsidies for higher education. Of the students with ENEM grade within 25 points of the eligibility threshold - i.e. students whit grades higher than 425 and lower than 475$23 \%$ of those who enrolled in private higher education enrolled with FIES, while only $4 \%$ enrolled with PROUNI. When we increase the range around the threshold the proportion of students enrolling with PROUNI increases, but even for a range as high as 100 points - 1.3 times the standard deviation in average grade - the proportion of students enrolling in private higher education with FIES - 26\% - is significantly higher than the proportion enrolling with PROUNI-9\%.

This results is not surprising. As detailed in section 1.3, PROUNI is a much more generous program from the students' perspective. As such, demand for PROUNI is stronger among students eligible for both programs and students enrolling in higher education with PROUNI tend to perform better at ENEM than students enrolling with FIES. Since the eligibility threshold represents a value in the lower end of ENEM grade distribution, it is unlikely that students whose ENEM performance is around this threshold would qualify for a large number of PROUNI scholarships. This results suggests that FIES is a more relevant program for the students in our analysis and that most of our findings are driven by the decisions and behavior of students enrolling in higher education with FIES. 
Table 1.12: Descriptive Statistics: Students' Choice Around the Eligibility Threshold

\begin{tabular}{ccccc}
\hline \hline & $(1)$ & $(2)$ & $(3)$ & $(4)$ \\
Variable & {$[-25$,} & {$[-50$,} & {$[-75$,} & {$[-100$,} \\
& $+25]$ & $+50]$ & $+75]$ & $+100]$ \\
\hline Proportion that Enroll in Private H.E. & 0.099 & 0.107 & 0.116 & 0.126 \\
Proportion that Enroll with FIES & 0.023 & 0.026 & 0.030 & 0.033 \\
Proportion that Enroll with PROUNI & 0.004 & 0.005 & 0.008 & 0.012 \\
Observations & 676,908 & $1,276,294$ & $1,742,644$ & $2,076,845$ \\
\hline
\end{tabular}

Notes: This table presents descriptive information on students' choice for students who obtained a ENEM grade within a given range from the eligibility threshold. In the first row, we present the proportion of students that enroll in private higher education. In the second row, proportion of students that enroll in private higher education with FIES funding, and in the third row, proportion of students that enroll in private higher education with a PROUNI scholarship. Different ranges from the eligibility threshold are presented in each column. In column (1), we have students who obtained a grade less than 25 points higher or lower than the eligibility threshold grade -450 . In column (2), we have students who obtained a grade 50 points higher or lower. In column (3) students who obtained a grade 75 points higher or lower, and, finally in column (4) students who obtained a grade 100 points higher or lower than the eligibility threshold.

To further evaluate how reasonable this conclusion is, we perform one extra exercise that explores the differences in FIES and PROUNI's rules. As detailed in section 1.3, PROUNI is more restrictive in terms of what type of students can be considered eligible for the program. In particular, only students who graduated from a public high school or from a private high school with full scholarship can apply for PROUNI. ${ }^{54}$ From ENEM data, we can observe which students graduated from public and which students graduated from private schools. We use this information and replicate our empirical design considering two separate samples, one only with students who graduated from public high schools and the other considering only students who graduated from private high schools. Table 1.13 presents the results from this exercise. According to these results, the eligibility effect on enrollment in private higher education for students eligible for PROUNI - students who graduated from public high schools - is very similar to the eligibility effect on students not eligible for PROUNI. Specifically, students who graduated from a public high

${ }^{54} \mathrm{We}$ do not consider separately students graduating from private schools with full scholarship because they represent a very small share of students in our data-less than $3 \%$ - and because these students are usually in the higher end of the ability distribution. 
school are only $9 \%$ more likely to enroll in private higher education in response to crossing the academic eligibility threshold for PROUNI and FIES than students graduating from private high schools. These results suggest that the main driver for results that measure the eligibility effect on students decision to enroll in private higher education is students' reaction to FIES eligibility.

Effects are different for these two groups of students when we consider enrollment in public higher education as the output variable. The negative eligibility effect on enrollment in public higher education is concentrated among students who graduated from public high schools. Considering that students who graduated from public high schools are eligible to both PROUNI and FIES, we cannot separately identify the impact of these two programs for decisions related to enrollment in public institutions.

Table 1.13: Eligibility Effect: Students Graduating from Public or Private High Schools

(1)

\begin{tabular}{cccc} 
Student Characteristic & Higher Education & Private H.E. & Public H.E. \\
\hline Graduates from Public High Schools & $0.0113 * * *$ & $0.0130 * * *$ & $-0.0021 * * *$ \\
& $(0.0014)$ & $(0.0014)$ & $(0.0007)$ \\
Graduates from Private High Schools & $0.0123 * *$ & $0.0119 * *$ & 0.0000 \\
& $(0.0060)$ & $(0.0060)$ & $(0.0015)$
\end{tabular}

Notes: This table presents the results of a regression discontinuity design on variables indicating enrollment of students who graduated from public and private high schools. We use information from the ENEM survey to split the final sample into students who graduated from public and private high schools. We then estimate a regression discontinuity for each different set of students. The first two rows present results for students who graduated from public high schools. The final two rows present results for students who graduated from private high schools. In each column, we test whether crossing the eligibility threshold has a significant impact on enrollment. Standard errors are presented in parenthesis. We implement a data driven non parametric version of the RD design and select optimal bandwidths according to a MSE selection procedure (Calonico, Cattaneo and Titiunik, 2015). For this table, we use a linear local polynomial estimator. $^{* * *}$ represents $\mathrm{p}$-value $<0.01,{ }^{* *}$ p-value $<0.05$, and ${ }^{*} \mathrm{p}$-value $<0.1$.

Robustness Analysis. For all results presented in this section, we estimate treatment effect using a data driven non parametric regression discontinuity design. In our preferred specification, we estimate a local linear regression on a small neighborhood around the minimum eligibility threshold. 
We determine this neighborhood by employing a mean square error (MSE) optimal bandwidth selection procedure as developed by Calonico, Cattaneo and Titiunik (2015). One of the main weaknesses of an RD design is that choice of specification can have a significant influence on results. We assess the robustness of our results replicating the analysis considering higher order local polynomial estimators and implementing a bias-corrected robust inference procedure (Calonico, Cattaneo and Titiunik, 2014)). Tables 6, 7, 8, and 9 in section A.1 detail this exercise and show that our results are significantly robust to different choices of specification. The estimates on the impact on enrollment and persistence up to two years remain stable across all different specifications. Results on the impact on persistence after three years are stable for all specifications except one - results are sensitive to estimating a cubic local regression. Considering that we only observe persistence after three years for students who took the ENEM exam in 2014 - roughly half of our sample - it is not surprising that we are not able to estimate the impact on this variable with the same confidence we have for other variables for more restrictive specifications.

Given our large sample size and the fact that our eligibility threshold is defined at a number multiple of 10 , one might worry that our estimates represent some sort of round number bias unrelated to financial aid eligibility. To investigate if this is the case, we perform a placebo exercise. We define a set of placebo thresholds ${ }^{55}$ and test the impact of crossing these thresholds on enrollment. Tables 10, 11, 12 in section A.1 present the results of this exercise. For all placebo thresholds except one-500-we find no significant impact on enrollment. Even in the case we find a significant impact, the estimates are not stable across specifications. These findings corroborate the robustness of our results.

\section{7 \\ Discussion}

In this paper, we explore discontinuities in access to subsidies for private higher education to investigate how eligibility for financial aid impact students' human capital investment decisions. We find that eligibility for financial aid has a positive and significant impact on students' likelihood to enroll in higher education and to persist up to three years after initial enrollment. We also conclude that the availability of subsidies for private education reduce students' enrollment in public tuition-free institutions, a finding consistent with the predictions of Peltzman (1973). Exploring heterogeneities by students'

\footnotetext{
${ }^{55}$ We consider the following placebo thresholds: 455, 460, 475, 500, 525, 550, 600, and 700
} 
background, we show that response to subsidies is increasing with income up to the income level in which students are not eligible for aid. This is consistent with the model we present in section 1.2 and with the allocation policy of the programs we evaluate. We also find that the eligibility effects is stronger for black students and that treatment effect is increasing with income also for the sample of only black students. We find that eligibility for financial aid does not influence investment in quality at the major level but decrease investment in quality at the institution level. Finally, we show that students eligible for aid are more likely to choose technical majors with higher than average labor market returns. In this section, we discuss these findings.

Our results suggests that there are inefficiencies in the distributions of subsidies for higher education in Brazil. Event though public institutions in Brazil play a leading role in funding and stimulating research ${ }^{56}$, not much evidence is available on the relative effectiveness of teaching at public institutions in Brazil. Students graduating from public institutions tend to outperform their peers on Brazil's national evaluation for graduating students (ENADE), but there is no evidence that public institutions in Brazil add more value and this performance difference does not necessarily holds once you control for the ability differential of incoming students (World Bank, 2017). Public institutions also seem slower to adapt to students and labor market changing needs. Between 2010 and 2017, there was a relatively homogeneous increase on the size of incoming cohorts by different fields of knowledge at public institution - between $32 \%$ and $55 \%$. For private institutions, the increase on the size of incoming cohorts was heterogeneous across fields. For higher cost or return fields, the size of incoming cohort almost doubled - an increase of $145 \%$ for health, $197 \%$ for agricultural sciences, and $254 \%$ for engineering. For other fields, like humanities, education, and social sciences the income cohort increased by much less-between $45 \%$ and $88 \%$. More research is needed to understand the role public institutions play in contributing with skill formation in Brazil and how to increase their effectiveness.

One of the concerns raised on policies that subsidize access to private education is that they might encourage enrollment in low-quality institutions that do not adequately prepare students to succeed in the labor market. Students who graduate from insufficient quality institutions might not fully access the benefits of higher education. Rau, Rojas and Urzúa (2013) find that a federal student credit program in Chile had a negative impact on the labor market wages of participants. They argue that program design incentivized

\footnotetext{
${ }^{56}$ According to 2017 Higher Education Census, $46 \%$ of lecturers in public institutions also worked doing research, while only $17 \%$ of lecturers in private institutions also worked as researchers.
} 
institutions to retain students at the expense of quality of education. This risk might be even higher when aid is used to fund enrollment in for profit institutions. Cellini and Koedel (2017) shows that students graduating from for profit institutions are more likely to borrow and default and have similar or worse labor market outcomes than comparable students from public colleges. For profit institutions enroll a large share of higher education students in Brazil and this number has increased in the past few years with the growth in public subsidies for private education. ${ }^{57}$ To minimize risks, policies must be designed to incentivize quality enhancement investments. A transparent and effective quality assurance system must also be in place.

More evidence is needed to understand the impact of Brazil's subsidy policy on labor market outcomes. In the next few years, as the affected cohorts enter the labor market, we will be able to directly evaluate the impact of these policies and their cost effectiveness. Some of the regulations in effect can help mitigate the risk that these subsidy policies will have a negative impact. Brazil has a well-established system to monitor, assess, and regulate the quality of private and public higher education institutions. This system is able to impede fraudulent or grossly unqualified institutions from entering the higher education market (OECD, 2018). Federal subsidies for private higher education are also only available to students enrolled in major-institutions that meet minimum quality requirements. Maintaining and improving the quality evaluation assessment system in Brazil as well as continuing to consider quality for eligibility seems to be important. Some alternative policies are tying the availability of subsidies to the financial outcomes of students from previous cohorts (Beyer et al., 2015) ${ }^{58}$ or creating a system that inform students of graduation rates, salary and unemployment rates of recent graduates at the major-institution level (Hastings, Neilson and Zimmerman (2015), OECD (2018)).

\section{8}

\section{Conclusion}

In this paper, we explore a discontinuity in access to subsidies for private higher education in Brazil to investigate the impact of eligibility for subsidies on students' educational decisions. In Brazil, students must obtain a minimum grade of 450 at the national standardized evaluation for high school students to be considered eligible for subsidies for private higher education. This eligibility

\footnotetext{
${ }^{57}$ In 2017 , approximately $57 \%$ of the students enrolled in private higher education in Brazil were enrolled in a for profit institutions. In 2010, this share was of $43 \%$.

${ }^{58}$ In the 2017 FIES reform the government included a risk sharing scheme in which higher education institutions would be partially responsible students' default.
} 
requirement affects students at the lower end of the ability distribution. We, first, develop a model to understand how different policies for higher education funding impact the behavior of students with different ability levels. Our model indicates that even lower ability students could respond positively to policies that subsidize, at least in part, the costs of higher education.

Exploring the impact of eligibility on students' decision to enroll in higher education, we find that that eligibility for financial aid increases students' likelihood of enrolling in higher education by $10 \%$. We also find that eligibility increases persistence up to three years after initial enrollment. Specifically, we find that eligibility for financial aid increases persistence by almost $10 \%$ for every year after initial enrollment - $8 \%$ after the first year, $10 \%$ after the second year, and $11 \%$ after the third year.

Evaluating how eligibility for subsidies to private education impact enrollment in public tuition-free schools, we find that eligibility for subsidies for private education decrease enrollment in public higher education institutions. Peltzman (1973) argues that in-kind subsidies to education could distort students' decision and reduce productive investment in private education. Our results are consistent with Peltzman's model.

To evaluate if students' background impact their response to subsidy eligibility we test for the presence of heterogeneous impact by family income. We split our sample into five different income cohorts and estimate eligibility impact for each cohort. Our results show that eligibility effect is increasing with income up to the income level in which students are restricted from applying to financial aid. We also explore heterogeneities in the response of black students and find that the eligibility effect is stronger for black students.

We also evaluate the impact of eligibility for aid on the decision to invest in quality. In our framework, understanding the impact of subsidies on quality is crucial. The supply of financial aid is constrained and students could, in theory, strategically choose less selective major-institutions to increase their chance of obtaining aid. We find that eligibility for financial aid does not have a clear impact on quality investment at the major level. We do find a negative impact on quality investment at the institutions level.

Our results are consistent with a framework in which students choose lower quality institutions to qualify for aid for enrollment in programs they consider a better match given their preferences. To investigate how aid impact choice between different programs we replicate our analysis to consider students decision between different majors. ${ }^{59}$ Our results indicate that students eligible

\footnotetext{
${ }^{59}$ In Brazil, students choose major during the application process.
} 
for aid increase their likelihood of choosing technical majors with higher than average enrollment costs or labor market returns. 


\section{2}

\section{The Effect of Credit Constraints on Major Choice: Evidence from a Large Scale Student Loan Program in Brazil}

\section{1 \\ Introduction}

Credit markets for investment in education are problematic (Becker, 1975). As such, credit constraints often impact students decision to enroll or not in higher education (Kane (2006), Belley and Lochner (2007), Lochner and Monge-Naranjo (2011), Solis (2017)). Enrolling is just one component of the decision to invest in higher education. When making human capital investment decisions, students must choose also how much to invest in terms of time enrolled, quality and type of investment. There is evidence that returns to higher education vary greatly across majors or fields of knowledge (Arcidiacono (2004), Hastings, Neilson and Zimmerman (2013)). Despite this great variability, much remains unknown about the factors that determine students' choice between different majors. Much also remains unknown on the constraints students face when choosing a major. In countries like Brazil-in which students choose major during the college application process and the costs of higher education vary at the major-institution level-the inability to obtain student loans might impact major choice. In this paper, we develop a structural model to investigate the factors that have a greater impact on choice of major. We then explore the expansion of a government funded student credit program in Brazil to evaluate how the availability of credit impacts major choice.

We start by documenting the evidence on the costs and returns to major choice in Brazil. Using an unique data set with information on tuition costs at the major-institution level, we show that there is, in fact, great variability in the costs of higher education at the major-institution level. Tuition costs vary significantly at the major level and this variability is consistent between different institutions - i.e. the same set of majors tend to be more or less expensive than average across institutions. Using evidence from the national registry of employees in the formal sector (RAIS), we show that there is also large variability in the wages from occupations more often associated with 
different majors. Finally, we show that there is a strong correlation between the average tuition and the average wage from a major at the metropolitan area (or state) level. This evidence suggests that students intending to enroll in higher return majors in Brazil often have to pay higher tuition costs.

Before 2010, Brazil had a very limited supply of credit for students interested in financing their education. The government offered a limited number of loans through a federal credit program and private credit markets for education were considerably small. In 2010, the government implemented an unexpected reform that greatly expanded its credit program. Brazil's federal student credit program-FIES - offers loans to students enrolled in private higher education institutions. Loans can be used to cover tuition in eligible major-institutions. We explore this large expansion and the eligibility criteria at the major-institution level - through a difference-in-differences strategyto evaluate if credit availability influences demand for higher education. Our results show that there is a positive and significant impact of credit availability on demand for private higher education. This analysis compares the demand trends of eligible and ineligible major-institutions and, thus, can inform on students susceptibility to respond to credit availability. It cannot be used to understand the impact of credit on the overall demand for private higher education or on the market share of different majors.

To understand the mechanisms through which credit availability can impact major choice, we develop a dynamic model of human capital investment. In this model, individuals enrolling in higher education must choose a major in the first period. In the following periods, individuals access labor markets. Wages are determined by first period human capital investment decision. In our model, we include the possibility that credit may not be readily available in the first period - i.e. that individuals might be constrained in their ability to finance educational decisions through borrowing. When credit is constrained, individuals can only enroll at a major they can afford with their first period income. In this framework, lower income individuals might be constrained in their ability to choose high-cost majors. A policy that loosens constraints to credit can thus impact the distribution of major choice across different income cohorts and impact their lifetime expected earnings.

To empirically estimate the determinants of major choice and the impact of credit availability on choice of major, we adapt our model to fit the framework of the classic discrete choice model with random parameters from the Industrial Organization literature (Berry, Levinsohn and Pakes, 1995). In our model, students must choose only one major between the options available in a given market. Students can also choose not to enroll in private higher 
education - the outside option. Students derive utility from the future returns associated with the investment in higher education. Students also derive utility from just being enrolled in higher education - i.e. we assume that there is a consumption value associated with higher education (Gullason (1989), Gong et al. (2019)). The costs of enrolling in higher education are represented by tuition costs. Costs and returns to higher education vary at the majormarket level. We include in this model the possibility that students might be constrained in their choice between different majors due to their inability to obtain student credit. In our empirical exercise, we assume that individuals making human capital decisions before the expansion of the government credit program were credit constrained while individuals making decisions after that period were not.

We estimate this demand model using data on costs, wages, and quality measures of different majors at the market level. We find that demand is significantly impacted by both the costs and returns to higher education. We also show that family income influences the sensitivity of demand to price changes, with lower income individuals being more sensitive to cost changes than higher income individuals. We use our estimated parameters to investigate how the availability of credit impacts market composition. We show that the expansion of the government credit program increased enrollment in private higher education as whole and had a higher than average impact on majors considered high cost and high return. Our results suggest that, in a frameworks in which costs vary at the major level, credit constraints play a significant role in determining the choices between different majors.

The rest of this paper is organized follows. In section 2.2, we describe our data and present some descriptive statistics. Section 2.3 introduces Brazil's federal government student loan program-FIES - and details its 2010 expansion. In section 2.4, we present the results of a difference-in-differences strategy that explores the sudden expansion of FIES and the rules that determine eligibility at the major-institution level to evaluate the impact of credit availability on enrollment. In section 2.5, we develop a dynamic model of major choice and in section 2.6 we adapt this model to obtain a tractable version that can be used to estimate demand parameters through a BLP (Berry, Levinsohn and Pakes, 1995). Section 2.7 presents the results of the BLP estimation. In section 2.8, we conclude this paper.

Related Literature. It is hard to establish well functioning private credit markets for investment in education. Human capital cannot be directly pledged as collateral. Return on investment is not fully observable and depends on borrowers unobserved talent and effort (Becker, 1975). If educational credit 
is constrained, students who cannot afford the costs of education might find themselves incapable of making profitable human capital investment decisions. Investment in human capital and skill formation are a crucial feature of any effective development strategy, as differences in human capital are related to differences in individual income both between and within countries (Hanushek and Woessmann (2008), Acemoglu and Dell (2010), Gennaioli et al. (2013)). To avoid under-investment, governments often intervene in credit markets for higher education. These policies are implemented under the argument that credit constraints do exist for investment in higher education and that they must be loosened in order to increase enrollment rates and guarantee a more equitable access to higher education.

There is an extensive empirical literature debating whether underdeveloped credit markets for higher education actually constrain behavior. We observe a positive relation between family income and enrollment in higher education for several countries. There is no consensus on whether short or long term credit constraints are the cause for this income gradient. Long term constraints can hinder parents from investing in the cognitive and non cognitive abilities of their children from early childhood (Cameron and Heckman (1998), Keane and Wolpin (2001), Carneiro and Heckman (2002)). Expanding access to higher education credit when long-term constraints are the cause for underinvestment would have no significant impact on enrollment. Short term constraints, on the other hand, represent students inability to obtain credit to fund their preferred educational investment decisions. Some recent studies find evidence of short term credit constraints in the U.S. and other countries (Kane (2006), Belley and Lochner (2007), Lochner and Monge-Naranjo (2011), Kaufmann (2014), Solis (2017)).

Despite evidence showing that major choice can have a substantial impact on students labor market outcomes, the literature on the determinants of major choice is still inconclusive. Hastings et al. (2016) use a large-scale survey of Chilean college applicants and students to explore the way students form beliefs about earnings and cost outcomes at different institutions and majors and shows the importance of these beliefs for major choice and persistence. Wiswall and Zafar (2015) estimate a structural life cycle model of college major and find a relatively low sensitivity to changes in earnings. Montmarquette, Cannings and Mahseredjian (2002), on the other hand, conclude that choice of college concentration depends decisively on expected earnings in a particular concentration.

We investigate the determinants of major choice and the impact of credit constraints on students' decision between different majors exploring the 
expansion of a large federal government program that offers loans to students enrolled in private higher education in Brazil. From a policy perspective, understanding how students in Brazil choose major is very important. In Brazil, students choose major during the college application process. Tuition is determined at the major-institution level and tuition costs vary greatly across majors, with some majors being consistently more expensive across institutions. In this framework, short term credit constraints could impact not only the decision to enroll in college but also major choice. If higher return majors are consistently more expensive, lower income students could be constrained in their ability to choose more profitable majors, a scenario that hinders intergenerational mobility.

Much remains unknown on the determinants of major choice. The literature also does not directly addresses - up to our knowledge - the impact of credit constraints on the choice between different majors. This paper contributes to this literature providing evidence on the determinants of major choice in a framework in which students are suddenly given the opportunity to obtain credit for higher education. We show that costs and returns to higher education impact students' major choice. We also show that credit availability induces students - especially lower income students - to choose high-cost highreturn majors, a result consistent with the existence of credit constraints at the major level.

\section{2 \\ Data and Descriptive analysis}

In this paper, we evaluate what factors students in Brazil take into consideration when deciding between different majors. We also analyze the impact of credit constraints on students' major choice in a framework in which the costs of enrolling at higher education vary at the major level. We use a broad definition of major, classifying majors within 11 different categories: Education; Humanities and Arts; Social Sciences and Business; Law; Sciences, Math and Computing; Engineering and Construction; Health; Medicine; Odontology; and Others. To perform our analysis, we need information on demand, tuition costs, labor market returns, and other relevant characteristics at the major level. We obtain these information from different data sources.

From the Higher Education Census, we obtain information on demand and other characteristics at the major-institution level. Every year, the Higher Education Census ${ }^{1}$ collects information from every higher education institution

\footnotetext{
${ }^{1}$ The Higher Education Census data are administered by INEP - an independent government agency linked to Brazil's Ministry of Education - and are publicly available (http://inep.gov.br/microdados).
} 
Chapter 2. The Effect of Credit Constraints on Major Choice: Evidence from a Large Scale Student Loan Program in Brazil

in the country. The Census contains information at the institution, major, instructor and student level. We use information from every edition of the Higher Education Census between 2006 and 2014. Information from the Census is available up until 2018, but considering that in 2015 access to credit was greatly restricted due to a new reform of FIES's rules, we do not not include more recent cohorts in our analysis. ${ }^{2}$ We use information from the Census to evaluate the determinants of demand for private higher education in Brazil. Table 2.1 describes how average demand for private education evolved through time at the major and at the institution level. Table 2.1 shows that average demand for private higher education was decreasing between 2006 and 2010. After 2010, we see a consistent expansion in number of enrolled students, applicant students, and maximum cohort size.

${ }^{2}$ We detail the 2015 reform in chapter 1 of this dissertation. 
Chapter 2. The Effect of Credit Constraints on Major Choice: Evidence from a Large Scale Student Loan Program in Brazil

Table 2.1: Descriptive Statistics - Characteristics at the Major-Institution Level

\begin{tabular}{|c|c|c|c|c|}
\hline & $(1)$ & $(2)$ & $(3)$ & $(4)$ \\
\hline Variable & Full Sample & 2006 & 2010 & 2014 \\
\hline Enrolled Students & $\begin{array}{c}230.80 \\
(329.44)\end{array}$ & $\begin{array}{c}252.55 \\
(359.09)\end{array}$ & $\begin{array}{c}218.39 \\
(317.17)\end{array}$ & $\begin{array}{c}249.22 \\
(339.38)\end{array}$ \\
\hline Enrolled Students (institution) & $\begin{array}{c}18451.85 \\
(40296.65)\end{array}$ & $\begin{array}{c}17263.85 \\
(33421.92)\end{array}$ & $\begin{array}{c}16853.74 \\
(36006.76)\end{array}$ & $\begin{array}{c}21573.96 \\
(49866.01)\end{array}$ \\
\hline Maximum Cohort Size & $\begin{array}{c}163.70 \\
(192.35)\end{array}$ & $\begin{array}{c}165.07 \\
(169.35)\end{array}$ & $\begin{array}{c}148.86 \\
(140.78)\end{array}$ & $\begin{array}{c}223.67 \\
(240.62)\end{array}$ \\
\hline Number of Applicants & $\begin{array}{c}223.31 \\
(506.72)\end{array}$ & $\begin{array}{c}210.68 \\
(360.02)\end{array}$ & $\begin{array}{c}186.62 \\
(328.58)\end{array}$ & $\begin{array}{c}298.00 \\
(596.43)\end{array}$ \\
\hline Applicants per Max. Cohort Size & $\begin{array}{c}1.47 \\
(3.75)\end{array}$ & $\begin{array}{c}1.37 \\
(1.70)\end{array}$ & $\begin{array}{c}1.33 \\
(2.27)\end{array}$ & $\begin{array}{c}1.43 \\
(3.19)\end{array}$ \\
\hline Number of Graduating Students & $\begin{array}{c}35.90 \\
(57.84)\end{array}$ & $\begin{array}{c}38.90 \\
(67.09)\end{array}$ & $\begin{array}{c}34.61 \\
(58.79)\end{array}$ & $\begin{array}{c}32.84 \\
(49.95)\end{array}$ \\
\hline Number of Majors Offered (institution) & $\begin{array}{c}81.46 \\
(176.41)\end{array}$ & $\begin{array}{c}75.54 \\
(152.06)\end{array}$ & $\begin{array}{c}76.43 \\
(164.11)\end{array}$ & $\begin{array}{c}88.08 \\
(202.99)\end{array}$ \\
\hline Faculty Quality (institution) & $\begin{array}{c}0.58 \\
(0.19)\end{array}$ & $\begin{array}{c}0.51 \\
(0.18)\end{array}$ & $\begin{array}{c}0.57 \\
(0.17)\end{array}$ & $\begin{array}{c}0.66 \\
(0.17)\end{array}$ \\
\hline Number of instructors (institution) & $\begin{array}{c}731.39 \\
(1447.90)\end{array}$ & $\begin{array}{c}723.66 \\
(1179.44)\end{array}$ & $\begin{array}{c}730.06 \\
(1570.63)\end{array}$ & $\begin{array}{c}737.82 \\
(1478.57)\end{array}$ \\
\hline $\mathrm{N}$ & 153765 & 13093 & 17808 & 18714 \\
\hline
\end{tabular}

$\overline{\overline{\text { Notes: } \text { This table presents descriptive statistics for the sample of private major-institutions }}}$ in Brazil. Information is obtained from the Higher Education Census editions from 2006 to 2014. At the major-institution level, this table presents information on the average number of enrolled students, maximum cohort size, number of applicant students, and the ratio between number of applicant students and maximum cohort size. At the institution level, this table presents information on number of enrolled students, number of majors offered, number of instructors, and a measure of faculty quality (proportion of faculty with at least a master's degree). The full sample - column (1) - contains 153765 observations. In columns (2), (3), and (4) we show how each variable varies between 2006 and 2014. This table shows that all variables related to demand for private higher education decreased between 2006 and 2010 and increased between 2010 and 2014 .

From Brazil's Ministry of Education, we obtain data on majorinstitutions' performance in the country's national evaluation of higher education quality. As we will detail in section 2.3, the expansion of student credit in Brazil was restricted to students enrolled in major-institutions that met minimum quality requirements, as defined by the Ministry of Education. We explore this heterogeneity to assess the impact of credit availability on students' decision. We use two different quality evaluations administered by the Ministry 
Chapter 2. The Effect of Credit Constraints on Major Choice: Evidence from a Large Scale Student Loan Program in Brazil

of Education to determine eligibility for credit at the major-institution level. The first is the Conceito Preliminar de Curso (CPC) or Preliminary Score of Major evaluation. The CPC assigns major-institutions' quality scores that range from one to five considering three dimension of quality: quality of faculty, quality of physical and academic resources, and enrolled students subjective evaluation of quality. The second is ENADE, a national exam that assess the performance of freshman and senior students enrolled in higher education in Brazil. Major-institutions are also assigned a grade from one to five based on their students' performance on ENADE. As we detail in section 2.4, only major-institutions with a grade higher than three on the appropriate quality evaluation are eligible to enroll students with government credit. We use information on major-institution performance at the 2010 quality evaluation to assess the impact of credit availability. Figure 2.1 presents the distribution of major-institutions' performance in the 2010 quality evaluation. 
Figure 2.1: Distribution of Major-Institutions' Performance on the 2010 National Quality Evaluation

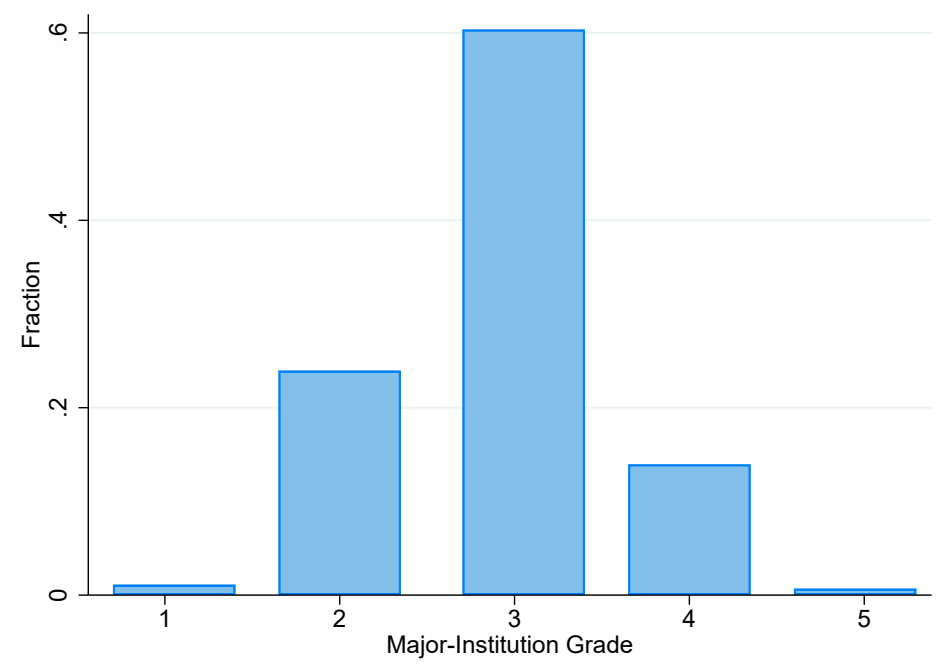

Notes: This figure presents the distribution of performance in the 2010 national quality evaluation of major-institutions for all the majorinstitutions in our sample. We measure 2010 performance as the 2010 grade at the Preliminary Score of Major (CPC) evaluation. The CPC evaluation assigns major-institutions' quality scores that range from one to five considering three dimensions: quality of faculty, quality of physical and academic resources, and enrolled students subjective evaluation of quality. For major-institutions with no CPC information available in 2010, we consider the 2010 ENADE grade. ENADE is a national exam that assess the performance of freshman and senior students enrolled in higher education in Brazil. We obtain information on CPC and ENADE from the Ministry of Education. The x-axis presents the grade on the 2010 national evaluation. The $y$-axis presents the proportion of major-institutions that were assigned each grade, from one to five.

In Brazil, tuition costs vary considerably across institutions and across different majors within the same institution. The Higher Education Census does not provide information on tuition and fees at the major-institution level. Instead, we collect information on tuition accessing a unique database from Hoper, a consultancy firm specialized in the education sector. The data cover $82 \%$ of private institutions in Brazil and contain information on tuition at the major-institution level from 2009 to 2013. Due to restrictions in the access of tuition data for more recent cohorts, we restrict our structural analysis to the 2009 to 2013 period.

In section 2.5, we develop a model of human capital investment in which students must choose between different majors. Students make decisions based 
on their best beliefs about the costs and returns to education at a given market. We define the metropolitan area (or state)-year pair as the relevant market. We analyze 36 metropolitan-areas (or states) through five years - from 2009 to 2013 - totalling 180 markets. $^{3}$ For our structural analysis, we aggregate information on major-institution costs, and basic characteristics at the majormarket level.

To obtain average labor market returns at the major-market level, we use information from Brazil's national registry of wage earners employed by the formal sector ${ }^{4}$ - Relação Anual de Informações Sociais or RAIS. The national registry of wage earners is an annual data set organized by Brazil's Ministry of Labor ${ }^{5}$. The registry contains information on wages, hours worked, and occupation at the firm and at the employee level. We restrict our analysis to 2055 years old working in the same position for at least 35 hours a week over one year. We then use Brazil's official classification of occupations-Classificação Brasileira de Ocupações or CBO - to connect each occupation in CBO's high skilled section with the major most often associated with it. Table 2.2 details the average characteristics for each of the majors we consider in our analysis at the market level. We present all financial information in 2000 Reais.

${ }^{3}$ In section B.1 we list the metropolitan-areas (or states) considered for our analysis.

${ }^{4} \mathrm{~A}$ large share of worker in Brazil are employed by the informal sector. Higher qualification workers with a college degree are more likely to be employed by the formal sector and we will not consider the informal sector in our analysis (Ulyssea, 2018). Due to data restrictions, we also do not consider self employed professionals in our analysis.

${ }^{5}$ Starting in 2019, the administration of RAIS was transferred to Brazil's Ministry of Economy 
Chapter 2. The Effect of Credit Constraints on Major Choice: Evidence from a Large Scale Student Loan Program in Brazil

Table 2.2: Descriptive Statistics - Characteristics at the major-market level

\begin{tabular}{|c|c|c|c|c|c|c|c|}
\hline Major & $\begin{array}{c}\text { Minimum } \\
\text { Tuition }\end{array}$ & $\begin{array}{l}\text { Mean } \\
\text { Tuition }\end{array}$ & $\begin{array}{l}\text { Mean } \\
\text { Wage }\end{array}$ & $\begin{array}{c}\text { Mean } \\
\text { Wage } \\
\text { (Young) }\end{array}$ & $\begin{array}{l}\text { Faculty } \\
\text { Quality }\end{array}$ & $\begin{array}{c}\text { Applicants } \\
\text { per } \\
\text { Max Size }\end{array}$ & $\mathrm{N}$ \\
\hline All & $\begin{array}{c}288.762 \\
(355.998)\end{array}$ & $\begin{array}{c}409.861 \\
(366.161)\end{array}$ & $\begin{array}{c}2124.434 \\
(1270.33)\end{array}$ & $\begin{array}{c}1477.26 \\
(881.4145)\end{array}$ & $\begin{array}{c}0.589 \\
(0.131)\end{array}$ & $\begin{array}{c}3.312 \\
(6.958)\end{array}$ & 1345 \\
\hline Education & $\begin{array}{l}122.195 \\
(44.099)\end{array}$ & $\begin{array}{l}212.009 \\
(47.722)\end{array}$ & $\begin{array}{l}1343.786 \\
(456.690)\end{array}$ & $\begin{array}{c}807.141 \\
(203.634)\end{array}$ & $\begin{array}{c}0.578 \\
(0.130)\end{array}$ & $\begin{array}{c}1.029 \\
(0.392)\end{array}$ & 143 \\
\hline Humanities/Arts & $\begin{array}{l}154.953 \\
(57.603)\end{array}$ & $\begin{array}{l}258.827 \\
(70.366)\end{array}$ & $\begin{array}{l}1085.491 \\
(414.324)\end{array}$ & $\begin{array}{c}722.513 \\
(222.775)\end{array}$ & $\begin{array}{c}0.624 \\
(0.110)\end{array}$ & $\begin{array}{c}1.198 \\
(0.528)\end{array}$ & 108 \\
\hline Social Sciences/Business & $\begin{array}{l}125.844 \\
(35.035)\end{array}$ & $\begin{array}{l}236.407 \\
(46.732)\end{array}$ & $\begin{array}{l}1501.647 \\
(577.566)\end{array}$ & $\begin{array}{c}966.414 \\
(343.776)\end{array}$ & $\begin{array}{c}0.536 \\
(0.132)\end{array}$ & $\begin{array}{c}1.875 \\
(3.782)\end{array}$ & 150 \\
\hline Law & $\begin{array}{l}233.966 \\
(55.812)\end{array}$ & $\begin{array}{l}330.755 \\
(52.463)\end{array}$ & $\begin{array}{c}3846.465 \\
(1679.942)\end{array}$ & $\begin{array}{l}2188.031 \\
(961.453)\end{array}$ & $\begin{array}{c}0.563 \\
(0.129)\end{array}$ & $\begin{array}{c}3.429 \\
(2.274)\end{array}$ & 144 \\
\hline Science/Math/Computing & $\begin{array}{l}156.933 \\
(53.094)\end{array}$ & $\begin{array}{l}276.497 \\
(51.986)\end{array}$ & $\begin{array}{l}2005.614 \\
(459.784)\end{array}$ & $\begin{array}{l}1340.972 \\
(280.508)\end{array}$ & $\begin{array}{c}0.578 \\
(0.125)\end{array}$ & $\begin{array}{c}1.341 \\
(0.498)\end{array}$ & 143 \\
\hline Engineering & $\begin{array}{l}228.796 \\
(83.543)\end{array}$ & $\begin{array}{l}373.656 \\
(77.737)\end{array}$ & $\begin{array}{c}3036.296 \\
(705.180)\end{array}$ & $\begin{array}{l}2288.643 \\
(556.869)\end{array}$ & $\begin{array}{c}0.621 \\
(0.116)\end{array}$ & $\begin{array}{c}2.073 \\
(0.892)\end{array}$ & 131 \\
\hline Agricultural Sciences & $\begin{array}{c}293.684 \\
(139.517)\end{array}$ & $\begin{array}{c}448.289 \\
(118.645)\end{array}$ & $\begin{array}{l}2771.314 \\
(700.443)\end{array}$ & $\begin{array}{l}1867.096 \\
(293.775)\end{array}$ & $\begin{array}{c}0.593 \\
(0.145)\end{array}$ & $\begin{array}{c}1.746 \\
(1.000)\end{array}$ & 90 \\
\hline Health & $\begin{array}{l}189.027 \\
(51.943)\end{array}$ & $\begin{array}{l}338.334 \\
(59.901)\end{array}$ & $\begin{array}{l}1401.813 \\
(308.904)\end{array}$ & $\begin{array}{l}1161.003 \\
(182.753)\end{array}$ & $\begin{array}{c}0.590 \\
(0.125)\end{array}$ & $\begin{array}{c}1.875 \\
(0.822)\end{array}$ & 148 \\
\hline Medicine & $\begin{array}{l}1492.669 \\
(421.149)\end{array}$ & $\begin{array}{l}1690.079 \\
(272.264)\end{array}$ & $\begin{array}{c}3677.180 \\
(1095.475)\end{array}$ & $\begin{array}{l}3127.782 \\
(988.523)\end{array}$ & $\begin{array}{c}0.655 \\
(0.109)\end{array}$ & $\begin{array}{c}25.376 \\
(14.450)\end{array}$ & 84 \\
\hline Odontology & $\begin{array}{c}626.356 \\
(180.637)\end{array}$ & $\begin{array}{c}734.383 \\
(163.382)\end{array}$ & $\begin{array}{l}1854.749 \\
(586.650)\end{array}$ & $\begin{array}{l}1529.229 \\
(356.727)\end{array}$ & $\begin{array}{c}0.637 \\
(0.139)\end{array}$ & $\begin{array}{c}2.812 \\
(1.317)\end{array}$ & 81 \\
\hline Others & $\begin{array}{c}153.892 \\
(53.190)\end{array}$ & $\begin{array}{c}241.977 \\
(68.278)\end{array}$ & $\begin{array}{c}1355.271 \\
(1251.453)\end{array}$ & $\begin{array}{c}929.214 \\
(930.851)\end{array}$ & $\begin{array}{c}0.566 \\
(0.134)\end{array}$ & $\begin{array}{c}1.185 \\
(0.696)\end{array}$ & 123 \\
\hline
\end{tabular}

Notes: This table presents descriptive statistics at the major-market level. For our structural analysis, we aggregate the information from different major-institutions at the major-market level. We classify majors into 11 different categories: Education, Humanities and Arts, Social Sciences and Business, Law, Sciences/Math and Computing, Engineering and Construction, Health, Medicine, Odontology, and Others. We define the state/ metropolitan region area as the relevant market. The list of markets is available in section B.1. Our full sample contains 1345 major-market pairs. We obtain information on tuition from Hoper, a consultancy firm specialized in the education sector. We collect information on major-market labor market outcomes from the national registry of employees in the formal sector (RAIS). We obtain information on quality at the major-market level from the Higher Education Census.

From table 2.2, we see that there is great variability in both the costsminimum tuition and mean tuition - and returns - average wage and average wage for young (20-30 years old) wage earners - to different majors. Mean tuition varies from 212.00 Reais - Education - to 1690.07 Reais-Medicine. The median tuition from our sample is 298.34 Reais. The average cost for enrolling 
in Education, Humanities and Arts, Social Sciences and Business, Science, Math and Computing and Others is below median. On the other hand the costs of enrolling in Law, Engineering, Agricultural Sciences and all health related majors is above median. Wages also vary significantly in our sample. The median wage is 1771.60 Reais. Students who graduate from Education, Humanities and Arts, Social Sciences and Business, Health and Others gain lower than median wages. Students who graduate from Law, Science, Math and Computing, Engineering, Agricultural Sciences, Medicine, and Odontology get higher than median wages. Our data reveals that there is a positive significant correlation between the tuition costs of a major and the wages associated with it at the market level. Figure 2.2 illustrates the results of a non-parametric local regression that assess the relation between tuition costs and wages for both the full sample and the sample of young wage earners. For young workers, there is a positive correlation for all wage levels. For the full sample, the correlation weakens for higher wage levels. This results is consistent with Deming and Noray (forthcoming), that show that the wage premium from technical majors fades with time as technological change makes skills obtained while in college obsolete.

Figure 2.2: Correlation Between Costs and Returns from Different Majors

(2.2(a)) Tuition vs. Wage Young

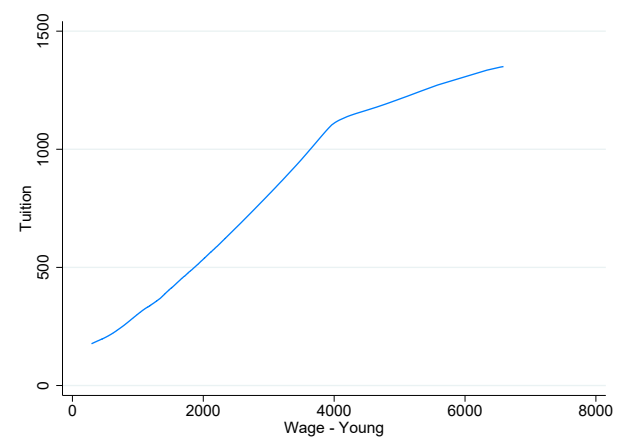

(2.2(b)) Tuition vs. Wage

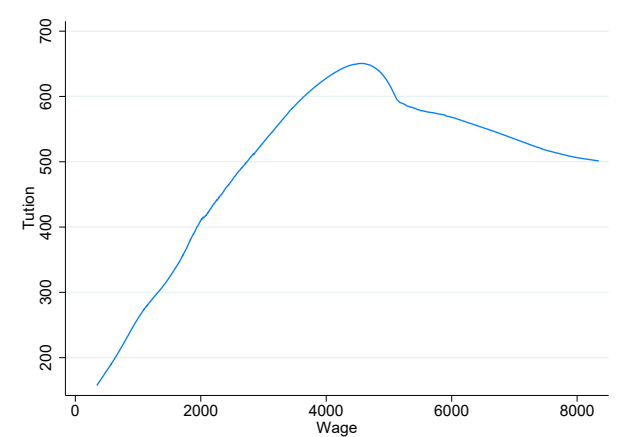

Notes: This figure presents the results of a non-parametric local weighted regression that evaluates the correlation between tuition costs and wages at the major-market level. The $\mathrm{y}$-axis presents information on tuition and the x-axis information on wages. For panel (a) we consider only the information on young wage earners - 20 to 30 years old. For panel (b) we consider the full sample.

In our model, students' educational decision are a function, among other things, of their first period income, i.e. their income at the moment they are choosing how much to invest in higher education. We assume first period income is given by parental transfers (Belley and Lochner, 2007). We estimate our model using the BLP method (Berry, Levinsohn and Pakes, 1995). For es- 
timation, we need information on the distribution of parental transfers at the market level. To obtain this information we use two data sets administered by the Brazilian Institute of Geography and Statistics: the National Household Sample Survey and the Consumer Expenditure Survey. The National Household Sample Survey (PNAD) collects information on socioeconomic status of a nationally representative sample of households, including information on income, employment, education, and household composition. From this survey, we obtain information on the distribution of family income at the market level. The Consumer Expenditure Survey contains information on household budget composition. We use information from the 2008-2009 edition to obtain an estimate of how much families spend on education.

\section{3}

\section{Institutional Background: FIES and the 2010 Intervention}

Brazil's federal government offers loans to students enrolled in private higher education through its subsidized student credit program (FIES). The program, created in 1999, became one of the most important sources of funding for higher education in the country following an unexpected reform of program's rules in $2010 .{ }^{6}$ The reform reduced participation costs for both students and institutions and was designed to increase enrollment rates. For students, the cost of funding decreased considerably. Interest rates dropped from $6.5 \%$ to $3.5 \%$ per year. The government established a rolling basis application process, allowing students to apply for loans at any moment of the year. A subsidized insurance scheme was created to eliminate the need of a cosigner for lower income students. Repayment conditions improved with the extension of loans' grace and amortization periods. The 2010 reform also benefited institutions with the establishment of a system that increased the liquidity of government FIES-related payments. ${ }^{7}$

To obtain funding from FIES, students must enroll in major-institutions that meet the program's eligibility requirements. Specifically, major institutions must obtain a minimum performance on the quality evaluations conducted by Brazil's Ministry of Education. In section 2.4, we detail this eligibility requirements and show how we explore heterogeneities in eligibility to

\footnotetext{
${ }^{6}$ Starting in 2015, FIES was once again completely reformulated. The first chapter of this dissertation details the 2015 reform.

${ }^{7}$ The government pays participant institutions through treasury bonds called Certificado Financeiro do Tesouro Série E (CFT-E), a special issue for FIES financing. The face value of these bonds corresponds to the tuition financed through FIES. The bonds are tradable for Social Security obligations. No secondary market exists for these bonds, but the government holds repurchase auctions. In 2010, the government established an official schedule of repurchase auctions and increased the minimum number of auctions to be held every year.
} 
obtain the causal impact of funding eligibility. FIES loans cover from $50 \%$ to $100 \%$ of tuition expenses. The fraction of tuition eligible for financing depends on family income and on the ratio between income and tuition. ${ }^{8}$ Students with family income higher than 20 minimum wages are not qualified for funding. Only families at the very top of Brazil's household income distribution do not meet FIES' income requirements.

In the years following the 2010 reform, there was a significant increase in the number of students enrolled with FIES financing. In figure 2.3, we illustrate the number of students enrolled in private higher education in Brazil-panel (a) - and the number of students enrolled with FIES funding-panel (b)in the period between 2006 and 2014. Throughout this period, the number of students enrolled in private higher education in Brazil increased by $37 \%$, growing from approximately 3.4 million students to 4.7 million students. The number of students enrolled with FIES funding increased considerably from a approximately 170 thousand in 2006 to 1.4 million in 2014. As figure 2.3 shows, the sharp increase in number of students enrolled with FIES funding occured after the 2010 reform.

Figure 2.3: Students Enrolled in Private Higher Education and FIES Funding (2.3(a)) Enrolled Students (thousand) (2.3(b)) Students with FIES funding (thousand)
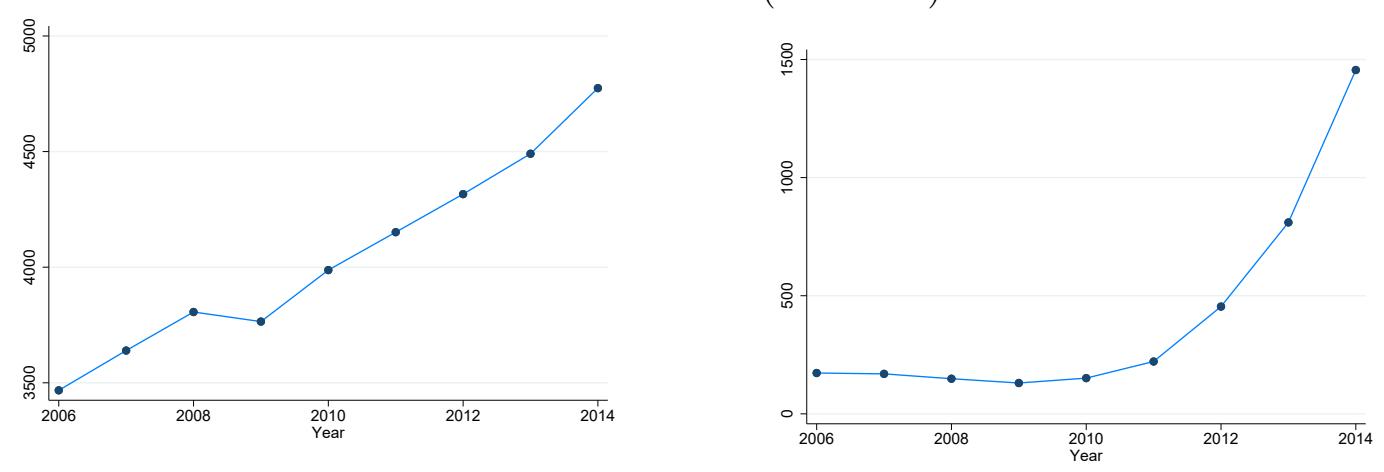

Notes: This figure presents the evolution between 2006 and 2014 of the number of students enrolled in private higher education institutions in Brazil-panel(a) - and number of students enrolled with FIES funding-panel (b). This figure shows that the number of students enrolled in private higher education increased considerably in the period-from 3.5 million in 2006 to 5 million in 2014. It also illustrates the sharp increase in the number of students enrolled with FIES funding starting in 2010.

${ }^{8}$ FIES covers: 1) up to full tuition for students with gross household income under 10 minimum wages, and tuition higher than $60 \%$ of the per capita household income; 2) up to $75 \%$ of tuition for students with gross family income under 15 minimum wages, and tuition between $40 \%$ and $60 \%$ of the per capita household income; 3) up to $50 \%$ of tuition for students with gross household income under 20 minimum wages, and tuition between $20 \%$ and $40 \%$ of the per capita household income. 


\section{4 \\ Reduced Form Evidence}

According to FIES' rules, a major-institution is considered eligible for enrolling students with FIES financing if it obtains a minimum performance in the Ministry of Education's quality evaluations. In this section, we explore heterogeinities in eligibility for enrolling students with FIES to obtain a causal estimate of the impact of credit availability on enrollment. For identification, we define treatment and control groups based on major-institutions ability to enroll students with FIES right after the programs' expansion. We argue that the expansion was unexpected and that major-institutions were limited in their ability to meet eligibility requirements in the short run. We show that availability of subsidized credit impacts enrollment decisions, causing students to choose major-institutions that offer the possibility of obtaining FIES funding. In the next sections, we will explore the impact of credit availability on overall demand for higher education and on major choice.

To be considered eligible to enroll students with FIES, a major-institution must obtain a grade of three or higher in one of three quality assessments, according to the following order of relevance: (i) the Score o Major (CC); (ii) the Preliminary Score of Major (CPC), if $\mathrm{CC}$ is not available; (iii) and the national exam for higher education students (ENADE), if CC and CPC are not available. The performance of major-institutions in a given period at these quality evaluations, thus, inform on their ability to enroll students with FIES funding. Information on performance at the $\mathrm{CC}$ evaluation is not readily available. This is not an issue because $\mathrm{CC}$ is an in loco evaluation and is not as broadly assessed as CPC or ENADE. We assign the eligibility status of different major-institutions considering their performance on CPC. For some major-institutions, $\mathrm{CPC}$ is not available but ENADE grade is. For these major-institutions, we consider performance on ENADE to assign eligibility. According to FIES rules, major-institutions not yet subject to their first evaluation are considered eligible pending evaluation. As such, we assign major institutions with no available CPC and ENADE performance as eligible for FIES funding.

We identify the causal impact of FIES exploring major-institutions' eligibility status right after FIES expansion through a Difference-in-Differences (DD) framework. Treatment is defined according to eligibility status in 2010, i.e., we consider part of the treatment group all major-institutions with $\mathrm{CPC}-$ or ENADE - grade three or higher in 2010. We also include as part of the treatment group major-institution with no evaluation available in 2010. We set the period between 2006 and 2010 as the pre-treatment period. The period 
between 2011 and 2014 represents the post-treatment period. We measure the causal impact of FIES eligibility on enrollment estimating the following equation:

$$
\text { Enrolled }_{j t}=\alpha_{1}+\alpha_{2} D_{t} * \text { Treat }_{j}+\alpha_{3} D_{t}+\alpha_{4} \text { Treat }_{j}+\beta X_{j t}+\varepsilon_{j t}
$$

The dependent variable is number of students enrolled at majorinstitution $j$ on year $t$. $D_{t}$ is a dummy variable that is equal to one for observations in the post-treatment period - 2011 to 2014. Treat ${ }_{j}$ represents a a dummy variable that is equal to one if the major-institution $j$ obtained the minimum performance required for eligibility for FIES in 2010. $X_{j t}$ represents a set of characteristics at the major institution level ${ }^{9}$ and $\varepsilon_{j t}$ represents an error term unobserved to the econometrician. Our parameter of interest- $\alpha_{2}$-represents the causal impact of being eligible to enroll students with FIES on number of enrolled students at the major-institution level for all major-institutions in our sample - the intent-to-treat parameter. Table 2.3 presents the results of this estimation. For all specifications considered, we find a positive and significant impact from being eligible for FIES on number of enrolled students. Specifically, we find that - even after including covariates, year, and institution fixed effects - major-institutions eligible to enroll students with FIES enrolled 17.32 more students after FIES's expansion than non-eligible major institutions.

\footnotetext{
${ }^{9}$ We include the following covariates in our main specification: maximum size of incoming cohort, number of majors offered by the institution, number of instructors at the institutions level, number of applicant students per maximum cohort size, institution size, and proportion of instructors with at least an MA. We also include institution and year fixed effects.
} 
Chapter 2. The Effect of Credit Constraints on Major Choice: Evidence from a

Table 2.3: Reduced Form Estimation

\begin{tabular}{lcccc}
\hline \multicolumn{1}{l}{$(1)$} & $(2)$ & $(3)$ & $(4)$ \\
Variables & & & & \\
\hline & & & & \\
Treatment Effect & $14.981^{* * *}$ & $12.588^{* *}$ & $12.564^{* *}$ & $17.328^{* * *}$ \\
& $(5.474)$ & $(5.521)$ & $(5.003)$ & $(4.961)$ \\
Year FE & & & & \\
Covariates & $\mathrm{n}$ & $\mathrm{y}$ & $\mathrm{y}$ & $\mathrm{y}$ \\
Institution FE & $\mathrm{n}$ & $\mathrm{n}$ & $\mathrm{y}$ & $\mathrm{y}$ \\
& & & $\mathrm{n}$ & $\mathrm{y}$ \\
Observations & 153,765 & 153,765 & 153,765 & 153,669 \\
R-squared & 0.000 & 0.002 & 0.269 & 0.341 \\
\hline
\end{tabular}

Notes: This table presents the results of a difference-in-differences (DD) analysis that compares the number of students enrolled in major-institutions eligible to enroll students with FIES in 2010 against number of enrolled students in non-eligible major-institutions (equation 2-1). In this $\mathrm{DD}$, the pre-treatment period consists of the years that precede FIES expansion (2006 through and 2010). The post-treatment period consists of the years after the expansion (2011 through 2014). The estimated coefficients associated with the "Treatment Effect" variable represent the impact of being eligible to FIES number of enrolled students. In columns (2), (3), and (4) we include year fixed effects. In columns (3) and (4) we include a set of time varying covariates. Covariates at the major-institution level include information on maximum cohort size and the ratio between applicants and maximum cohort size. Covariates at the institution level include information on faculty quality, number of majors offered, number of instructors and enrolled students. In column (4), we include institution fixed effects. Standard errors were computed with observations clustered at HEI level. ${ }^{* * *}$ represents p-value $<0.01,{ }^{* *}$ p-value $<0.05$, and* p-value $<0.1$.

Controlling for selection bias is one of the main identification challenges in a framework like ours. We determine eligibility based on the 2010 quality evaluation of major-institutions with the purpose to minimize the risk of including as part of the treatment group major-institutions that altered their behavior with the intent to become eligible for FIES. We make this decision based on the assumption that FIES expansion was largely unexpected and, as such, major-institutions were unable to implement quality enhancing investments that would increase their chances of becoming eligible in the 
short run. We are able to evaluate the robustness of this hypothesis using our data. If major-institutions were making investment decisions to enhance their performance in response to an expected increase in student credit, we would see a shift in the distribution of the quality evaluation scores towards higher grades in the years following FIES expansion. In figure 2.4, we plot the distribution of quality evaluation grades for major-institutions in our sample in the period between 2009 and 2013. This figure shows no evidence of majorinstitutions managing to significantly improve their quality evaluation in the short run. This result is not surprising, given that quality evaluations from the Ministry of Education are based in factors not easily manipulated in the short run - e.g. academic performance of graduating students, level of qualification of instructors, or quality of physical infrastructure - and there is a three-year interval between major-institution level evaluations.

Figure 2.4: Major-HEI Quality Score - Kernel Density

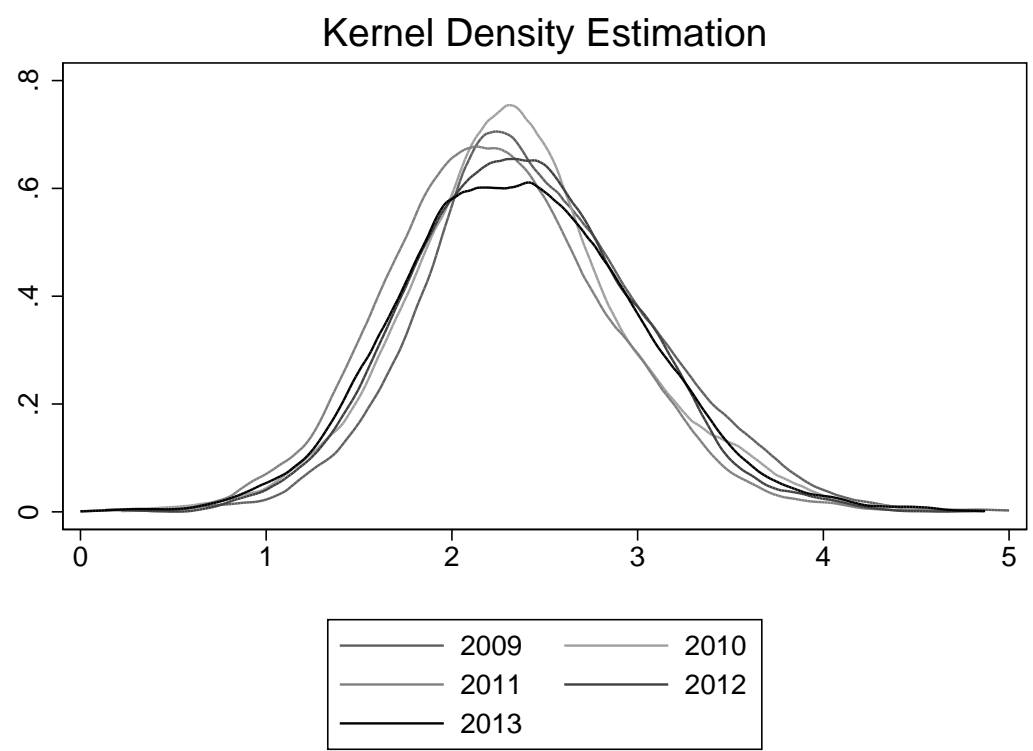

Notes: This figure shows the trend through time of the quality indicator that determines eligibility for FIES. Specifically, it shows the kernel estimate of the density function of the CPC quality evaluation, if CPC is available, and of the ENADE score, for the cases in which the CPC is not available, for every year from 2009 through 2013

Identification on a Difference-in-Differences framework lies on the assumption that the variable of interest - enrollment - was following the same trend for treatment and control units before the policy implementation-before FIES expansion - and would have continued following parallel trends if there had not been an intervention, i.e., in a counterfactual scenario. We cannot test how reasonable the counterfactual parallel trend hypothesis is. However, 
we can test the differential pre-trend hypothesis. In figure 2.5 we present the result of a event study analysis performed using our data. In this analysis, we compare the number of enrolled students for units in the treatment and control groups in the period before and after FIES expansion. Our results show that, before FIES expansion, there is no discernible differential trend when we compare treatment and control units. After the expansion, on the other hand, we see a consistent increase on number of students enrolled in major-institutions that are eligible to enroll students funded through FIES.

Figure 2.5: Impact of Credit Availability on Enrollment

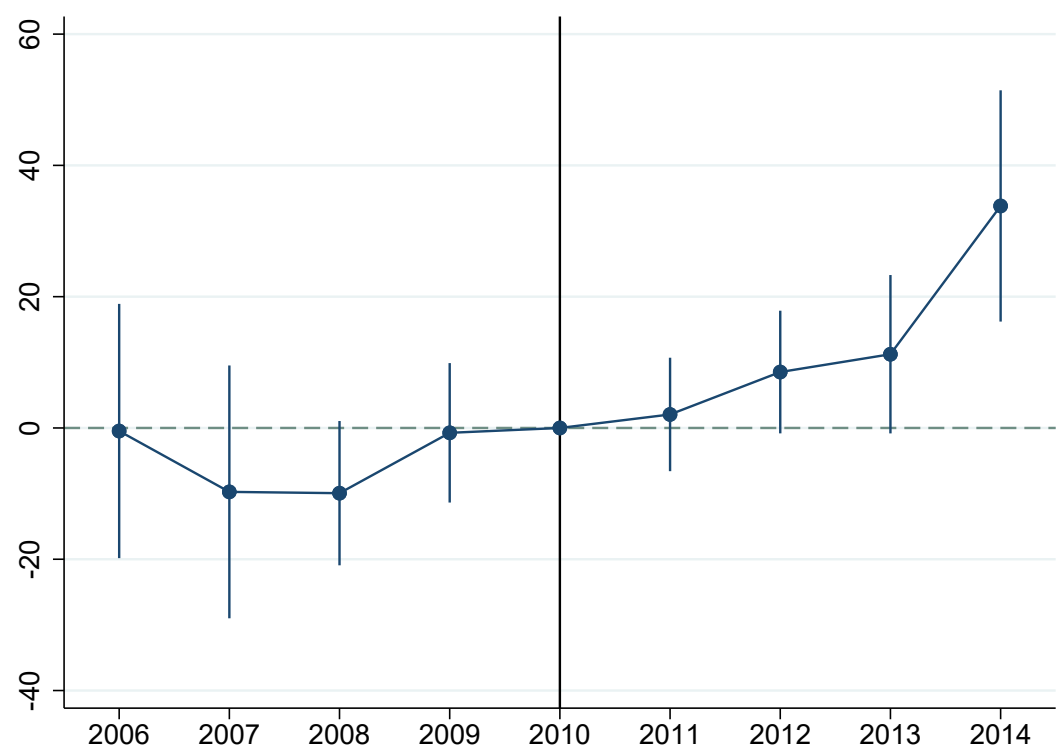

Notes: This figure shows the result of a event study analysis that compares the trend in number of enrolled students at major-institutions in the treatment group against number of enrolled students at major-institutions in the the control group. We include as part of the treatment group all major-institutions that were eligible to enroll students with FIES in 2010. The dots in the graph represent the point estimates of the eligibility effect for each year. Vertical lines represent a 95\% confidence interval. The specification in this figure includes institution fixed effects and a set of time-varying covariates. Covariates at the major-institution level include information on maximum cohort size and the ratio between applicants and maximum cohort size. Covariates at the institution level include information on faculty quality, number of majors offered, number of instructors and enrolled students. Standard errors were computed with observations clustered at HEI level.

Our results suggest that availability of credit influences human capital decisions and that students are more likely to enroll in major-institutions that 
Chapter 2. The Effect of Credit Constraints on Major Choice: Evidence from a Large Scale Student Loan Program in Brazil

can offer them the possibility of obtaining government funding. There are a few important questions that this analysis does not address. These results cannot be used to estimate the impact of credit availability on number of enrolled students in the private higher education market as a whole. Considering that in Brazil students choose career upon entrance and that tuition vary greatly across majors, we would like to investigate if the expansion of credit altered students decision to enroll in different majors. Table 2.4 shows that between 2006 and 2014 the market share of different majors changed considerably in Brazil, with a significant increase in the market share of higher than average cost majors like Engineering, Agricultural Sciences, Medicine, and Odontology. Our results so far also cannot be used to understand how credit availability impact the share of students enrolled in each major and how students background or major-level costs and return influence this decision. In the following sections, we introduce a structural model of demand to analyze how credit constraints influence the choice between different majors. 
Chapter 2. The Effect of Credit Constraints on Major Choice: Evidence from a Large Scale Student Loan Program in Brazil

Table 2.4: Major Market Share Evolution

\begin{tabular}{|c|c|c|c|c|c|c|}
\hline \multirow[b]{3}{*}{ Major } & \multicolumn{3}{|c|}{ Enrolled Students } & \multicolumn{3}{|c|}{ Market Share } \\
\hline & 2006 & 2014 & Growth & 2006 & 2014 & Growth \\
\hline & & & Rate & & & Rate \\
\hline Education & 522991 & 435827 & -0.167 & 0.151 & 0.091 & -0.397 \\
\hline Humanities/Arts & 98861 & 100624 & 0.018 & 0.029 & 0.021 & -0.276 \\
\hline Social Sciences/Business & 1165395 & 1423028 & 0.221 & 0.336 & 0.298 & -0.113 \\
\hline Law & 525684 & 740451 & 0.409 & 0.152 & 0.155 & 0.020 \\
\hline Science/Math/Computing & 258648 & 249841 & -0.034 & 0.075 & 0.052 & -0.307 \\
\hline Engineering & 215618 & 849438 & 2.940 & 0.062 & 0.178 & 1.871 \\
\hline Agricultural Sciences & 44470 & 90473 & 1.034 & 0.013 & 0.019 & 0.462 \\
\hline Health & 490575 & 651202 & 0.327 & 0.141 & 0.136 & -0.035 \\
\hline Medicine & 38047 & 75240 & 0.978 & 0.011 & 0.016 & 0.455 \\
\hline Odontology & 30161 & 69571 & 1.307 & 0.009 & 0.015 & 0.667 \\
\hline Others & 76892 & 88360 & 0.149 & 0.022 & 0.019 & -0.136 \\
\hline
\end{tabular}

Notes: This table presents descriptive statistics on the evolution of demand for different majors between 2006 and 2014. We obtain information on demand for private higher education from the Higher Education Census. For all 11 majors considered in our analysisEducation, Humanities and Arts, Social Sciences and Business, Law, Sciences/Math and Computing, Engineering and Construction, Health, Medicine, Odontology, and Otherswe present information on number of enrolled students and market share both in 2006 and in 2014. We also present information on the growth rate of demand-measured as number of enrolled students and market share-between 2006 and 2014 for all majors considered in our analysis.

\section{5}

\section{A Simple Model of Major Choice}

There is an extensive literature documenting how credit constraints can impact the decision to enroll or not in higher education (Lochner and MongeNaranjo, 2011). In this paper, we evaluate the impact of credit constraints on the choice between different majors. Assume individuals live $t=\{1, \ldots T\}$ periods. In period $t=1$, a schooling decision is made. In $t=2$, individuals enter the labor market, the absorbing state. Students enrolling in higher education must choose to invest in one between $K$ majors. That is, an individual must choose only one major among the choice set $k=\{1, \ldots, K\}$.

Each individual is endowed with an initial parental transfer $T_{i}$. In our empirical exercise, we assume that families spend a given fraction of their income with education. Higher education is costly and both the minimum and 
the average cost of education are heterogeneous across majors. We represent the cost of enrolling at major $k$ as $\tau_{k}$. We ignore the relevance of possible differences in quality between majors and make the reasonable assumption that investment in education is indivisible. We assume that major choice determines returns from labor at the market level. We use $w_{k t}$ to represent the wages at market $t$ for individuals who graduated from major $k$ in the first period. In our model, we assume that students observe the wages associated with different majors before enrolling in higher education.

A growing literature highlights how students can be ill informed on the expected returns of different majors. Wiswall and Zafar (2015) collects information on the expectations of undergraduate students of New York University and finds that students have biased beliefs about the distribution of earnings from different majors Hastings et al. (2016) collects data o large scale surveys of Chilean college students and finds that students systematically overestimates earnings of past graduates. Even though this is a shortcoming of our model, adding uncertainty on expected wages would greatly complicate our empirical analysis and we opt to to use-Lochner and Monge-Naranjo (2011) - a simplifying assumption.

Individuals derive utility from consumption. At each period, individual utility is represented as $u\left(c_{t}\right) .{ }^{10}$ We assume that, at period $t=1$, individuals can borrow an amount $d$ at an interest rate $R$. The loan must be repaid in the following periods. The value function of individual $i$ when choosing major $k$ is given by

$$
V_{k}\left(T_{i}, w_{k t}, \tau_{k}, R\right)=\max _{d}\left[\sum_{t=1}^{T} \beta^{t-1} u\left(c_{t}\right)\right]
$$

The parameter $\beta$ represents the intertemporal discount rate. Individuals will choose the major that maximize their lifetime utility, i.e., individuals will choose major $k=k^{*}$ if

$$
V_{k}^{*}>V_{j} \quad \forall j \neq k^{*}
$$

That choice is made considering a set of constraints. In a world without borrowing constraints individuals must abide to the following budget constraint at $t=1$.

$$
c_{1 k}=T-\tau_{k}+d
$$

\footnotetext{
${ }^{10}$ The literature highlights the role of non-pecuniary characteristics on students' decision between different majors. In our empirical exercise, we consider the possibility that students make decisions based on their individual preferences for major characteristics including a term $\xi_{i k}$ that accounts for the consumption value individual $i$ assigns to major $j$ (Gullason (1989), Gong et al. (2019)).
} 
For $t \geq 2$

$$
c_{t k}=w_{k}-i_{k}
$$

In which $i_{k}$ represents a stream of repayments. In a world with borrowing constraints, debt is constrained to an specific amount. To represent this framework, we add the following restriction.

$$
d \leq \bar{d}
$$

To illustrate the mechanisms through which credit constraints might impact major choice, we find the solution - with and without credit constraintsfor a two period, two majors version of our model. In a two period framework without credit constraints, we have that:

$$
\begin{gathered}
c_{1 k}=T-\tau_{k}+d \\
c_{2 k}=w_{k}-R d
\end{gathered}
$$

Each individual solves the following optimization problem

$$
\max _{d} U\left(T i-\tau_{k}+d_{1}\right)+\beta U\left(w_{k}-R d\right)
$$

The following expression represents the solution of this optimization problem:

$$
U^{\prime}\left(c_{1}\right)=\beta R U^{\prime}\left(c_{2}\right)
$$

Assuming $\beta R=1$, we have that consumption is perfectly smoothed between the two periods, i.e., $c_{1}=c_{2}$, i.e.,

$$
T i-\tau_{k}+d=w_{k}-R d
$$

In this framework, the first period optimal amount of debt-represented by $d^{*}$ - is a function of parental transfers and of the costs and returns associated with choosing a given major $k$. Specifically, first period debt is negatively correlated with parental transfer and positively correlated with tuition and second period wage.

$$
d^{*}=\frac{w_{k}-T_{i}+\tau_{k}}{(1+R)}
$$

With no constraints, lower income individuals, who cannot fully afford the costs of higher education, respond to an increase in the costs of major $k$ 
by increasing the amount of debt they would take to finance enrollment at major $k$. This is not necessarily the case when credit constraints are binding. In a framework with borrowing constraints, the maximum amount students can borrow is bounded by a given limit $\bar{d}$. If the optimal amount of debt is lower than this limit-i.e. if $d^{*}<\bar{d}$ - the constrained solution is identical to the unconstrained one. If that is not the case, individuals can only borrow an amount $\bar{d}$ that is insufficient to cover the costs of enrolling at major $k$. In this simple framework, a individual can only enroll at major $k$ if the parental transfers they receive are at least as high as the sum of tuition and maximum debt $T_{i}+\bar{d} \geq w_{k}$. Lower income individual - even those who can afford some college - might then be constrained in their ability to choose more expensive majors.

Assume a high cost-high return major (major $k$ ) and a low cost-low return major (major $j$ ). An individual enrolling in college must choose between these two majors. In our simple framework, with no credit constraints, majorspecific costs and returns are the only variables determining choice. In this case, individuals will choose major $k$ every time the relative earnings between major $k$ and major $j$ crosses a given threshold that compensates for the higher costs of major $k$. We define $w_{k} / w_{j}=w_{k j}^{*}$ as relative earnings at this indifference threshold.

When credit constraints are binding, parental transfers will also influence decision. Now, individuals will choose major $k$ if relative earnings crosses the indifference threshold and parental transfers are large enough to compensate for the unavailability of credit. In this scenario, individuals with low parental transfers are constrained in their choice and will choose the low-return lowcost major regardless of the differences in relative returns. Figure 2.6 illustrates how relative returns between majors $j$ and $k$ and parental transfers influence students' choice when the costs of different majors are taken as given. In panel (a) there are no credit constraints. In this case, all students choose the high cost major once the returns from this major cross a threshold that compensates for its higher costs. When credit constraints are binding - panel (b) - students with lower parental transfers are constrained from choosing the high cost major. In this case, only students with parental transfers higher than $T_{\min }$ are able to choose the high-cost high-return major. 
Figure 2.6: Higher Education Enrollment Model

(2.6(a)) Without Credit Constraints

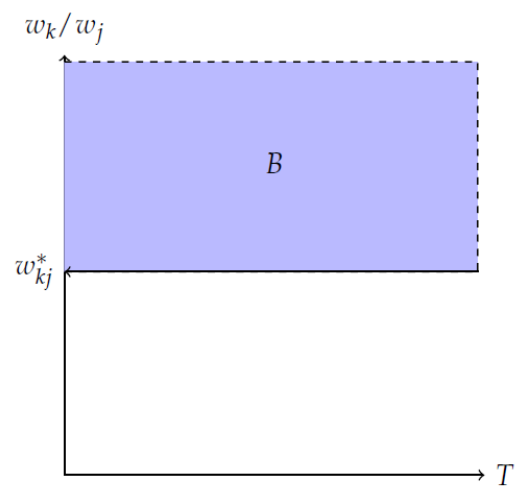

(2.6(b)) With Credit Constraints

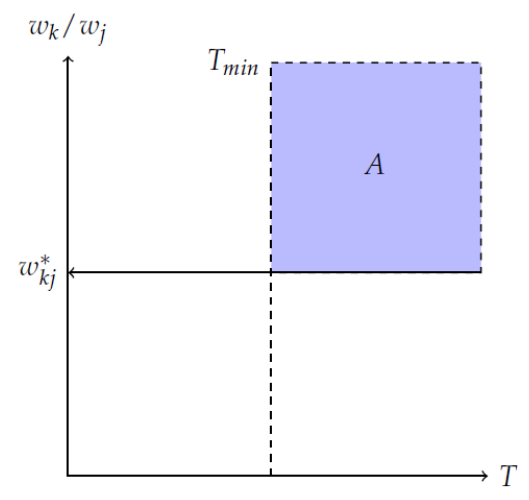

Notes: This figure illustrates the relationship between parental transfers - $\mathrm{x}$-axis - and choice of major in a framework with a high cost-high return major (major $k$ ) and a low cost-low return major (major $j$ ) according to our major choice model. The y-axis in this figure represents relative earnings, i.e., the ratio between labor market earnings from major $k\left(w_{k}\right)$ and labor market earnings from major $j\left(w_{j}\right)$. According to this simple version of our model, students would like to choose the high cost-high return major (major $k$ ) every time the relative earnings of this major cross a indifference threshold that compensate for its higher costs $\left(w_{k} / w_{j}=w_{k j}^{*}\right)$. With no credit constraints - panel (a) - all students choose the high cost-high return major once relative returns cross the indifference threshold (area B). If credit is not available, only students who can afford a major can enroll in it. Thus, only students with high enough parental transfers (higher than $T_{\min }$ ) are able to choose the high cost major (area A). Students in the lower end of the parental distribution are thus constrained in their ability to choose major $k$.

This two period exercise illustrates how credit constraints and family income can shape individual choice. In a framework with varying costs at the major level, lower income individuals can be not only constrained in their choice of enrolling at higher education - as it is standard in the literaturebut also in their choice between different majors. In the next section, we investigate the determinants of demand for higher education and how credit constraints impact choice. We empirically evaluate the demand for different majors adapting our model to fit the framework of the BLP method (Berry, Levinsohn and Pakes, 1995). Using this framework, we are able to estimate the parameters of the demand function and calculate empirical elasticities that inform on how students demand react to price changes with and without credit constraints. 
Chapter 2. The Effect of Credit Constraints on Major Choice: Evidence from a

Large Scale Student Loan Program in Brazil

\section{6}

\section{Model of Major Choice - Empirical Implementation}

As the model in section 2.5 illustrates, in a framework in which the costs of higher education vary at the major level, availability of credit can impact the choice between different majors. Changes in lending standards, thus, could affect the demand for specific majors, having an impact on their market share. In this section, we adapt our model to fit the framework of a randomcoefficients logit model of demand (or BLP) (Berry, Levinsohn and Pakes, 1995). In the BLP framework, products are defined by a set of characteristics. The utility of each consumer - in our case prospective student - is a function of observed and unobserved product characteristics. It is a discrete choice model in the sense that each consumer will choose only one product that maximizes their utility. Consumers are allowed to have different preferences for different characteristics. With the BLP method, we are able to estimate demand for differentiated products using aggregate data (Nevo, 2000).

We adapt our human capital investment model to fit the demand for differentiated products of the BLP method. Assume that there are $m=$ $\{1, \ldots, M\}$ markets for higher education with $i=\left\{1, \ldots, I_{m}\right\}$ consumers or potential students in each of these markets. In each market, consumers are able to choose one between $j=\{1, \ldots, J\}$ majors. The price of product $j$ at market $m$ is represented by tuition $\tau_{j m}$. Demand is constrained within markets. That is, each individual participates of a given market and is only able to choose majors being offered at that market. As in section 2.5, we assume that individuals live $t=\{1, \ldots, T\}$ periods. In the first period, students receive a transfer from their parents - $T_{i m}$ - and must choose one of the majors being offered by private higher education institutions in the market they participate. To enroll at major $j$ offered at market $m$ students must pay $\tau_{j m}$. Students can also choose to not enroll in any of the offered majors either because they decided not to enroll in higher education or because they decided to enroll in public tuition free institutions. The choice to not enroll in private higher education represents the outside option in our framework $(j=0)$. The cost of not enrolling is zero $\left(\tau_{0 m}=0\right)$. In the following periods, students enter the labor market and obtain major-specific earnings. We assume that returns to education $-w_{j m}$ - are constant through time. In a framework with no credit markets for higher education, the first period consumption of student $i$ who chooses a major $j$ at market $m$ is given by:

$$
c_{i j m 1}=T_{i m}-\tau_{j m}
$$


In the following periods, consumption is given by:

$$
c_{i j m t}=w_{j m}
$$

The literature suggests that students derive utility from just being enrolled in higher education (Gullason (1989), Gong et al. (2019)). We define utility in period $t=1$ as a function of consumption in that period and of the consumption value of each major $-\xi_{i j m t}$. In the following periods, utility is a function of consumption only-i.e. $\xi_{i j m t}=0 \forall t \geq 2$. We explore the consumption value of education to adapt our human capital investment model to the BLP framework. Specifically, we assume that the consumption value of major $j$ at market $m$ for individual $i$ is a function of a vector of parameters $\gamma$, of major-market level amenities $-X_{j m}$ and of an individual unobserved idiosyncratic value associated with choice $j, \epsilon_{i j t}$.

$$
\xi_{i j m 1}(\gamma)=\gamma_{0}+\gamma_{\mathbf{1}} \boldsymbol{X}_{j m}+\epsilon_{i j m}
$$

According to the model in section 2.5, consumption is a function of parental transfers, major-specific tuition, and labor market earnings. For each period $t$, we define an indirect utility from consumption- $v_{i j m t}$. In the first period, indirect utility is a function of parental transfer and tuition. In the following periods, indirect utility is a function of labor market earnings.

Total indirect utility at period $t-V_{i j m t}$ - is given by the sum between the indirect utility from consumption and the consumption value of higher education. We assume indirect utility is also a function of two set of unknown parameters. The first - $\theta$ - is fixed across all individuals. The second - $\chi_{t i}$ - is an individual parameter. We assume $\chi_{t i}$ only affects first period utility, i.e. $\chi_{1 i}=\chi_{i}$ and $\chi_{t i}=0 \forall t \geq 2$.

$$
V_{i j m t}=\theta v_{i j m t}\left(\tau_{j m}, T_{i m}, w_{j m}\right)+\chi_{t i} v_{i j m t}\left(\tau_{j m}, T_{i}, w_{j m}\right)+\xi_{i j m t}\left(X_{j m} ; \gamma\right)
$$

In this framework, we can represent the value function $V_{i j m}$ by the following expression:

$$
V_{i j m}=\sum_{t=1}^{\infty} \beta^{t-1}\left[v_{i j m t}\left(\tau_{j m}, T_{i m}, w_{j m} ; \theta_{t}, \chi_{t i}\right)+\xi_{i j m}\left(X_{j m t} ; \gamma\right)\right]
$$

We need a few more assumptions before obtaining an specification we can estimate with our data. We start by assuming that our utility function is logarithmic, i.e. we assume $u\left(c_{t}\right)=\ln \left(c_{t}\right)$. Under this assumption, we can show that indirect utility from consumption at period $t=1$ is given by $\ln \left(T_{i m}-\tau_{k m}\right)$ 
and at every period afterwards by $\ln \left(w_{k m}\right)$.

We introduce parameter $\chi_{i}$ to include the possibility that individuals assign varying weights to the utility they derive from education costs. The idea is that some students might be more sensitive to the financial costs of enrolling in higher education. We assume, as in Petrin (2002), that the individual parameter of the indirect utility function $-\chi_{i}$-varies across three different income cohorts. That is, we include the possibility that low, middle and high income individuals respond differently to the costs of higher education. Specifically, we assume that:

$$
\chi_{i}= \begin{cases}\chi_{1} & \text { if } T_{i}<y_{1} \\ \chi_{2} & \text { if } y_{1}<T_{i}<y_{2} \\ \chi_{3} & \text { if } T_{i}>y_{2}\end{cases}
$$

Finally, we make two standard assumptions for a BLP estimation. First, we assume that utility of the outside option - the option of not enrolling in private higher education - is zero. Second, we assume that the unobserved idiosyncratic value associated with the consumption value of higher education follows an Extreme Value Type I distribution. Students will choose the major that assigns them the highest utility conditional on budget and credit constraints. Define $\delta_{i l m}$ as:

$$
\delta_{i l m}=\gamma_{0}+\left(\theta+\chi_{i}\right) \ln \left(T_{i m}-\tau_{l m}\right)+\theta \beta /(1-\beta) \ln \left(w_{l m}\right)+\gamma_{1} X_{l m}
$$

Under the above assumptions, it is straightforward to show that the probability of prospective student $i$ choosing major $j$ at market-year $m$ is given by:

$$
P(j \mid i, m)=\frac{\exp \left(\delta_{i j m}\right)}{1+\sum_{k} \exp \left(\delta_{i k m}\right)}
$$

With no credit markets, only individuals who can afford a major will be able to enroll in it, i.e. only individuals with parental transfers $-T_{i m}-$ higher than tuition charged for a given major $j-\tau_{j m}$-will be able to choose major $j .{ }^{11}$ In this case the market share of major $j$ at market $m-s_{j m}$-is a function of the probability of enrolling at that specific major and the distribution of parental transfers at the market level, $f(t i)$ :

$$
s_{j m}=\int_{i} \mathbb{1}\left[T_{i m} \geq \tau_{j m}\right] \operatorname{Pr}(j \mid i, m) f(t i)
$$

When credit for higher education is available, students can borrow an amount $d_{i j m}$ in the first period to finance their education. First period

\footnotetext{
${ }^{11}$ If $T_{i m}<\tau_{j m}$, then $V_{i j m}^{C C}(n) \rightarrow-\infty$
} 
consumption is then given by:

$$
c_{i j m 1}=T_{i}-\tau_{j m}+d_{i j m}
$$

After the first first period, students must pay back what they borrowed. $i_{i j m t}$ represents this stream of repayments. For $t \geq 2$ :

$$
c_{i j t}=w_{j m}-i_{i j m t}
$$

We assume debt can only be used to finance tuition. In this case, we have $d_{i j m}=\phi_{i} \tau_{j m}$ with $0 \leq \phi_{i} \leq 1$. The stream of repayments $i_{i j m t}$ is a function of debt- $\phi_{i} \tau_{j m}$-and of market level interest rates $r_{m}$. The amount that students must pay back each period is then given by:

$$
i_{i j m t}=\sum_{t=1}^{\infty}\left(\frac{1}{1+r_{m}}\right)^{t} i_{i j m t}=\left(\frac{r_{m}}{1+r_{m}}\right) \phi_{i} \tau_{j m}
$$

Define $\delta_{i l m}^{\prime \prime}$ as:

$$
\delta_{i l m}^{\prime \prime}=\gamma_{0}+\left(\theta+\chi_{i}\right) \ln \left(T_{i m}-\tau_{l m}+d_{i l m}\right)+\theta \frac{\beta}{(1-\beta)} \ln \left(w_{l m}-i_{i l m t}\right)+\gamma_{1} X_{l m}
$$

Under the same assumptions as in the case with no credit markets, it is straightforward to show that the probability of prospective student $i$ choosing major $j$ at market-year $m$ is given by:

$$
P^{\prime \prime}(j \mid i, m)=\frac{\exp \left(\delta_{i j m}^{\prime \prime}\right)}{1+\sum_{k} \exp \left(\delta_{i k m}^{\prime \prime}\right)}
$$

When student credit is available, we can represent the market share of major $j$ at market $m$ by the following expression:

$$
s_{j m}^{\prime \prime}=\int_{i} \mathbb{1}\left[T_{i} \geq\left(1-\phi_{i}\right) \tau_{j m}\right] \operatorname{Pr}^{\prime \prime}(j \mid i, m) f(t i)
$$

From these theoretical market shares, we can estimate the model parameters using data aggregated at the market level (Nevo, 2000). We can also obtain measures of price-elasticities of demand. In the next section, we take this model to the data.

\section{7}

\section{Model of Major Choice - Results}

We estimate the model outlined in section 2.6 exploring FIES's significant 2010 expansion. As detailed in section 2.3, FIES was a relatively small program before 2010. After the program's reform in 2010, FIES-funded credit became largely available, even for students with relatively high family income. Since 
there is no evidence of a large private market for student loans in Brazil and FIES is the only federal government program that offers student loans, we assume that credit was unavailable before 2010 and largely available after 2010. That is, we assume a framework in which there are no credit markets before 2010 and no credit constraints after 2010 .

We define debt following FIES's rules at the time. According to these rules, FIES's loans would cover up to $100 \%$ of tuition expenses. The fraction of the tuition eligible for financing depends on family income and on the share between family income and tuition. We define debt as a share of tuition$d_{i j m}=\phi_{i} \tau_{j m}$. We assume that debt size depends on the ratio between tuition and family income. Specifically $\phi_{i}=1$ if tuition amounts to more than $60 \%$ of household income, $\phi_{i}=0.75$ if tuition is between $40 \%$ and $60 \%$ of household income, $\phi_{i}=0.5$ if tuition is between $20 \%$ and $40 \%$ of household income and $\phi_{i}=0$ otherwise.

We define market as the metropolitan area (or state)-year pair according to Brazil's National Household Sample Survey (PNAD) division. We define market size as the total population of 15-24 years old living in that market. Since the higher education industry is characterized by supply constraints, it is not trivial to define demand. We use two alternative definitions of demand: number of enrolled students - our preferred specification - and number of applicant students.

In section 2.6, we argue that the market share of a given major is a function of parental transfers net of tuition, wages and product characteristics. ${ }^{12}$ We obtain these information aggregating major-institution variables at the major-market level, as detailed in section 2.2. For most variables we use sample averages. For tuition, we consider market level minimums, as we are interested in estimating the impact of being constrained from choosing a given major. Later in this section we present the results obtained from using market means. From the National Household Sample Survey (PNAD), we obtain information on the distribution of income at the market level and, from the Consumer Expenditure Survey, we estimate the share of income families spend with education in Brazil. We draw parental transfer from these empirical distributions (Nevo, 2000).

Many unobserved characteristics can affect the cost of a major and it is not reasonable to assume that tuition is an exogenous variable. Identification, thus, requires the definition of a set of instruments $\left(Z_{j m}\right)$. It is reasonable to assume that the tuition charged for a given major is a function of the costs of

\footnotetext{
${ }^{12}$ We include the following characteristics in our estimation: proportion of faculty with at least a master's degree, number of applicants per maximum cohort size, standard deviation of major level wage, and average compensation for low skilled workers at the market level.
} 
Chapter 2. The Effect of Credit Constraints on Major Choice: Evidence from a Large Scale Student Loan Program in Brazil

supplying that major. It is also reasonable to assume that, once we control for tuition, individuals are not influenced by these costs when choosing a major. Cost shifters can thus be used as instruments for tuition. We consider the following cost shifters: wage of instructors (within each major), mean expense with faculty, mean expense with maintenance costs and mean expense with investment.

In table 2.5, we present the results of our structural estimation of demand. Results show that students care mostly about the costs and returns to different majors. For both definitions of demand, there is a significant and positive relation between major demand and parental transfers net of tuition. That is, students increase demand in response to either an increase in parental transfers or a reduction in tuition. Results reveal that sensitivity to net parental transfers varies across different income cohorts. Poorer individual are more sensitive to variations in net family income than higher income individuals. Demand is also positively and significantly related to major-specific labor market earnings. Other characteristics do not seem as relevant. 
Chapter 2. The Effect of Credit Constraints on Major Choice: Evidence from a Large Scale Student Loan Program in Brazil

Table 2.5: Demand for Higher Education Estimation

\begin{tabular}{lcc}
\hline & & $(1)$ \\
Variables & Enrolled & Applicant \\
& Students & Students \\
& & \\
\hline Parental Transfers net of Tuition - Low Income Cohort & $4.178^{* * *}$ & $3.115 * * *$ \\
& $(0.273)$ & $(0.238)$ \\
Parental Transfers net of Tuition - Middle Income Cohort & $2.621 * * *$ & $2.182 * * *$ \\
& $(0.255)$ & $(0.209)$ \\
Parental Transfers net of Tuition - High Income Cohort & $0.943 * * *$ & $0.842 * * *$ \\
Labor Market Returns & $(0.203)$ & $(0.176)$ \\
Faculty Quality & $2.004 * * *$ & $0.924 * * *$ \\
Applicants per Max Class Size & $(0.146)$ & $(0.124)$ \\
Major 0 Average Compensation & 0.316 & -0.286 \\
Wage Standard Deviation & $(0.525)$ & $(0.452)$ \\
Constant & $-0.076 * * *$ & -0.001 \\
& $(0.015)$ & $(0.015)$ \\
& -0.001 & 0.011 \\
& $(0.016)$ & $(0.015)$ \\
& $-0.001 * * *$ & 0.000 \\
& $(0.000)$ & $(0.000)$ \\
& $-34.752 * * *$ & $-23.535 * * *$ \\
& $(0.519)$ & $(0.468)$ \\
\hline
\end{tabular}

Notes: This table presents the results of a structural estimation of demand for different majors. We estimate a discrete choice model of demand that allows coefficients to vary at the individual level (Berry, Levinsohn and Pakes, 1995). Specifically, we allow the coefficient associated with sensitivity to net parental transfers - the difference between parental transfers and minimum market-level tuition - to vary according to individuals position in the market income distribution. The theoretical market shares we use in our estimation procedure are based on equation 2-8 for the period in which credit is not available - before the expansion of Brazil's federal government student credit program (FIES) - and equation 2-11 for the period in which credit is available - after FIES expansion. According to these equations, the demand for a given depends on parental transfers net of tuition, expected labor market returns, and major-level characteristics. We include the following major-level characteristics in our estimation: proportion of faculty with at least an MA (faculty quality), number of applicants per maximum cohort size, standard deviation of major level wage, and average compensation for low skilled workers at the market level. To control for the endogeneity of price we use four cost-shifters as instruments: wage of instructors (within each major), mean expense with faculty, mean expense with maintenance costs and mean expense with investment. We consider two alternative measures of demand: number of enrolled students - column (1) - and number of applicant students - column (2). We also included year and field of study fixed effects. Standard errors in parentheses. ${ }^{* * *} \mathrm{p}<0.01,{ }^{* *} \mathrm{p}<0.05,{ }^{*} \mathrm{p}<0.1$ 
Chapter 2. The Effect of Credit Constraints on Major Choice: Evidence from a Large Scale Student Loan Program in Brazil

Having estimated the structural parameters of demand, we are now able to assess how the expansion of student credit influences the demand for a given major. We use the results from the previous estimation to perform a counterfactual exercise that evaluates the impact of credit availability on the market share of different majors. Specifically, we use our estimated parameters to infer what would the market share of each major be in the post FIES period if credit were still unavailable. We then compare the counterfactual market shares with actual market shares. Table 2.6 presents the results of this exercise. Results show that the market share of all major increased after the introduction of a credit market for education. This result indicates that the market share of the outside option, not enrolling at private higher education decreased. Credit availability increased, thus, overall demand for private higher education. Table 2.6 also shows that the market share increase was not homogeneous across majors. The increase in number of enrolled students was higher for some of the above median cost and return majors in our sample-Medicine, Engineering and Law. 
Chapter 2. The Effect of Credit Constraints on Major Choice: Evidence from a Large Scale Student Loan Program in Brazil

Table 2.6: Counterfactual Exercise - Average Market Share Change

\begin{tabular}{lc}
\hline & $(1)$ \\
Major & Enrolled Students \\
& \\
\hline Education & 0.25 \\
Humanities/Arts & 0.33 \\
Social Sciences/Business & 0.27 \\
Law & 0.37 \\
Science/Math/Computing & 0.35 \\
Engineering & 0.40 \\
Agricultural Sciences & 0.26 \\
Health & 0.37 \\
Medicine & 0.43 \\
Odontology & 0.25 \\
Others & 0.36 \\
\hline
\end{tabular}

Notes: This table presents the results of a counterfactual exercise based on the estimated parameters of table 2.5 column (1). This exercise calculates the impact of credit availability on demand. Specifically, we compute what would the market share of each major be in the period after the expansion of Brazil's federal government student credit program (FIES) if credit for higher education was unavailable in that period - the counterfactual market shares. We then compare these counterfactual market shares whit the market shares actually observed in the post credit expansion period. This table presents the average increase in market share across markets for each major.

We use the empirical demand model outlined in section 2.6 to calculate the elasticity of demand for a given major to variation in tuition prices. ${ }^{13}$ The price elasticity of demand is a measure of how strongly consumers respond to changes in the price of a product. Several factors can influence how sensitive consumers are to price change. In our framework, availability of credit can be one such factor. When credit is available, consumers that have strong preference for higher education can afford to enroll, even when prices increase considerably. We can use our framework to calculate: (i) the price elasticity of demand for different majors, and (ii) the variation in price elasticity before and after the introduction of a market for student credit in Brazil. Table 2.7 presents the results of this exercise. Results show that there is considerable variation in price elasticity across majors both before and after the introduction of a credit market. Results also reveal that demand becomes less sensitive to

\footnotetext{
${ }^{13}$ We derive the functional form of empirical elasticities in section B.2.
} 
price for all majors after the introduction of FIES. The relative decreases is again heterogeneous across majors and was more significant for a set of high cost high returns majors: Medicine, Engineering, Law, and Odontology.

Table 2.7: Average Price Elasticity of Demand

\begin{tabular}{cccc}
\hline \hline & $(1)$ & $(2)$ & $(3)$ \\
Major & Price Elasticity & Price Elasticity & Variation in \\
& Pre FIES & Post FIES & Price Elasticity \\
\hline Education & -5.046 & -4.354 & -0.137 \\
Humanities/Arts & -6.310 & -3.779 & -0.401 \\
Social Sciences/Business & -5.028 & -3.914 & -0.222 \\
Law & -3.178 & -1.192 & -0.625 \\
Science/Math/Computing & -5.382 & -3.394 & -0.369 \\
Engineering & -4.703 & -1.657 & -0.648 \\
Agricultural Sciences & -2.680 & -1.626 & -0.393 \\
Health & -5.908 & -2.525 & -0.573 \\
Medicine & -1.610 & -0.187 & -0.884 \\
Odontology & -0.958 & -0.015 & -0.985 \\
Others & -6.505 & -3.915 & -0.398 \\
\hline
\end{tabular}

Notes: This table presents the estimated price elasticity of demand for different majors both in the period in which student credit was not available - the pre FIES period - and the period in which student credit was available - the post FIES period. We also show in this table the variation in price elasticity between the pre and post FIES periods (column (3)). We compute the empirical price elasticity of demand for each market using he estimated parameters of table 2.5 column (1) and the price elasticity expressions derived in section B.2. In this table we present the average elasticity of demand across markets.

Finally, as a robustness check, we estimate our model considering a different measure of cost, mean tuition for each major-market pair. Results are shown in table 2.8 and are consistent with previous estimates. Again, cost and returns are shown to have significant influence over major choice and demand of poorer individuals is more sensitive to market conditions. 
Table 2.8: Demand for Higher Education Estimation - Robustness

\begin{tabular}{lcc}
\hline & & \\
Variables & Enrolled & Applicant \\
& Students & Students \\
\hline Parental Transfers net of Tuition - Low Income Cohort & $3.955 * * *$ & $3.922 * * *$ \\
Parental Transfers net of Tuition - Middle Income Cohort & $(0.266)$ & $(0.271)$ \\
& $3.095 * * *$ & $3.166 * * *$ \\
Parental Transfers net of Tuition - High Income Cohort & $(0.292)$ & $(0.276)$ \\
Labor Market Returns & 0.018 & 0.167 \\
Faculty Quality & $(0.227)$ & $(0.219)$ \\
Applicants per Max Class Size & $2.176 * * *$ & $1.107 * * *$ \\
Major 0 Average Compensation & $(0.151)$ & $(0.151)$ \\
Standard Deviation of Wage & 1.379 & 0.855 \\
& $(0.634)$ & $(0.636)$ \\
& $-0.061 * * *$ & 0.011 \\
& $(0.012)$ & $(0.017)$ \\
& 0.003 & 0.005 \\
& $(0.014)$ & $(0.017)$ \\
& $-0.001 * * *$ & 0 \\
& $-37.505 * * *$ & $-30.184 * * *$ \\
& $(0.55)$ & $(0.582)$ \\
\hline
\end{tabular}

Notes: This table presents the results of a structural estimation of the demand for different majors. We estimate a discrete choice model of demand that allows coefficients to vary at the individual level (Berry, Levinsohn and Pakes, 1995). Specifically, we allow the coefficient associated with sensitivity to net parental transfers - the difference between parental transfers and mean market-level tuition - to vary according to individuals position in the market income distribution. The theoretical market shares we use in our estimation procedure are based on equation 2-8 for the period in which credit is not available - before the expansion of Brazil's federal government student credit program (FIES) - and equation 2-11 for the period in which credit is available - after FIES expansion. According to these equations, the demand for a given depends on parental transfers net of tuition, expected labor market returns, and major-level characteristics. We include the following majorlevel characteristics in our estimation: proportion of faculty with at least an MA (faculty quality), number of applicants per maximum cohort size, standard deviation of major level wage, and average compensation for low skilled workers at the market level. To control for the endogeneity of price we use four cost-shifters as instruments: wage of instructors (within each major), mean expense with faculty, mean expense with maintenance costs and mean expense with investment. We consider two alternative measures of demand: number of enrolled students - column (1) - and number of applicant students - column (2). We also included year and field of study fixed effects. Standard errors in parentheses. $* * * \mathrm{p}<0.01$, ** $\mathrm{p}<0.05, * \mathrm{p}<0.1$ 


\section{8}

\section{Conclusion}

In this paper we aim to investigate what factors influence students' choice between different majors. We also evaluate how credit constraints can impact major choice in a context in which students choose major during the college application process and the costs of higher education vary at the major level. To understand how credit constraints can determine major choice, we develop a dynamic model of human capital investment. In the framework of our model, lower income individuals are constrained in their choice between different majors when credit is unavailable. We show that, in Brazil, there is a strong correlation between the average tuition and the average wage from a major at the metropolitan area (or state) level. This evidence suggests that students intending to enroll in higher return majors often have to pay higher tuition costs. According to our model, these individuals might be constrained in their ability to choose high-cost high-returns majors. A policy that expands access to student credit can, thus, impact the distribution of major choice across different income cohorts.

To empirically evaluate the determinants of major choice and the role credit constraints play on students' decision, we adapt our model to fit the framework of a classic discrete choice model of demand (Berry, Levinsohn and Pakes, 1995). We estimate the model exploring the expansion of a large government-funded student credit program in Brazil (FIES). Specifically, we assume that individuals making human capital decisions before the expansion of the government credit program were credit constrained while individuals making decisions after that period were not. We estimate the model using data on demand for different majors offered by private higher education institutions in Brazil. Our results show that demand is significantly influenced by both the costs and returns to higher education. Our results also indicate that the demand of individuals from the lower end of the household income distribution is more sensitive to changes in tuition prices. Using our estimated parameters to investigate the impact of credit availability on market composition, we show that the expansion of FIES increased enrollment in private higher education as whole and had a higher than average impact on majors considered high cost and high return. Our results fit the predictions of our theoretical analysis, i.e., we show that lower income individuals increase their demand for high-cost high-return when student loans are available. 


\section{3}

\section{The Impact of Water Scarcity on Educational Outcomes: Evidence from a Water Rationing Policy in Brazil}

\section{1 \\ Introduction}

As climate change unfolds, extreme climate events - and the direct and indirect losses caused by it - are likely to become more frequent. Understanding their consequences and how to mitigate their costs is crucial for effective policy making. In this paper, we investigate if water shortages caused by an extreme climate event have an impact on educational performance. We answer this question exploring the consequences of a water rationing policy in Brazil. In 2017, following a record-breaking drought, the regional government of Brazil's Federal District - the federal unit where the country's capital, Brasília, is located-implemented a water rationing schedule for neighborhoods served by two water reservoirs that were severely hit by the drought. We estimate the causal impact of the water rationing on academic outcomes evaluating its impact on students' performance in standardized evaluations. Through a difference-in-differences design, we compare the performance of students enrolled in schools located in areas subject to the rationing scheme against the performance of students enrolled in schools located in unaffected areas, controlling for differences in performance and other relevant factors that were present before the rationing. We find that the water rationing has a negative and significant impact on academic performance.

Similar shortages in water supply are likely to occur in Brazil's Federal District and other regions around the globe as climate change increases variability in precipitation (Pendergrass et al., 2017) and decreases the reliability of water supply systems in urban areas (O'Hara and Georgakakos, 2008). From a policy perspective, it is crucial to understand the consequences of such shortages and the mechanisms through which inadequate water supply can impact skill formation. Our results show that a predictable shortage in water supply caused by an extreme climate event has a significant negative impact on students' performance in standardized evaluations. This impact does not vary by students socioeconomic background, but it is significantly stronger for students 
enrolled in schools with poor infrastructure. There is a growing literature exploring what type of investments are needed to mitigate the consequences of climate change (Bento et al., 2020). We show that schools with good infrastructure can partially offset the negative impact of unreliable water supply systems on students' performance. Our results, thus, suggest the importance of investing in climate resilient infrastructure at the school level, as we adapt to the consequences of climate change.

Related Literature: We build upon three distinct strands of literature. First, our work contributes to a literature that evaluates the impact of extreme climate events on educational outcomes. According to this literature, climate shocks can impact educational performance through children's exposure to extreme temperatures or precipitation conditions. Many of the papers in this literature focus on the impact of being exposed to extreme climate during early childhood. Randell and Gray (2019) investigate the impact of climatic conditions experienced in utero and during early childhood on educational attainment using data from 30 countries. They find that children exposed to higher than average temperatures in Southeast Asia attain fewer years of education and that rainfall is positively correlated with attainment in Southeast Asia and West and Central Africa and negatively correlated with attainment in Central America and the Caribbean. Aguilar and Vicarelli (2018) explore exogenous extreme weather variations caused by the El Niño Southern Oscilation and find that children exposed to extreme climate events during early childhood present lower cognitive development between the ages of 2 and 6 years old. Shah and Steinberg (2017) show that positive rainfall shocks in India, if experienced during early childhood, improve educational outcomes. In this paper, we explore the impact of an extreme climate event that led to the implementation of a water rationing schedule on the academic performance of school-age children. We find a negative impact of rationing on academic performance, showing that older children in urban environments are also vulnerable to the consequences of extreme climate shocks.

Our work also contributes to a literature that explores the impact of school resources and investment in physical capital on educational attainment. The evidence on the relationship between infrastructure and educational attainment is mixed. In an extensive review of the early literature, Hanushek (1997) finds no systematic relationship between school resources and academic output. More recent studies also find mixed results. Neilson and Zimmerman (2014) evaluate the impact of a large infrastructure investment program in a poor, urban U.S. school district and find a positive impact on reading scores for elementary and middle school students. Martorell, Stange and McFarlin (2016) 
explore discontinuities in the approval of school capital bonds at the school district level in Texas to estimate their impact on students' outcome. They find a significant impact of bond approval on capital investment, but no effect on achievement. Papers exploring the importance of infrastructure in regions with poor or non existent school facilities tend to find larger effects (Duflo (2001), Aaronson and Mazumder (2011), Jasper, Le and Bartram (2012)).

Finally, our work contributes to a growing literature on climate adaptation and on the investments required to mitigate the impact of extreme climate events (Council (2010), Smith (2011), Deschênes and Greenstone (2011), Carleton et al. (2020) Bento et al. (2020)). We show that the negative impact of water rationing on students' performance is significantly stronger for students enrolled in schools with poor infrastructure. In this sense, our work is closely related to Goodman et al. (2018) and their evaluation of the impact of heat on educational attainment. Goodman et al. (2018) evaluate the relation between the performance of PSAT-retakers and their exposure to extreme heat in the years before the exam and concludes that cumulative heat exposure hinders cognitive development. Using data on air-conditioning at the school level, they conclude that infrastructure largely offsets the impact of heat. Both our work and Goodman et al. (2018) highlight how proper infrastructure at the schoollevel can serve an important role mitigating the impact of extreme climate events. As climate change increases the likelihood of such events, the relationship between investment in infrastructure and educational achievement is likely to become more pronounced.

\section{2}

\section{Institutional Framework}

To evaluate if shocks in water supply impact students' performance, we analyze the academic outcomes of students enrolled in schools subject to a water rationing scheme implemented by the regional government of Brazil's Federal District. The Federal District - or Distrito Federal (DF) - is one of Brazil's 27 federal units. It is the smallest federal unit in the country and it is where the capital of the country-Brasilia - is located. The district is organized into 33 administrative regions (ARs) and all administrative regions are administered by a single elected official, the region's Governor.

Distrito Federal is located in an area of tropical savanna climate with two distinctive seasons: a rainy season from October to April and a dry season from May to September. The water supply in the region is organized at the Administrative Region level, i.e., all households within a given Administrative Region get their public water supply from the same system. Two large 
reservoirs-Descoberto and Santa Maria - serve 27 Administrative Regions. The other six Administrative Regions ${ }^{1}$ get their water supply from independent systems.

In the past decade, changes in regular rain schedules, a growing urban population, and insufficient investment in the systems for storage and distribution of water have seriously compromised the reliability of the region's water supply. In the years of 2016, 2017, and 2018 the water supply crisis reached its peak. Figure 3.1 illustrates the precipitation accumulated between rainy seasons on the reservoirs of Santa Maria and Descoberto through the years between 2001 and 2019. Figure 3.1 shows that accumulated precipitation tends to average between 1000 and 1500 millimeters per year, with some variation between years. Lower than average rainfall years are usually followed by higher than average rainfall years. Figure 3.1 also shows that this was not the case for the years of 2015, 2016, and 2017. A lower than average rainfall year-2015was followed by a record breaking drought in 2016 and by another lower than average rainfall year in 2017. Precipitation levels have a direct impact on the volume of the region's water reservoirs. Figure 3.2 shows the water volume of Descoberto - panel (a) — and Santa Maria - panel (b) - reservoirs as a percentage of total capacity in the years between 2010 and 2018. Between 2010 and 2015, water capacity in the two reservoirs followed a similar pattern reaching a peak of $100 \%$ during the rainy season and a minimum of approximately $50 \%$ at Descoberto and $75 \%$ at Santa Maria during the dry season. Starting in 2016, we see a clear change in this pattern. By the end of 2016, Descoberto reached $20 \%$ of capacity and Santa Maria 40\%. With the rainy season, the water volume increased, but by less than what was needed to reach full capacity, with Descoberto and Santa Maria reaching only $50 \%$ of capacity by the end of the rainy season. By the end of 2017, Descoberto reached $6 \%$ of capacity and Santa Maria 20\%.

${ }^{1}$ Brazlândia, Fercal, Planaltina, Sobradinho, Sobradinho II, and São Sebastião 
Figure 3.1: Precipitation Accumulated Between Rainy Seasons (mm)

(3.1(a)) Descoberto Reservoir

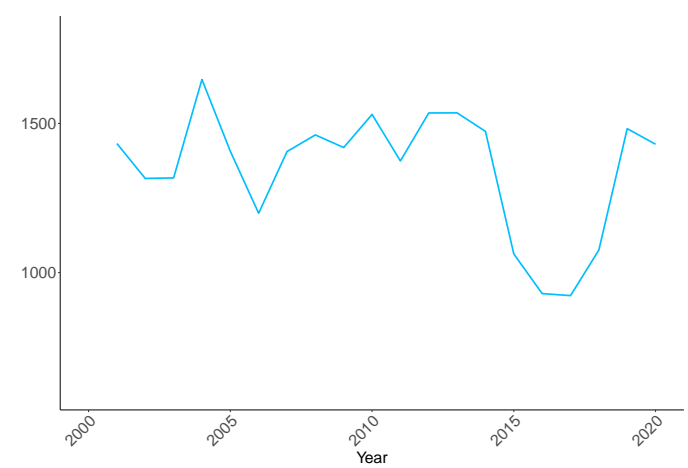

(3.1(b)) Santa Maria Reservoir

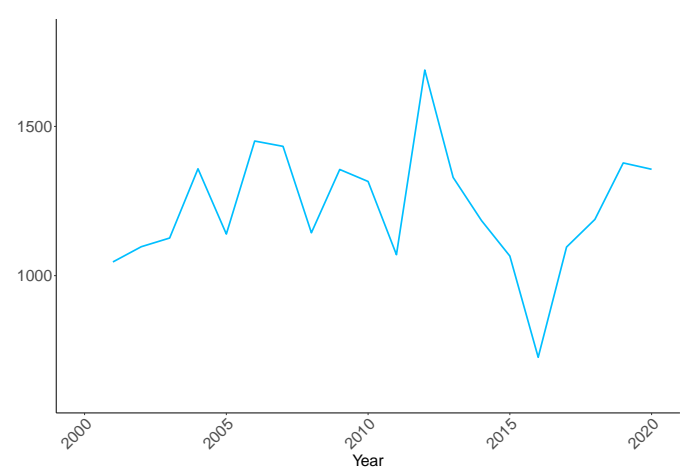

Notes: This figure illustrates the precipitation accumulated between rainy seasons on the reservoirs of Santa Maria and Descoberto through the years from 2001 to 2019. The data source is the Regulatory Agency of Water, Energy and Basic Sanitation of the Federal District (ADASA).

Figure 3.2: Water Volume at the End of the Month (\% of Total Capacity)

(3.2(a)) Descoberto Reservoir

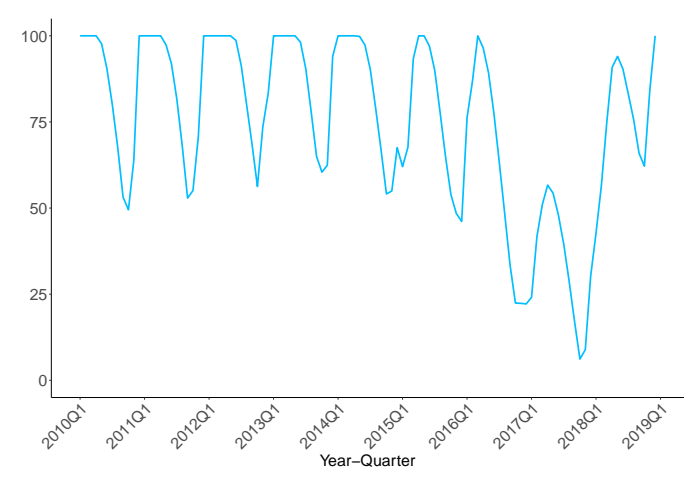

(3.2(b)) Santa Maria Reservoir

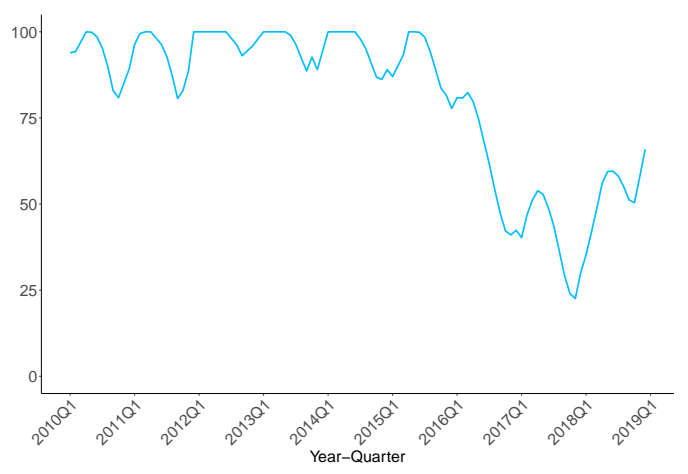

Notes: This figure illustrates the water volume of Descoberto and Santa Maria reservoirs as a percentage of total capacity in the years between 2010 and 2018. The data source is the Regulatory Agency of Water, Energy and Basic Sanitation of the Federal District (ADASA).

As an initial response to the water crisis, the regional government established, in October of 2016, an emergency tariff, increasing the costs of water supply for consumers. The emergency tariff did not significantly decrease consumption and additional measures were needed to avoid a total collapse of the region's water supply system. In February of 2017, the regional government established a water rationing schedule for all Administrative Regions served by the Descoberto reservoir - 16 ARs total. Three weeks later the water rationing schedule was extended to the regions served by the Santa Maria reservoir - 11 ARs. The regions served by the independent systems were only included in the 
rationing schedule nine months later, by the end of the academic year. The water rationing lasted until June of 2018.

The rationing was established at the Administrative Region level. According to the rationing schedule, neighborhoods in the affected area would have their water supply shut down for a period of 24 hours every six days, possibly having to wait an additional 24 hours for normalized supply. Figure 3.3 presents a map of Distrito Federal that identifies the Administrative Regions impacted by the rationing - the Treatment Group. The rationing did impact water consumption. Detailed data on water consumption are not available, but according to a report from the local planning and development agency - CODEPLANthe consumption of water in the region decreased by $9.5 \%$ between 2017 and 2016 (Codeplan, 2018). The report also shows that the Administrative Regions not initially included in the rationing - our Control Group-decreased their consumption of water at a significantly lower rate than affected ARs.

Figure 3.3: Distrito Federal Map - Treatment and Control Groups

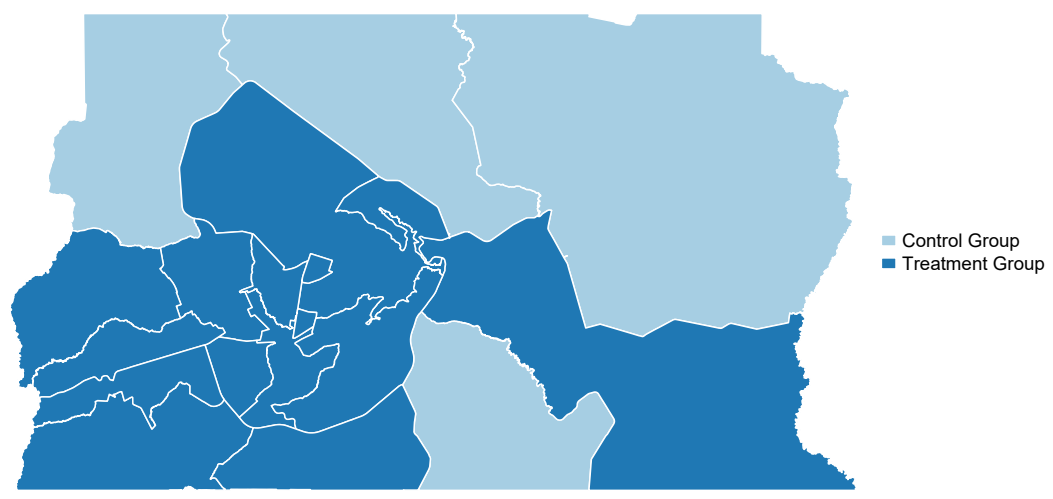

\section{3}

Data

We evaluate the impact of water supply shortages on students' performance using data from Brazil's national evaluation of primary education schools, the Sistema de Avaliação da Educação Básica (SAEB). The SAEB evaluation is conducted every two years by INEP, an independent government agency linked to Brazil's Ministry of Education. All public schools that enroll at least ten students in fifth and ninth grade and a sample of private schools that meet these criteria are included in the evaluation. The SAEB data contains information on a set of surveys administered to students, teachers and principals. These surveys collect information on students' social economic background, schools' resources, safety and infrastructure and teachers perspective 
on learning environment and main challenges for education. SAEB data also provide information on student-level performance in a standardized test designed to evaluate students academic readiness in math and portuguese - the Prova Brasil. The data are publicly available. ${ }^{2}$.

We use data from Prova Brasil to evaluate how shocks in water supply at the school level impact students' academic performance. We restrict our sample to students taking the Prova Brasil exam between 2007 and 2017 while enrolled in a school located at Distrito Federal. ${ }^{3}$ SAEB data does not contain neighborhood or location information. From SAEB's school code, we are able to identify the neighborhood in which the school is located using data provided by INEP. ${ }^{5}$ We present descriptive statistics on table 13 of section C.1. We have information on 317,734 students. Students in our sample are mostly from public schools and from underprivileged backgrounds. $50 \%$ of the students are female, and $60 \%$ are black or brown. $30 \%$ of the students do not have access to a computer at home and $40 \%$ do not own a car. Only $13 \%$ (or 12\%) of the students in our sample have a mother (or father) that completed higher education. $30 \%$ of the students in our sample have failed a grade in the past.

To explore mechanisms, we use information at the school level. Specifically, we collect information on school's physical infrastructure, safety measures, and available resources through SAEB's school survey. This survey is based on the evaluation of an external reviewer. We use this information to explore how different school-level factors impact students' performance. We present descriptive information on table 14 of section C.1. $94 \%$ of the schools in our sample are public and $91 \%$ are located on urban areas. The quality of school infrastructure and available resources is measured in a scale from one - nonexistent - to four-good. Safety measures are evaluated as existent or nonexistent.

\section{4}

\section{Empirical Strategy}

The Administrative Regions originally included in the rationing schedule are different from the ones not included in several aspects. As table 3.1 details, students from the control region are on average poorer and from less educated households. They also have lower grades in both the portuguese and math exams from Prova Brasil and are more likely to have failed a grade

${ }^{2} \mathrm{SAEB}$ data is available through http://inep.gov.br/microdados

${ }^{3}$ According to SAEB rules ${ }^{4}$, Prova Brasil results from schools in which less than ten students or less than $80 \%$ of enrolled students took the exam are not made publicly available. We do not include these schools in our sample.

${ }^{5}$ http://idebescola.inep.gov.br/ideb/consulta-publica. 
in the past. To estimate the causal impact of the water rationing, we must control for observable and unobservable characteristics unrelated to treatment. We identify the causal impact of the water rationing on students' academic performance using a Difference-in-Differences (DD) framework.

Table 3.1: Descriptive Statistics - Treatment vs. Control Groups

\begin{tabular}{|c|c|c|c|c|}
\hline \multirow[b]{2}{*}{ Variable } & \multicolumn{2}{|c|}{ Treatment Group } & \multicolumn{2}{|c|}{ Control Group } \\
\hline & Mean & S.D. & Mean & S.D \\
\hline Grade Mean - Portuguese $(0,1)$ & -0.46 & $(0.92)$ & -0.56 & $(0.88)$ \\
\hline Grade Mean - Math $(0,1)$ & -0.24 & $(0.86)$ & -0.33 & $(0.81)$ \\
\hline Female Student & 0.50 & $(0.50)$ & 0.50 & $(0.50)$ \\
\hline Black Student & 0.10 & $(0.31)$ & 0.11 & $(0.31)$ \\
\hline Brown Student & 0.49 & $(0.50)$ & 0.50 & $(0.50)$ \\
\hline Does your family own a car? (Y/N) & 0.62 & $(0.49)$ & 0.57 & $(0.49)$ \\
\hline Do you have a computer at home? (Y/N) & 0.71 & $(0.46)$ & 0.64 & $(0.48)$ \\
\hline Mother Education - Never Studied or Less than elementary & 0.05 & $(0.22)$ & 0.07 & $(0.26)$ \\
\hline Mother Education - Elementary School & 0.13 & $(0.34)$ & 0.16 & $(0.37)$ \\
\hline Mother Education - College & 0.14 & $(0.34)$ & 0.10 & $(0.30)$ \\
\hline Father Education - Less than elementary & 0.07 & $(0.25)$ & 0.09 & $(0.29)$ \\
\hline Father Education - Elementary School & 0.10 & $(0.30)$ & 0.12 & $(0.33)$ \\
\hline Father Education - College & 0.13 & $(0.33)$ & 0.09 & $(0.29)$ \\
\hline Parents Incentive Score & 4.39 & $(1.07)$ & 4.38 & $(1.07)$ \\
\hline Do you work? (Y/N) & 0.09 & $(0.29)$ & 0.10 & $(0.30)$ \\
\hline Have you ever failed a grade $(\mathrm{Y} / \mathrm{N})$ & 0.29 & $(0.45)$ & 0.33 & $(0.47)$ \\
\hline Have you ever dropout of school? $(\mathrm{Y} / \mathrm{N})$ & 0.05 & $(0.21)$ & 0.05 & $(0.22)$ \\
\hline Observations & 242382 & & 70352 & \\
\hline
\end{tabular}

$\overline{\overline{N o t e s} \text { : This table presents descriptive statistics for the final students' sample. This sample }}$ includes students who took the math and portuguese Prova Brasil exam between 2007 and 2017 while enrolled at a school located at Distrito Federal. We do not include in our sample schools that are not identifiable in the date. We divide the sample by treatment status. In the treatment groups we include all students enrolled in schools located on a neighborhood subject to Distrito Federal's water rationing. In the control group we include students enrolled in non-affected schools.

Identification on a Difference-in-Differences framework relies on the assumption that the variable of interest - in our case, academic performancewas following a parallel trend for treatment and control units before the policy implementation - before the rationing schedule was implemented - and would have continued following a parallel trend if there had not been an intervention, i.e., in a counterfactual scenario. We cannot test how reasonable the counterfactual parallel trend hypothesis is. However, we can test the differential pre-trend hypothesis. In figure 3.4 we present the result of a event 
study analysis performed using our data. In this analysis, we compare students' performance in the Prova Brasil exam for students enrolled in schools that are part of the treatment group against students enrolled in schools part of the control group for every year with information available between 2007 and 2017. According to the results of this analysis, the difference in academic performance between units in the treatment and control group followed an increasing trend before the 2017 rationing, i.e., the difference between treatment and control units was decreasing through time at a constant rate. In 2017, we see a clear break from the previous trend, with a significant negative shock on the academic performance of students enrolled in schools located on neighborhoods affected by the rationing.

Figure 3.4: Impact of Water Rationing on Academic Performance

(3.4(a)) Portuguese

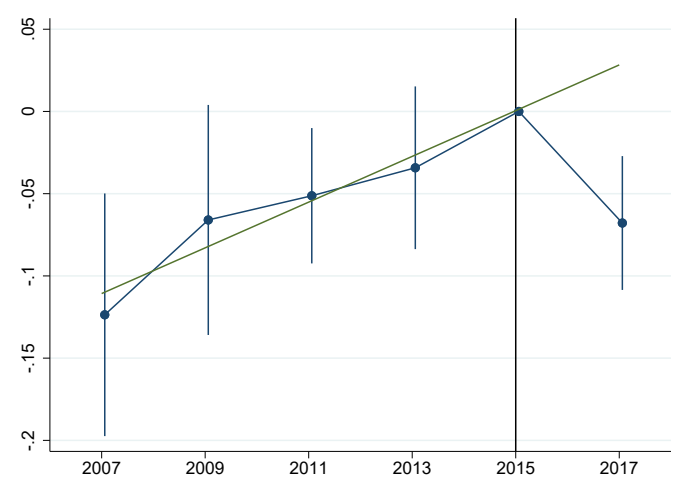

(3.4(b)) Math

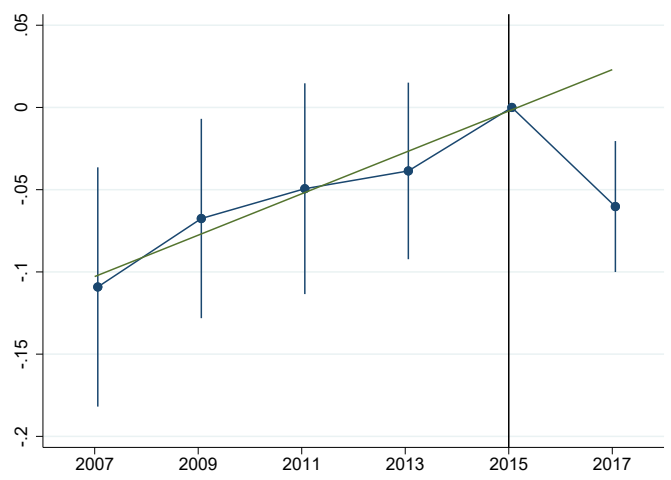

Notes: This figure shows the result of a event study analysis that represents the difference in academic performance on Prova Brasil of students enrolled in schools located in neighborhoods impacted by the water rationing (treatment group) against academic performance of students enrolled in non-affected schools (control group). The dots in the graph represent the point estimates of the treatment effect for each year. The vertical lines represent a $95 \%$ confidence interval. We also include in this figure a line representing the increasing trend that existed before treatment. The specification in this figure includes school and school-grade fixed effects. It also includes student level covariates, including information on gender, race, family income, parents' education, parents' support, and information on grade retention and school abandonment. Standard errors were computed with observations clustered at neighborhood level.

To obtain an estimate of the causal impact of being enrolled in a school located in a region subject to water rationing on students' academic performance, we run the following regression: 
Grade $_{i j t}=\alpha_{1}+\alpha_{2} D_{t} *$ Treatment $_{j}+\alpha_{3} D_{t}+\alpha_{4}$ Treatment $_{j}+\alpha_{5} X_{i j t}+\alpha_{6} t_{i t}+\varepsilon_{i j t}$

Here Grade $_{i j t}$ represents the outcome of interest, the performance of student $i$, enrolled at school $j$ on year $t$ in the Prova Brasil exam. Treatment is a binary variable that takes the value of one if school $j$ is located on a neighborhood impacted by the water rationing. The binary variable $D_{t}$ takes the value of zero for the pre treatment period - the years of 2007, 2009, 2011, 2013, and 2015 - and the value of one for the post treatment period, i.e., for observations in the year of 2017. We include student-level covariates $\left(X_{i j t}\right)$ and time, school and school-grade fixed effects $\left(\varepsilon_{i j t}\right)$. To control for the fact that the difference in academic performance of students in the treatment and control groups was following an increasing constant trend through time before treatment, we include the variable $t_{i t}$ representing years since the treatment for units in the treatment group (Gross, Notowidigdo and Wang, 2020). We present the results from this estimation on table 3.2. For all specifications considered, the treatment effect - the impact of being enrolled at a school located on a neighborhood affected by the water rationing - is negative and significant. Specifically, we find that students enrolled in affected schools get a grade 0.076 points smaller in the language exam and 0.08 smaller in the math exam, even after controlling for year, school, school-grade fixed effects and a set of covariates at the student level. In the next section, we explore some possible mechanisms for this result. 
Chapter 3. The Impact of Water Scarcity on Educational Outcomes: Evidence from a Water Rationing Policy in Brazil

Table 3.2: Treatment Effect: Water Rationing on Academic Performance

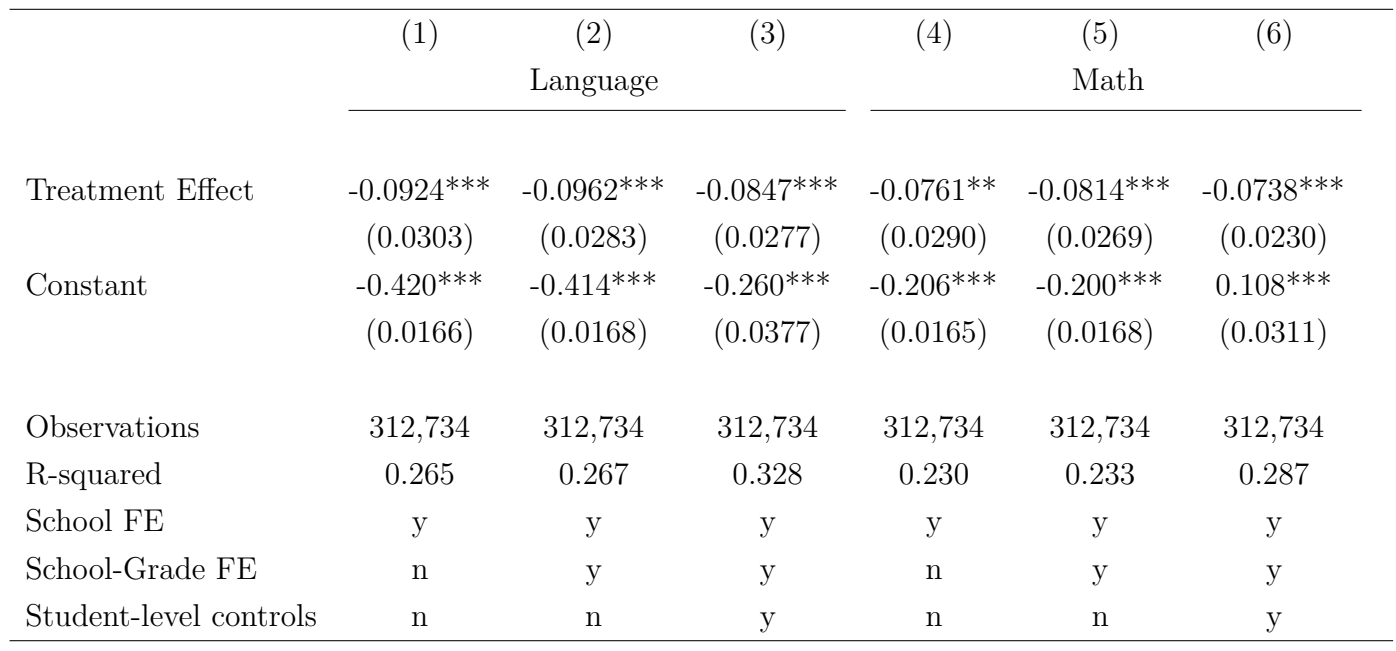

Notes: This table presents the results of a difference-in-differences (DD) analysis that compares the academic performance on Prova Brasil of students enrolled in schools located in neighborhoods impacted by the water rationing against academic performance of students enrolled in non-affected schools (equation 3-1). In this DD, the pre-treatment period consists of the years that precede water rationing (2007, 2009, 2011, 2013, and 2015). The post-treatment period consists of the year the water rationing was implemented (2017) the expansion (2011 through 2014). The estimated coefficients associated with the "Treatment Effect" variable represent the impact of being enrolled in a school subject to rationing on academic performance. In columns (1), (2), and (3) we use students' grade on the Prova Brasil Language evaluation as a measure of academic performance. In columns (4), (5), and (6) we use students grade on the Math evaluation as a measure of academic performance. We include year fixed effects in all specifications. Student level controls include information on gender, race, family income, parents' education, parents' support, and information on grade retention and school abandonment. Standard errors were computed with observations clustered at neighborhood level. ${ }^{* * *}$ represents p-value $<0.01,{ }^{* *}$ p-value $<0.05$, and ${ }^{*}$ p-value $<0.1$.

\section{5}

\section{Mechanisms}

In section 3.4, we conclude that being enrolled at a school located on a neighborhood subject to the water rationing schedule cause students to get lower grades in Prova Brasil's math and language evaluations. There are a few mechanisms through which water scarcity could affect students performance. In this section, we explore which factors are related to the negative impact of rationing on performance and discuss possible mechanisms. We start by collecting information on teachers' beliefs regarding the factors that affect students' academic performance and evaluating if these factors change for 
schools affected by the rationing. The Prova Brasil teachers' survey asks teachers to identify the factors they believe are relevant in explaining the poor performance of some of their students. According to the Prova Brasil survey, teachers believe that students' performance depend on students' individual characteristics, family and socioeconomic background, attendance, school-level resources, and teachers' work conditions and motivation. Table 15 of section C.1 presents descriptive information on these data. To evaluate if there is a differential impact for any of these factors between treatment and control units after the treatment-i.e. after the beginning of the water rationingwe perform a difference-in-differences analysis for each factor mentioned in the teachers' survey. Table 3.3 presents the results of this analysis. Results show a significant impact for only one factor, school infrastructure. We find that teachers from schools in the treatment group significantly increased their likelihood of indicating schools' infrastructure as one of the culprits for the poor performance of their students. 
Table 3.3: Treatment Effect : Reasons for Students' Poor Performance

\begin{tabular}{|c|c|c|}
\hline $\begin{array}{l}\text { Reason for Students' } \\
\text { Poor Performance }\end{array}$ & $\begin{array}{c}\text { Treatment } \\
\text { Effect }\end{array}$ & $\mathrm{N}$ \\
\hline School Infrastructure & $\begin{array}{c}0.062^{*} \\
(0.034)\end{array}$ & 12125 \\
\hline Pedagical Supervision & $\begin{array}{c}0.050 \\
(0.034)\end{array}$ & 7609 \\
\hline Inadequate Curriculum & $\begin{array}{c}0.042 \\
(0.031)\end{array}$ & 12103 \\
\hline Past Learning & $\begin{array}{c}-0.035 \\
(0.048)\end{array}$ & 12127 \\
\hline Excess Work for Teachers & $\begin{array}{c}0.008 \\
(0.021)\end{array}$ & 12083 \\
\hline Teachers' Lack of Motivation & $\begin{array}{c}0.003 \\
(0.029)\end{array}$ & 12019 \\
\hline Students' Social Environment & $\begin{array}{c}-0.002 \\
(0.009)\end{array}$ & 12093 \\
\hline Parents' Cultural Level & $\begin{array}{c}0.026 \\
(0.019)\end{array}$ & 12100 \\
\hline Parents' Lack of Assistance & $\begin{array}{c}-0.013 \\
(0.012)\end{array}$ & 12107 \\
\hline Students' Low Self Esteem & $\begin{array}{c}-0.043 \\
(0.030)\end{array}$ & 12128 \\
\hline Students' Poor Motivation/Effort & $\begin{array}{l}-0.015 \\
(0.013)\end{array}$ & 12116 \\
\hline Students' Indiscipline & $\begin{array}{c}0.018 \\
(0.037)\end{array}$ & 12113 \\
\hline Students' Poor Attendance & $\begin{array}{c}0.010 \\
(0.050)\end{array}$ & 7611 \\
\hline
\end{tabular}

Notes: Each line of this table present the results of a difference-in-differences (DD) analysis comparing how teachers' perception on different culprits for students' poor performance changed for teachers in the treatment group against teachers in the control group. We include in the treatment group teachers in schools located in neighborhoods impacted by the water rationing a and in the control group teachers in non-affected schools. In this $\mathrm{DD}$, the pre-treatment period consists of the years that precede the water rationing (2007, 2009, 2011, 2013, and 2015). The post-treatment period consists of the year the water rationing was implemented (2017). The first column lists the different independent variables included in this analysis. The second column presents the estimated coefficients associated with "Treatment Effect" and standard errors (in parenthesis). The third column presents sample size. We include school and year fixed effects. Standard errors were computed with observations clustered at neighborhood level. ${ }^{* * *}$ represents p-value $<0.01$, ** $\mathrm{p}$-value $<0.05$, and ${ }^{*}$ p-value $<0.1$. 
To evaluate if teachers' impression on the growing importance of infrastructure for the performance of students enrolled in schools affected by the rationing is consistent with the available information on the quality of infrastructure at the school level, we perform a heterogeneous treatment analysis. From the Prova Brasil data, we collect information on school-level characteristics. ${ }^{6}$ From these characteristics, we build three different school-level factors that measure, first, the quality of infrastructure, second, school-level measures to guarantee safety and, finally, a factor that measures the quality of school resources. We then perform a heterogeneous treatment analysis to evaluate if the impact of the water rationing was distinct for schools with different characteristics. Specifically, for each factor, we run the specification of equation 3-1 including the possibility that treatment varies by school level factors. Table 3.4 presents the results of this analysis. Including the possibility that treatment effect varies with school characteristics does not significantly alter our previous conclusions. The treatment effect is negative for all specifications. When we include infrastructure and safety factors, results remain statistically significant for all specifications. When we consider the factor that measure schools' resources we loose a considerable number of observations and are no longer able to precisely estimate the treatment effect. Table 3.4 shows that the only characteristic that consistently impacts the effect of water rationing on students' performance is school infrastructure. Specifically, our results show that the water rationing has a significantly stronger negative impact on the academic performance of students enrolled in schools with poor infrastructure. In appendix C.2, we replicate this analysis for each individual school-level characteristics (tables 16, 17, and 18). The results from this analysis largely corroborate our conclusions from the factor analysis.

${ }^{6}$ We detail these data on table 14 . 
Chapter 3. The Impact of Water Scarcity on Educational Outcomes: Evidence from a Water Rationing Policy in Brazil

Table 3.4: Heterogeneous Treatment Effect by School Characteristics

\begin{tabular}{|c|c|c|c|c|c|c|}
\hline \multirow[b]{2}{*}{ Covariate } & \multicolumn{2}{|c|}{ Language } & \multicolumn{2}{|c|}{ Math } & \multirow[b]{2}{*}{$\begin{array}{c}\text { Student Level } \\
\text { Covariates }\end{array}$} & \multirow[b]{2}{*}{$\mathrm{N}$} \\
\hline & $\begin{array}{l}\text { Treatment } \\
\text { Effect }\end{array}$ & HTE. & $\begin{array}{l}\text { Treatment } \\
\text { Effect }\end{array}$ & HTE & & \\
\hline Infrastructure - PCA & $\begin{array}{c}-0.103^{* *} \\
(0.034)\end{array}$ & $\begin{array}{c}0.029^{* * *} \\
(0.005)\end{array}$ & $\begin{array}{c}-0.091^{* *} \\
(0.031)\end{array}$ & $\begin{array}{c}0.030^{* * *} \\
(0.005)\end{array}$ & $\mathrm{n}$ & 276716 \\
\hline Safety - PCA & $\begin{array}{c}-0.152^{* *} \\
(0.066)\end{array}$ & $\begin{array}{c}0.022 \\
(0.018)\end{array}$ & $\begin{array}{l}-0.136^{*} \\
(0.066)\end{array}$ & $\begin{array}{c}0.018 \\
(0.019)\end{array}$ & $\mathrm{n}$ & 204696 \\
\hline Resources - PCA & $\begin{array}{l}-0.076^{*} \\
(0.042)\end{array}$ & $\begin{array}{c}0.016^{*} \\
(0.008)\end{array}$ & $\begin{array}{c}-0.086 \\
(0.057)\end{array}$ & $\begin{array}{c}0.006 \\
(0.011)\end{array}$ & $\mathrm{n}$ & 132797 \\
\hline Infrastructure - PCA & $\begin{array}{c}-0.090^{* *} \\
(0.033)\end{array}$ & $\begin{array}{c}0.031^{* * *} \\
(0.004)\end{array}$ & $\begin{array}{c}-0.080^{* *} \\
(0.027)\end{array}$ & $\begin{array}{c}0.030^{* * *} \\
(0.005)\end{array}$ & $\mathrm{y}$ & 276716 \\
\hline Safety - PCA & $\begin{array}{c}-0.146^{* *} \\
(0.067)\end{array}$ & $\begin{array}{c}0.027 \\
(0.016)\end{array}$ & $\begin{array}{l}-0.123^{*} \\
(0.061)\end{array}$ & $\begin{array}{c}0.019 \\
(0.018)\end{array}$ & $\mathrm{y}$ & 204696 \\
\hline Resources - PCA & $\begin{array}{c}-0.057 \\
(0.049)\end{array}$ & $\begin{array}{c}0.014 \\
(0.011)\end{array}$ & $\begin{array}{c}-0.079 \\
(0.064)\end{array}$ & $\begin{array}{c}0.003 \\
(0.013)\end{array}$ & $\mathrm{y}$ & 132797 \\
\hline
\end{tabular}

Notes: This table presents the results of a difference-in-differences (DD) analysis that:

(i) estimates the difference in performance for students enrolled in schools located in neighborhoods impacted by the water rationing against academic performance of students enrolled in non-affected schools, i.e. the "Treatment Effect" and, (ii) estimates how the treatment effect varies with school level characteristics - the heterogeneous treatment effect or HTE. In this DD, the pre-treatment period consists of the years that precede water rationing (2007, 2009, 2011, 2013, and 2015). The post-treatment period consists of the year the water rationing was implemented (2017). From the Prova Brasil data we build three different school-level factors that measure the quality of infrastructure, school-level measures to guarantee safety and the quality of school resources. The first two columns consider performance in the Language evaluation as independent variable. The following two columns consider performance in the math evaluation. We include school, year and school-grade fixed effects in all specifications. Student level controls includes information on gender, race, family income, parents' education, parents' support, and information on grade retention and school abandonment. Standard errors were computed with observations clustered at neighborhood level. ${ }^{* * *}$ represents p-value $<0.01,{ }^{* *} \mathrm{p}$-value $<0.05$, and ${ }^{*}$ pvalue $<0.1$.

Our results highlight the importance of school-level resources on mitigating the impact of negative shocks on students' performance and contributes to a growing literature on how school-level characteristics can have a significant impact on students learning function (Duflo (2001), Aaronson and Mazumder (2011), Neilson and Zimmerman (2014)). There are a few mechanisms through which water scarcity could impact the performance of students enrolled in schools ill prepared to deal with the challenges brought by a water rationing 
schedule. Schools with poor infrastructure might not be able to store water properly and, thus, be unable to serve students and teachers with a clean, hygienic environment on water rationing days. This could affect teachers' attendance rates. There is a literature exploring the impact of teachers' absenteeism on students' performance both at developed and developing countries. Suryadarma et al. (2006) collect data on teachers' absenteeism in Indonesia and find a strong negative correlation between teachers' absenteeism and students' performance. Duflo and Hanna (2005) evaluates the impact of a policy designed to reduce absenteeism among teachers in India and finds a positive strong impact of increased attendance on performance. Miller, Murnane and Willett (2008) find a strong impact of teachers' attendance on the performance in math of children enrolled in schools in the northern United States.

Water shortage can also impact schools' ability to prepare and serve lunch to students. All children enrolled in public schools in Brazil's Federal District are part of the country's national school meal program. Meals are usually prepared at the school kitchen and water scarcity can impact schools' ability to serve these meals or their quality. If students rely on school meals to obtain their daily nutritional needs, skipping meals or replacing high nutritional value meal for lower quality meals could impact their cognitive performance (Gómez-Pinilla (2008), Imberman and Kugler (2014) Frisvold (2015), Anderson, Gallagher and Ritchie (2017)).

Finally, it is possible that water scarcity affects students through its impact on children's exposure to heat and dehydration. During the dry season, temperatures in the Federal District can reach 30 degrees Celsius with humidity levels as low as $10 \%$. If drinking water is not available on rationing days, students can be more vulnerable to heat exposure which, in turn, can have an impact on cognitive functions and academic performance ( Goodman et al. (2018) Isen, Rossin-Slater and Walker (2017)).

School-level characteristics are just one determinant of students' performance. Students background and socioeconomic status can influence how students cope with challenging scenarios. Student-level characteristics can also matter because the water rationing did not only affect schools, but also households. It is probably the case that students enrolled in schools located in neighborhoods affected by the water rationing reside themselves in those neighborhoods and, as such, also suffered the consequences of the water rationing in their homes. Living in a household with inconsistent access to running water could impact students performance if the water rationing impacts the general health, income or well-being of their families. It could also be the case that students reduce their school attendance on rationing days. If household 
level characteristics are to blame, we would expect to see a stronger effect for poorer students, whose family is unable to invest in a water storage system. To evaluate if treatment effect varies by students' characteristics, we replicate the previous heterogeneity analysis considering student-level factors. Table 3.5 presents the results from this analysis. ${ }^{7}$ We do not find evidence that studentlevel characteristics have a differential impact on treatment effect. This result indicates that students from different backgrounds were equally affected by the rationing and suggests that factors equally affecting students from all backgrounds - for instance, school level factors - are the likely cause for our results.

${ }^{7}$ In appendix C.2, tables 19 and 20 we present a more detailed analysis. The results of this detailed analysis are consistent with the results from table 3.5. 
Chapter 3. The Impact of Water Scarcity on Educational Outcomes: Evidence from a Water Rationing Policy in Brazil

Table 3.5: Heterogeneous Treatment Effect by Student Characteristics

\begin{tabular}{|c|c|c|c|c|c|}
\hline \multirow[b]{2}{*}{ Covariate } & \multicolumn{2}{|c|}{ Language } & \multicolumn{2}{|c|}{ Math } & \multirow[b]{2}{*}{$\mathrm{N}$} \\
\hline & $\begin{array}{c}\text { Treatment } \\
\text { Effect }\end{array}$ & HTE. & $\begin{array}{c}\text { Treatment } \\
\text { Effect }\end{array}$ & HTE & \\
\hline Female Student & $\begin{array}{c}-0.097^{* *} \\
(0.029)\end{array}$ & $\begin{array}{c}0.005 \\
(0.018)\end{array}$ & $\begin{array}{c}-0.089^{* *} \\
(0.024)\end{array}$ & $\begin{array}{c}0.014 \\
(0.023)\end{array}$ & 312734 \\
\hline Black Student & $\begin{array}{c}-0.098^{* *} \\
(0.028)\end{array}$ & $\begin{array}{c}0.014 \\
(0.021)\end{array}$ & $\begin{array}{c}-0.077^{* *} \\
(0.025)\end{array}$ & $\begin{array}{c}-0.042 \\
(0.027)\end{array}$ & 312734 \\
\hline Brown Student & $\begin{array}{c}-0.104^{* *} \\
(0.032)\end{array}$ & $\begin{array}{c}0.016 \\
(0.034)\end{array}$ & $\begin{array}{c}-0.097^{* *} \\
(0.031)\end{array}$ & $\begin{array}{c}0.032 \\
(0.020)\end{array}$ & 312734 \\
\hline Parents Incentive - PCA & $\begin{array}{c}-0.087^{* *} \\
(0.025)\end{array}$ & $\begin{array}{c}0.002 \\
(0.016)\end{array}$ & $\begin{array}{c}-0.072^{* *} \\
(0.024)\end{array}$ & $\begin{array}{c}0.012 \\
(0.013)\end{array}$ & 271097 \\
\hline Income - PCA & $\begin{array}{c}-0.089^{* *} \\
(0.026)\end{array}$ & $\begin{array}{c}-0.007 \\
(0.006)\end{array}$ & $\begin{array}{c}-0.077^{* *} \\
(0.022)\end{array}$ & $\begin{array}{c}-0.006 \\
(0.008)\end{array}$ & 276711 \\
\hline Mother Education & $\begin{array}{c}-0.113^{* * *} \\
(0.027)\end{array}$ & $\begin{array}{c}0.007^{*} \\
(0.004)\end{array}$ & $\begin{array}{c}-0.096^{* * *} \\
(0.023)\end{array}$ & $\begin{array}{c}0.007 \\
(0.004)\end{array}$ & 312734 \\
\hline Father Education & $\begin{array}{c}-0.087^{* *} \\
(0.026)\end{array}$ & $\begin{array}{c}-0.007 \\
(0.005)\end{array}$ & $\begin{array}{c}-0.081^{* *} \\
(0.023)\end{array}$ & $\begin{array}{c}-0.002 \\
(0.006)\end{array}$ & 312734 \\
\hline
\end{tabular}

Notes: This table presents the results of a difference-in-differences (DD) analysis that: (i) estimates the difference in performance for students enrolled in schools located in neighborhoods impacted by the water rationing against academic performance of students enrolled in non-affected schools,i.e. the "Treatment Effect" and, (ii) estimates how the treatment effect varies with student level characteristics - the heterogeneous treatment effect or HTE. In this DD, the pre-treatment period consists of the years that precede water rationing $(2007,2009,2011,2013$, and 2015). The post-treatment period consists of the year the water rationing was implemented (2017). We obtain student-level information from the Prova Brasil data. The first two columns consider performance in the Language evaluation as independent variable. The following two columns consider performance in the math evaluation. We include school, year and school-grade fixed effects in all specifications. Student level controls includes information on gender, race, family income, parents' education, parents' support, and information on grade retention and school abandonment. Standard errors were computed with observations clustered at neighborhood level. *** represents p-value $<0.01,{ }^{* *}$ p-value $<0.05$, and ${ }^{*}$ p-value $<0.1$.

\section{6}

\section{Conclusion}

In this paper, we explore the consequences of an extreme climate event that affected the supply of water in Brazil's Federal District to evaluate the impact of water scarcity on educational outcomes. After a record-breaking drought in 2017, Federal District's government imposed a water rationing schedule for neighborhoods served by the region's two main water reservoirs. 
According to the schedule, affected neighborhoods would have their water supply shut down for a period of 24 hours every six days, possibly having to wait an additional 24 hours for usual supply. We estimate the causal impact of water scarcity on academic performance comparing the educational outcomes of students enrolled in schools located in neighborhoods affected by the rationing against the outcomes of students enrolled in non-affected schools through a difference-in-differences design.

We find that water scarcity at the school level has a negative and significant impact on the performance of enrolled students in standardized language and math evaluations. Using information on a teacher-level survey, we find that teachers from affected schools increased their likelihood of blaming school infrastructure for students' poor performance. This results is consistent with the results we obtain exploring heterogeneities in treatment effect by school-level characteristics. Using data on school characteristics, we find that students enrolled in schools with poor infrastructure are more negatively affected by the water rationing. These results suggest that schools' inability to mitigate the impacts of the water rationing is the main mechanism through which water scarcity impacts academic outcomes. Our results highlight the importance of investing in school-level infrastructure for coping with the consequences of water scarcity caused by extreme climate events. 


\section{Bibliography}

Aaronson, Daniel, and Bhashkar Mazumder. 2011. "The Impact of Rosenwald Schools on Black Achievement." Journal of Political Economy, 119(5): 821-888.

Acemoglu, Daron, and Melissa Dell. 2010. "Productivity Differences between and within Countries." American Economic Journal: Macroeconomics, 2(1): 169-88.

Acemoglu, Daron, and Pascual Restrepo. 2020. "Robots and Jobs: Evidence from US Labor Markets." Journal of Political Economy, 128(6): 21882244 .

Aguilar, Arturo, and Marta Vicarelli. 2018. "El Niño and Mexican children: Medium term effects ofearly-life weather shocks on cognitive and health outcomes." Working Paper.

Almeida, Rita K., and Truman G. Packard. 2018. Skills and Jobs in Brazil: An Agenda for Youth. The World Bank.

Alon, Sigal. 2011. "Who Benefits Most from Financial Aid? The Heterogeneous Effect of Need-Based Grants on Students' College Persistence*: Who Benefits Most from Financial Aid?" Social Science Quarterly, 92(3): 807829 .

Anderson, Michael L, Justin Gallagher, and Elizabeth Ramirez Ritchie. 2017. "School Lunch Quality and Academic Performance." National Bureau of Economic Research Working Paper 23218.

Andrews, Rodney J., Scott A. Imberman, and Michael F. Lovenheim. 2020. "Recruiting and supporting low-income, high-achieving students at flagship universities." Economics of Education Review, 74: 101923.

Angel-Urdinola, Diego F., and Renata Mayer Gukovas. 2018. A SkillsBased Human Capital Framework to Understand the Phenomenon of Youth Economic Disengagement. Policy Research Working Papers, The World Bank. 
Angrist, Joshua, David Autor, Sally Hudson, and Amanda Pallais. 2014. "Leveling Up: Early Results from a Randomized Evaluation of PostSecondary Aid." National Bureau of Economic Research w20800, Cambridge, MA.

Arcidiacono, Peter. 2004. "Ability sorting and the returns to college major." Journal of Econometrics, 121(1): 343 - 375. Higher education (Annals issue).

Arcidiacono, Peter, Esteban Aucejo, Arnaud Maurel, and Tyler Ransom. 2016. "College Attrition and the Dynamics of Information Revelation." National Bureau of Economic Research Working Paper 22325.

Arendt, Jacob Nielsen. 2008. "The Impact of Public Student Grants on Drop-Out and Completion of Higher Education - Evidence from a Student Grant Reform." Social Science Research Network SSRN Scholarly Paper ID 1133046, Rochester, NY.

Autor, David H., Frank Levy, and Richard J. Murnane. 2003. "The Skill Content of Recent Technological Change: An Empirical Exploration*." The Quarterly Journal of Economics, 118(4): 1279-1333.

Avery, Christopher, and Caroline M Hoxby. 2003. "Do and Should Financial Aid Packages Affect Students' College Choices?" National Bureau of Economic Research Working Paper 9482.

Bandura, Albert, Claudio Barbaranelli, Gian Vittorio Caprara, and Concetta Pastorelli. 2001. "Self-Efficacy Beliefs as Shapers of Children's Aspirations and Career Trajectories." Child Development, 72(1): 187-206.

Barrow, Lisa, Lashawn Richburg-Hayes, Cecilia Elena Rouse, and Thomas Brock. 2014. "Paying for Performance: The Education Impacts of a Community College Scholarship Program for Low-Income Adults." Journal of Labor Economics, 32(3): 563-599.

Becker, Gary S. 1975. "Human Capital: A Theoretical and Empirical Analysis, with Special Reference to Education, Second Edition."

Belley, Philippe, and Lance Lochner. 2007. "The Changing Role of Family Income and Ability in Determining Educational Achievement." Journal of Human Capital, 1(1): 37-89.

Bento, Antonio, Noah S Miller, Mehreen Mookerjee, and Edson R Severnini. 2020. "A Unifying Approach to Measuring Climate Change 
Impacts and Adaptation." National Bureau of Economic Research Working Paper 27247.

Berry, Steven, James Levinsohn, and Ariel Pakes. 1995. "Automobile Prices in Market Equilibrium." Econometrica, 63(4): 841-890.

Bettinger, Eric. 2004. "How Financial Aid Affects Persistence." National Bureau of Economic Research Working Paper 10242.

Bettinger, Eric. 2015. "Need-Based Aid and College Persistence: The Effects of the Ohio College Opportunity Grant." Educational Evaluation and Policy Analysis, 37(1_suppl): 102S-119S.

Bettinger, Eric, Oded Gurantz, Laura Kawano, Bruce Sacerdote, and Michael Stevens. 2019. "The Long-Run Impacts of Financial Aid: Evidence from California's Cal Grant." American Economic Journal: Economic Policy, 11(1): 64-94.

Beyer, Harald, Justine Hastings, Christopher Neilson, and Seth Zimmerman. 2015. "Connecting Student Loans to Labor Market Outcomes: Policy Lessons from Chile." American Economic Review, 105(5): 508-13.

Brown, Duane. 2002. "Career Choice and Development, 4th Edition | Wiley." Library Catalog: www.wiley.com.

Calonico, Sebastian, Matias D. Cattaneo, and Rocio Titiunik. 2014. "Robust Nonparametric Confidence Intervals for Regression-Discontinuity Designs: Robust Nonparametric Confidence Intervals." Econometrica, 82(6): 2295-2326.

Calonico, Sebastian, Matias D. Cattaneo, and Rocío Titiunik. 2015. "Optimal Data-Driven Regression Discontinuity Plots." Journal of the American Statistical Association, 110(512): 1753-1769.

Cameron, Stephen V., and James J. Heckman. 1998. "Life Cycle Schooling and Dynamic Selection Bias: Models and Evidence for Five Cohorts of American Males." Journal of Political Economy, 106(2): 262-333.

Carlana, Michela. 2019. "Implicit Stereotypes: Evidence from Teachers' Gender Bias*." The Quarterly Journal of Economics, 134(3): 1163-1224.

Carlana, Michela, Eliana La Ferrara, and Paolo Pinotti. 2018. "Goals and Gaps: Educational Careers of Immigrant Children." Library Catalog: www.hks.harvard.edu. 
Carleton, Tamma A, Amir Jina, Michael T Delgado, Michael Greenstone, Trevor Houser, Solomon M Hsiang, Andrew Hultgren, Robert E Kopp, Kelly E McCusker, Ishan B Nath, James Rising, Ashwin Rode, Hee Kwon Seo, Arvid Viaene, Jiacan Yuan, and Alice Tianbo Zhang. 2020. "Valuing the Global Mortality Consequences of Climate Change Accounting for Adaptation Costs and Benefits." National Bureau of Economic Research Working Paper 27599.

Carneiro, Pedro, and James J. Heckman. 2002. "The Evidence on Credit Constraints in Post-secondary Schooling." Economic Journal, 112(482): 705734 .

Castleman, Benjamin L., and Bridget Terry Long. 2016. "Looking beyond Enrollment: The Causal Effect of Need-Based Grants on College Access, Persistence, and Graduation." Journal of Labor Economics, 34(4): 1023-1073. Publisher: The University of Chicago Press.

Cattaneo, Matias D., Michael Jansson, and Xinwei Ma. 2018. "Manipulation Testing Based on Density Discontinuity." The Stata Journal, 18(1): 234-261.

Cellini, Stephanie Riegg. 2009. "Crowded Colleges and College Crowd-Out: The Impact of Public Subsidies on the Two-Year College Market." American Economic Journal: Economic Policy, 1(2): 1-30.

Cellini, Stephanie Riegg, and Cory Koedel. 2017. "The Case For Limiting Federal Student Aid to For-Profit Colleges." Journal of Policy Analysis and Management, 36(4): 934-942.

Codeplan. 2018. "Análise do Consumo de Água Tratada no Período de Racionamento no Distrito Federal."

Cohodes, Sarah R., and Joshua S. Goodman. 2014. "Merit Aid, College Quality, and College Completion: Massachusetts' Adams Scholarship as an In-Kind Subsidy." American Economic Journal: Applied Economics, 6(4): 251-285.

Council, National Research. 2010. Adapting to the Impacts of Climate Change. Washington, DC:The National Academies Press.

Dearden, Lorraine, and Paulo Meyer Nascimento. 2019. "Modelling alternative student loan schemes for Brazil." Economics of Education Review, 71: 83 - 94. Higher Education Financing: Student Loans. 
de Mello, João, and Isabela Duarte. forthcoming. "The Effect of the Availability of Student Credit on Tuitions: Testing the Bennett Hypothesis using Evidence from a Large-Scale Student Loan Program in Brazil." Economía.

Deming, David, and Susan Dynarski. 2010. "College Aid." Targeting Investments in Children: Fighting Poverty When Resources are Limited, 283-302. University of Chicago Press.

Deming, David J, and Christopher R Walters. 2017. "The Impact of Price Caps and Spending Cuts on U.S. Postsecondary Attainment." National Bureau of Economic Research Working Paper 23736.

Deming, David J., and Kadeem Noray. forthcoming. "Earnings Dynamics, Changing Job Skills, and STEM Careers." Quarterly Journal of Economics.

Denning, Jeffrey T., Benjamin M. Marx, and Lesley J. Turner. 2019. "ProPelled: The Effects of Grants on Graduation, Earnings, and Welfare." American Economic Journal: Applied Economics, 11(3): 193-224.

Deschênes, Olivier, and Michael Greenstone. 2011. "Climate Change, Mortality, and Adaptation: Evidence from Annual Fluctuations in Weather in the US." American Economic Journal: Applied Economics, 3(4): 152-85.

Duflo, Esther. 2001. "Schooling and Labor Market Consequences of School Construction in Indonesia: Evidence from an Unusual Policy Experiment." American Economic Review, 91(4): 795-813.

Duflo, Esther, and Rema Hanna. 2005. "Monitoring Works: Getting Teachers to Come to School." National Bureau of Economic Research Working Paper 11880.

Dutz, Mark A. 2018. Jobs and Growth: Brazil's Productivity Agenda. The World Bank.

Espinoza, Ricardo, and Sergio Urzúa. 2015. "Las Consecuencias Económicas de un Sistema de Educación Superior Gratuito en Chile." Revista de Educación, , (370).

Estevan, Fernanda, Thomas Gall, and Louis-Philippe Morin. forthcoming. "Redistribution without Distortion: Evidence from An Affirmative Action Programme At a Large Brazilian University." The Economic Journal. 
Fack, Gabrielle, and Julien Grenet. 2015. "Improving College Access and Success for Low-Income Students: Evidence from a Large Need-Based Grant Program." American Economic Journal: Applied Economics, 7(2): 1-34.

Ferreira, Francisco H. G., Sergio Firpo, and Julian Messina. 2014. "A More Level Playing Field? Explaining the Decline in Earnings Inequality in Brazil, 1995-2012." IRIBA Working Paper: 12.

Ferreyra, María Marta, Ciro Avitabile, Javier Botero Álvarez, Francisco Haimovich Paz, and Sergio Urzúa. 2017. "At a Crossroads Higher Education in Latin America and the Caribbean." Directions in Development Human Development.

Francis, Andrew M., and Maria Tannuri-Pianto. 2012. "Using Brazil's Racial Continuum to Examine the Short-Term Effects of Affirmative Action in Higher Education." Journal of Human Resources, 47(3).

Francis-Tan, Andrew, and Maria Tannuri-Pianto. 2018. "Black Movement: Using discontinuities in admissions to study the effects of college quality and affirmative action." Journal of Development Economics, 135(C): 97116.

Frisvold, David E. 2015. "Nutrition and cognitive achievement: An evaluation of the School Breakfast Program." Journal of public economics, 124: 91104.

Gennaioli, Nicola, Rafael La Porta, Florencio Lopez-de Silanes, and Andrei Shleifer. 2013. "Human Capital and Regional Development*." The Quarterly Journal of Economics, 128(1): 105-164.

Gómez-Pinilla, Fernando. 2008. "Brain foods: the effects of nutrients on brain function." Nature reviews neuroscience, 9(7): 568-578.

Gong, Yifan, Lance Lochner, Ralph Stinebrickner, and Todd $\mathbf{R}$ Stinebrickner. 2019. "The Consumption Value of College." National Bureau of Economic Research Working Paper 26335.

Goodman, Joshua, Michael Hurwitz, Jisung Park, and Jonathan Smith. 2018. "Heat and Learning." National Bureau of Economic Research Working Paper 24639.

Gross, Tal, Matthew J. Notowidigdo, and Jialan Wang. 2020. "The Marginal Propensity to Consume over the Business Cycle." American Economic Journal: Macroeconomics, 12(2): 351-84. 
Gullason, Edward T. 1989. "The Consumption Value of Schooling: An Empirical Estimate of One Aspect." The Journal of Human Resources, 24(2): 287-298.

Hanushek, Eric A. 1997. "Assessing the Effects of School Resources on Student Performance: An Update." Educational Evaluation and Policy Analysis, 19(2): 141-164.

Hanushek, Eric A, and Ludger Woessmann. 2008. "The Role of Cognitive Skills in Economic Development." Journal of Economic Literature, 46(3): 607-668.

Hastings, Justine, Christopher A Neilson, and Seth D Zimmerman. 2015. "The Effects of Earnings Disclosure on College Enrollment Decisions." National Bureau of Economic Research Working Paper 21300.

Hastings, Justine S, Christopher A Neilson, and Seth D Zimmerman. 2013. "Are Some Degrees Worth More than Others? Evidence from college admission cutoffs in Chile." National Bureau of Economic Research Working Paper 19241.

Hastings, Justine S., Christopher A. Neilson, Anely Ramirez, and Seth D. Zimmerman. 2016. "(Un)informed college and major choice: Evidence from linked survey and administrative data." Economics of Education Review, 51: 136 - 151. Access to Higher Education.

Imberman, Scott A, and Adriana D Kugler. 2014. "The effect of providing breakfast in class on student performance." Journal of Policy Analysis and Management, 33(3): 669-699.

Isen, Adam, Maya Rossin-Slater, and Reed Walker. 2017. "Relationship between season of birth, temperature exposure, and later life wellbeing." Proceedings of the National Academy of Sciences, 114(51): 13447-13452.

Jasper, Christian, Thanh-Tam Le, and Jamie Bartram. 2012. "Water and Sanitation in Schools: A Systematic Review of the Health and Educational Outcomes." International Journal of Environmental Research and Public Health, 9(8): 2772-2787.

Kane, Thomas J. 2006. "Public Intervention in Post-Secondary Education." In . Vol. 2 of Handbook of the Economics of Education, , ed. E. Hanushek and F. Welch, 1369-1401. Elsevier. 
Kaufmann, Katja Maria. 2014. "Understanding the income gradient in college attendance in Mexico: The role of heterogeneity in expected returns." Quantitative Economics, 5(3): 583-630.

Keane, Michael P., and Kenneth I. Wolpin. 2001. "The Effect of Parental Transfers and Borrowing Constraints on Educational Attainment." International Economic Review, 42(4): 1051-1103.

Lochner, Lance J., and Alexander Monge-Naranjo. 2011. "The Nature of Credit Constraints and Human Capital." American Economic Review, 101(6): 2487-2529.

Londoño-Vélez, Juliana, Catherine Rodríguez, and Fabio Sánchez. 2020. "Upstream and Downstream Impacts of College Merit-Based Financial Aid for Low-Income Students: Ser Pilo Paga in Colombia." American Economic Journal: Economic Policy, 12(2): 193-227.

Long, Bridget Terry. 2006. "Does the Format of a Financial Aid Program Matter? The Effect of State In-Kind Tuition Subsidies." Archive Location: 238 Main St., Suite 500, Cambridge, MA 02142-1046 USA journalsinfo@mit.edu Library Catalog: www.mitpressjournals.org Publisher: MIT Press 238 Main St., Suite 500, Cambridge, MA 02142-1046 USA journalsinfo@mit.edu.

Machado, Cecilia, and Christiane Szerman. 2016. "Centralized Admission and the Student-College Match." Institute of Labor Economics (IZA) IZA Discussion Papers 10251.

MacLeod, W. Bentley, and Miguel Urquiola. 2015. "Reputation and School Competition." American Economic Review, 105(11): 3471-88.

MacLeod, W. Bentley, Evan Riehl, Juan E. Saavedra, and Miguel Urquiola. 2017. "The Big Sort: College Reputation and Labor Market Outcomes." American Economic Journal: Applied Economics, 9(3): 223-61.

Martorell, Paco, Kevin Stange, and Isaac McFarlin. 2016. "Investing in schools: capital spending, facility conditions, and student achievement." Journal of Public Economics, 140: 13 - 29.

McCrary, Justin. 2008. "Manipulation of the running variable in the regression discontinuity design: A density test." Journal of Econometrics, 142(2): 698 - 714. The regression discontinuity design: Theory and applications. 
Melguizo, Tatiana, Fabio Sanchez, and Tatiana Velasco. 2016. "Credit for Low-Income Students and Access to and Academic Performance in Higher Education in Colombia: A Regression Discontinuity Approach." World Development, 80: $61-77$.

Mello, Ursula. 2019. "Centralized Admissions, Affirmative Action and Access of Low-income Students to Higher Education." Working Paper.

Michaels, Guy, Ashwini Natraj, and John Van Reenen. 2014. "Has ICT Polarized Skill Demand? Evidence from Eleven Countries over Twenty-Five Years." The Review of Economics and Statistics, 96(1): 60-77.

Miller, Raegen T., Richard J. Murnane, and John B. Willett. 2008. "Do Teacher Absences Impact Student Achievement? Longitudinal Evidence from One Urban School District." Educational Evaluation and Policy Analysis, 30(2): 181-200.

Montenegro, Claudio E., and Harry Anthony Patrinos. 2014. "Comparable estimates of returns to schooling around the world." The World Bank Policy Research Working Paper Series 7020.

Montmarquette, Claude, Kathy Cannings, and Sophie Mahseredjian. 2002. "How do young people choose college majors?" Economics of Education Review, 21(6): 543 - 556.

Murphy, Richard, Judith Scott-Clayton, and Gill Wyness. 2019. "The end of free college in England: Implications for enrolments, equity, and quality." Economics of Education Review, 71: 7 - 22. Higher Education Financing: Student Loans.

Neilson, Christopher A., and Seth D. Zimmerman. 2014. "The effect of school construction on test scores, school enrollment, and home prices." Journal of Public Economics, 120: 18 - 31.

Nevo, Aviv. 2000. "A Practitioner's Guide to Estimation of RandomCoefficients Logit Models of Demand." Journal of Economics $\&$ Management Strategy, 9(4): 513-548.

Nguyen, Hieu. 2019. "Free tuition and college enrollment: evidence from New York's Excelsior program." Education Economics, 27(6): 573-587.

Nguyen, Tuan D., Jenna W. Kramer, and Brent J. Evans. 2019. "The Effects of Grant Aid on Student Persistence and Degree Attainment: A Systematic Review and Meta-Analysis of the Causal Evidence." Review 
of Educational Research, 89(6): 831-874. Publisher: American Educational Research Association.

OECD. 2015. "How confident are students in their ability to solve mathematics problems?" OECD Publishing, , (56).

OECD. 2018. Rethinking Quality Assurance for Higher Education in Brazil. Paris:OECD.

OECD. 2019. Education at a Glance 2019: OECD Indicators. Education at a Glance, Paris:OECD.

OECD. 2020. Students' self-efficacy and fear of failure. Paris:OECD.

Oppedisano, Veruska. 2011. "The (adverse) effects of expanding higher education: Evidence from Italy." Economics of Education Review, 30(5): 997 - 1008. Special Issue on Education and Health.

O'Hara, Jeffrey K., and Konstantine P. Georgakakos. 2008. "Quantifying the Urban Water Supply Impacts of Climate Change." Water Resources Management, 22(10): 1477-1497.

Peltzman, Sam. 1973. "The Effect of Government Subsidies-in-Kind on Private Expenditures: The Case of Higher Education." Journal of Political Economy, 81(1): 1-27.

Pendergrass, Angeline G., Reto Knutti, Flavio Lehner, Clara Deser, and Benjamin M. Sanderson. 2017. "Precipitation variability increases in a warmer climate." Scientific Reports, 7(1): 17966.

Petrin, Amil. 2002. "Quantifying the Benefits of New Products: The Case of the Minivan." Journal of Political Economy, 110(4): 705-729.

Prada, María F., and Sergio Urzúa. 2017. "One Size Does Not Fit All: Multiple Dimensions of Ability, College Attendance, and Earnings." Journal of Labor Economics, 35(4): 953-991.

Randell, Heather, and Clark Gray. 2019. "Climate change and educational attainment in the global tropics." Proceedings of the National Academy of Sciences, 116(18): 8840-8845.

Rau, Tomás, Eugenio Rojas, and Sergio Urzúa. 2013. "Loans for Higher Education: Does the Dream Come True?" National Bureau of Economic Research w19138, Cambridge, MA. 
Scott-Clayton, Judith, and Basit Zafar. 2019. "Financial aid, debt management, and socioeconomic outcomes: Post-college effects of meritbased aid." Journal of Public Economics, 170: 68 - 82.

Shah, Manisha, and Bryce Millett Steinberg. 2017. "Drought of Opportunities: Contemporaneous and Long-Term Impacts of Rainfall Shocks on Human Capital." Journal of Political Economy, 125(2): 527-561.

Smith, V. Kerry. 2011. "How Can Policy Encourage Economically Sensible Climate Adaptation?" The Design and Implementation of U.S. Climate Policy, 229-242. University of Chicago Press.

Solis, Alex. 2017. "Credit Access and College Enrollment." Journal of Political Economy, 125(2): 562-622.

Spilimbergo, Antonio, and Krishna Srinivasan. 2019. Brazil : Boom, Bust, and the Road to Recovery. Washington, DC:International Monetary Fund.

Stinebrickner, Todd, and Ralph Stinebrickner. 2012. "Learning about Academic Ability and the College Dropout Decision." Journal of Labor Economics, 30(4): 707-748.

Suryadarma, Daniel, Asep Suryahadi, Sudarno Sumarto, and F. Halsey Rogers. 2006. "Improving Student Performance in Public Primary Schools in Developing Countries: Evidence from Indonesia." Education Economics, 14(4): 401-429.

Tanzi, Giulia Martina, Francesca Modena, and Enrico Rettore. 2020. "The Effect of Grants on University Drop-Out Rates: Evidence on the Italian Case." Journal of Human Capital, 710220.

Travitzki, Rodrigo, Jorge Calero, and Carlota Boto. 2014. "What does the National High School Exam (ENEM) tell Brazilian society?” , (9).

Ulyssea, Gabriel. 2018. "Firms, Informality, and Development: Theory and Evidence from Brazil." American Economic Review, 108(8): 2015-47.

Upton, Gregory B. 2016. "The Effects of Merit-Based Scholarships on Educational Outcomes." Journal of Labor Research, 37(2): 235-261.

U.S. Department of Education, National Center for Education Statistics. 2019. "The Condition of Education 2019 (NCES 2019-144), Undergraduate Retention and Graduation Rates." 
Wiswall, Mattew, and Basit Zafar. 2015. "Determinants of College Major Choice: Identification using an Information Experiment." The Review of Economic Studies, 82(2 (291)): 791-824.

World Bank. 2017. "A fair adjustment : efficiency and equity of public spending in Brazil : Volume 1 - Overview (English)." The World Bank Group.

Zimmerman, Seth D. 2014. "The Returns to College Admission for Academically Marginal Students." Journal of Labor Economics, 32(4): 711-754. Publisher: The University of Chicago Press. 
A

Appendix: The Impact of Subsidies to Higher Education on Low-Ability Students: Evidence from Brazil 


\section{A.1 \\ Robustness Analysis}

Table 6: Eligibility Effect: Enrollment

\begin{tabular}{|c|c|c|c|c|c|c|}
\hline Variables & $\begin{array}{c}\text { Higher } \\
\text { Education }\end{array}$ & $\begin{array}{c}\text { Private } \\
\text { H.E. }\end{array}$ & $\begin{array}{c}\text { Public. } \\
\text { H.E. }\end{array}$ & $\begin{array}{c}\text { Higher } \\
\text { Education } \\
\text { (Robust) }\end{array}$ & $\begin{array}{c}\text { Private } \\
\text { H.E. } \\
\text { (Robust) }\end{array}$ & $\begin{array}{c}\text { Public } \\
\text { H.E. } \\
\text { (Robust) }\end{array}$ \\
\hline Coeff & $0.011 * * *$ & $0.013 * * *$ & $-0.002 * * *$ & $0.01 * * *$ & $0.012 * * *$ & $-0.002 * * *$ \\
\hline $\mathrm{SE}$ & $(0.002)$ & $(0.001)$ & $(0.001)$ & $(0.002)$ & $(0.002)$ & $(0.001)$ \\
\hline BW & 28.783 & 31.753 & 25.909 & 28.783 & 31.753 & 25.909 \\
\hline Local-Poly. & 1 & 1 & 1 & 1 & 1 & 1 \\
\hline $\mathrm{N}$ & 774977 & 849834 & 700943 & 1332020 & 1377131 & 1167871 \\
\hline Coeff & $0.01 * * *$ & $0.012 * * *$ & $-0.002 * * *$ & $0.01 * * *$ & $0.012 * * *$ & $-0.002 * * *$ \\
\hline $\mathrm{SE}$ & $(0.002)$ & $(0.002)$ & $(0.001)$ & $(0.002)$ & $(0.002)$ & $(0.001)$ \\
\hline BW & 48.703 & 52.852 & 44.528 & 48.703 & 52.852 & 44.528 \\
\hline Local-Poly. & 2 & 2 & 2 & 2 & 2 & 2 \\
\hline $\mathrm{N}$ & 1248670 & 1336995 & 1155649 & 1711329 & 1717088 & 1749738 \\
\hline Coeff & $0.01 * * *$ & $0.012 * * *$ & $-0.002 * * *$ & $0.009 * * *$ & $0.012 * * *$ & $-0.002 * * *$ \\
\hline $\mathrm{SE}$ & $(0.002)$ & $(0.002)$ & $(0.001)$ & $(0.002)$ & $(0.002)$ & $(0.001)$ \\
\hline BW & 67.06 & 72.453 & 72.15 & 67.06 & 72.453 & 72.15 \\
\hline Local-Poly. & 3 & 3 & 3 & 3 & 3 & 3 \\
\hline $\mathrm{N}$ & 1610177 & 1701686 & 1696745 & 1998972 & 2052604 & 2086925 \\
\hline
\end{tabular}

Notes: This table presents the results of a regression discontinuity design on variables indicating enrollment. The final sample includes all students taking the ENEM exam between 2014 and 2015 who are expected to graduate from high school in that same year and who obtained a grade higher than zero on ENEM's essay - 2,876,864 students total. In each column, we test whether crossing the eligibility threshold has a significant impact on enrollment. In columns (1) and (4) we test the impact on any type of enrollment (public or private), in columns (2) and (5) enrollment in private institutions, and in columns (3) and (6) enrollment in public institutions. We implement a data driven non parametric version of the RD design and select optimal bandwidths according to a MSE selection procedure (Calonico, Cattaneo and Titiunik, 2015). We assess the robustness of our results using local polynomial estimators of various orders and implementing a bias-corrected robust inference procedure (Calonico, Cattaneo and Titiunik, 2014) - columns (4), (5) and (6). Row Coeff. presents the estimate of treatment effect, row S.E. presents standard errors, row B.W. presents the optimal bandwidth, row Local-Poly. presents the order of the local polynomial estimator and row $N$ presents the number of effective observations. 
Table 7: Eligibility Effect: Attainment - Enrolled by the end of 1st year

\begin{tabular}{ccccccc}
\hline \hline & $(1)$ & $(2)$ & $(3)$ & $(4)$ & $(5)$ & $(6)$ \\
Variables & Higher & Private & Public. & Higher & Private & Public \\
& Education & H.E. & H.E. & $\begin{array}{c}\text { Education } \\
\text { (Robust) }\end{array}$ & $\begin{array}{c}\text { H.E. } \\
\text { (Robust) }\end{array}$ & $\begin{array}{c}\text { H.E. } \\
\text { (Robust) }\end{array}$ \\
\hline Coeff & $0.0084 * * *$ & $0.0096 * * *$ & $-0.0011 * *$ & $0.0082 * * *$ & $0.0092 * * *$ & $-0.0011 * *$ \\
SE & $(0.001)$ & $(0.001)$ & $(5 \mathrm{e}-04)$ & $(0.0012)$ & $(0.0012)$ & $(0.0006)$ \\
BW & 37.148 & 32.082 & 27.922 & 37.148 & 32.082 & 27.922 \\
Local-Poly. & 1 & 1 & 1 & 1 & 1 & 1 \\
N & 1520542 & 1330836 & 1169205 & 2357602 & 2159349 & 1730395 \\
& & & & & & \\
Coeff & $0.0081 * * *$ & $0.0092 * * *$ & $-0.0011 * *$ & $0.0079 * * *$ & $0.0092 * * *$ & $-0.0013 * *$ \\
SE & $(0.0013)$ & $(0.0012)$ & $(5 \mathrm{e}-04)$ & $(0.0014)$ & $(0.0014)$ & $(0.0006)$ \\
BW & 54.492 & 53.048 & 44.792 & 54.492 & 53.048 & 44.792 \\
Local-Poly. & 2 & 2 & 2 & 2 & 2 & 2 \\
N & 2108724 & 2064162 & 1792940 & 2758612 & 2638937 & 2618112 \\
& & & & & & \\
Coeff & $0.0078 * * *$ & $0.0092 * * *$ & $-0.0013 * *$ & $0.0078 * * *$ & $0.0091 * * *$ & $-0.0014 * *$ \\
SE & $(0.0015)$ & $(0.0014)$ & $(0.0006)$ & $(0.0016)$ & $(0.0015)$ & $(0.0006)$ \\
BW & 70.276 & 71.398 & 72.372 & 70.276 & 71.398 & 72.372 \\
Local-Poly. & 3 & 3 & 3 & 3 & 3 & 3 \\
N & 2550820 & 2578792 & 2603013 & 3049645 & 3079287 & 3121912 \\
\hline
\end{tabular}

Notes: This table presents the results of a regression discontinuity design on variables indicating persistence in the first year. The final sample includes all students taking the ENEM exam between 2014 and 2015 who are expected to graduate from high school in that same year and who obtained a grade higher than zero on ENEM's essay — 2,876,864 students total. In each column, we test whether crossing the eligibility threshold has a significant impact on persistence. In columns (1) and (4) we test the impact on any type of persistence (public or private), in columns (2) and (5) persistence in private institutions, and in columns (3) and (6) persistence in public institutions. We implement a data driven non parametric version of the RD design and select optimal bandwidths according to a MSE selection procedure (Calonico, Cattaneo and Titiunik, 2015). We assess the robustness of our results using local polynomial estimators of various orders and implementing a bias-corrected robust inference procedure (Calonico, Cattaneo and Titiunik, 2014) - columns (4), (5) and (6). Row Coeff. presents the estimate of treatment effect, row S.E. presents standard errors, row B.W. presents the optimal bandwidth, row Local-Poly. presents the order of the local polynomial estimator and row $N$ presents the number of effective observations. 
Table 8: Eligibility Effect: Attainment - Enrolled by the end of 2nd year

\begin{tabular}{|c|c|c|c|c|c|c|}
\hline \multirow{3}{*}{ Variables } & $(1)$ & $(2)$ & (3) & $(4)$ & $(5)$ & $(6)$ \\
\hline & Higher & Private & Public. & Higher & Private & Public \\
\hline & Education & H.E. & H.E. & $\begin{array}{c}\text { Education } \\
\text { (Robust) }\end{array}$ & $\begin{array}{c}\text { H.E. } \\
\text { (Robust) }\end{array}$ & $\begin{array}{c}\text { H.E. } \\
\text { (Robust) }\end{array}$ \\
\hline Coeff & $0.0069 * * *$ & $0.008 * * *$ & $-0.0012 * * *$ & $0.0067 * * *$ & $0.0079 * * *$ & $-0.0013 * * *$ \\
\hline SE & $(0.001)$ & $(0.001)$ & $(0.0005)$ & $(0.0012)$ & $(0.0012)$ & $(0.0005)$ \\
\hline BW & 37.159 & 35.318 & 33.66 & 37.159 & 35.318 & 33.66 \\
\hline Local-Poly. & 1 & 1 & 1 & 1 & 1 & 1 \\
\hline $\mathrm{N}$ & 982369 & 937714 & 897042 & 1510343 & 1398960 & 1447605 \\
\hline Coeff & $0.0066 * * *$ & $0.0079 * * *$ & $-0.0015 * *$ & $0.0063 * * *$ & $0.008 * * *$ & $-0.0017 * *$ \\
\hline SE & $(0.0013)$ & $(0.0011)$ & $(0.0006)$ & $(0.0014)$ & $(0.0013)$ & $(0.0006)$ \\
\hline BW & 54.257 & 55.545 & 43.037 & 54.257 & 55.545 & 43.037 \\
\hline Local-Poly. & 2 & 2 & 2 & 2 & 2 & 2 \\
\hline $\mathrm{N}$ & 1365744 & 1392169 & 1121371 & 1814904 & 1789237 & 1727850 \\
\hline Coeff & $0.0062 * * *$ & $0.0079 * * *$ & $-0.0017 * * *$ & $0.006 * * *$ & $0.0079 * * *$ & $-0.0018 * * *$ \\
\hline $\mathrm{SE}$ & $(0.0015)$ & $(0.0013)$ & $(0.0006)$ & $(0.0016)$ & $(0.0014)$ & $(0.0007)$ \\
\hline BW & 71.331 & 74.585 & 69.443 & 71.331 & 74.585 & 69.443 \\
\hline Local-Poly. & 3 & 3 & 3 & 3 & 3 & 3 \\
\hline $\mathrm{N}$ & 1683263 & 1736258 & 1651821 & 2027165 & 2066895 & 2043225 \\
\hline
\end{tabular}

Notes: This table presents the results of a regression discontinuity design on variables indicating persistence in the second year. The final sample includes all students taking the ENEM exam between 2014 and 2015 who are expected to graduate from high school in that same year and who obtained a grade higher than zero on ENEM's essay — 2,876,864 students total. In each column, we test whether crossing the eligibility threshold has a significant impact on persistence. In columns (1) and (4) we test the impact on any type of persistence (public or private), in columns (2) and (5) persistence in private institutions, and in columns (3) and (6) persistence in public institutions. We implement a data driven non parametric version of the RD design and select optimal bandwidths according to a MSE selection procedure (Calonico, Cattaneo and Titiunik, 2015). We assess the robustness of our results using local polynomial estimators of various orders and implementing a bias-corrected robust inference procedure (Calonico, Cattaneo and Titiunik, 2014) - columns (4), (5) and (6). Row Coeff. presents the estimate of treatment effect, row S.E. presents standard errors, row B.W. presents the optimal bandwidth, row Local-Poly. presents the order of the local polynomial estimator and row $N$ presents the number of effective observations. 
Table 9: Eligibility Effect: Attainment - Enrolled by the end of 3rd year

\begin{tabular}{ccccccc}
\hline \hline & $(1)$ & $(2)$ & $(3)$ & $(4)$ & $(5)$ & $(6)$ \\
Variables & Higher & Private & Public. & Higher & Private & Public \\
& Education & H.E. & H.E. & $\begin{array}{c}\text { Education } \\
\text { (Robust) }\end{array}$ & $\begin{array}{c}\text { H.E. } \\
\text { (Robust) }\end{array}$ & $\begin{array}{c}\text { H.E. } \\
\text { (Robust) }\end{array}$ \\
\hline Coeff & $0.0026 * * *$ & $0.0033 * * *$ & $-0.0008 * *$ & $0.0027 * * *$ & $0.0033 * * *$ & $-0.0008 * *$ \\
SE & $(0.0008)$ & $(0.0007)$ & $(0.0004)$ & $(0.001)$ & $(0.0009)$ & $(0.0005)$ \\
BW & 42.219 & 40.011 & 43.376 & 42.219 & 40.011 & 43.376 \\
Local-Poly. & 1 & 1 & 1 & 1 & 1 & 1 \\
N & 532302 & 507335 & 545610 & 786894 & 746101 & 796737 \\
& & & & & & \\
Coeff & $0.002 * *$ & $0.003 * * *$ & $-0.0009 *$ & $0.0017 * *$ & $0.0028 * * *$ & $-0.001 *$ \\
SE & $(0.001)$ & $(0.0009)$ & $(0.0005)$ & $(0.0011)$ & $(0.001)$ & $(0.0005)$ \\
BW & 55.122 & 54.975 & 58.69 & 55.122 & 54.975 & 58.69 \\
Local-Poly. & 2 & 2 & 2 & 2 & 2 & 2 \\
N & 670595 & 669046 & 706045 & 951949 & 909916 & 991281 \\
& & & & & & \\
Coeff & 0.0009 & $0.0023 * *$ & $-0.001 *$ & 0.0006 & $0.0021 * *$ & $-0.0011 *$ \\
SE & $(0.0012)$ & $(0.001)$ & $(0.0005)$ & $(0.0013)$ & $(0.0011)$ & $(0.0006)$ \\
BW & 67.292 & 69.149 & 92.092 & 67.292 & 69.149 & 92.092 \\
Local-Poly. & 3 & 3 & 3 & 3 & 3 & 3 \\
N & 785673 & 801893 & 971735 & 1011195 & 1022950 & 1201613 \\
\hline
\end{tabular}

Notes: This table presents the results of a regression discontinuity design on variables indicating persistence in the third year. The final sample includes all students taking the ENEM exam between 2014 and 2015 who are expected to graduate from high school in that same year and who obtained a grade higher than zero on ENEM's essay — $2,876,864$ students total. In each column, we test whether crossing the eligibility threshold has a significant impact on persistence. In columns (1) and (4) we test the impact on any type of persistence (public or private), in columns (2) and (5) persistence in private institutions, and in columns (3) and (6) persistence in public institutions. We implement a data driven non parametric version of the RD design and select optimal bandwidths according to a MSE selection procedure (Calonico, Cattaneo and Titiunik, 2015). We assess the robustness of our results using local polynomial estimators of various orders and implementing a bias-corrected robust inference procedure (Calonico, Cattaneo and Titiunik, 2014) - columns (4), (5) and (6). Row Coeff. presents the estimate of treatment effect, row S.E. presents standard errors, row B.W. presents the optimal bandwidth, row Local-Poly. presents the order of the local polynomial estimator and row $N$ presents the number of effective observations. 
Table 10: Robustness: - Enrollment in Higher Education Varying RD Cutoff

\begin{tabular}{ccccccccc}
\hline \hline & $(1)$ & $(2)$ & $(3)$ & $(4)$ & $(5)$ & $(6)$ & $(7)$ & $(8)$ \\
Variables & $\mathrm{c}+5$ & $\mathrm{c}+10$ & $\mathrm{c}+25$ & $\mathrm{c}+50$ & $\mathrm{c}+75$ & $\mathrm{c}+100$ & $\mathrm{c}+150$ & $\mathrm{c}+250$ \\
\hline Coeff & 0.002 & 0.001 & $-0.003 *$ & $0.004 * *$ & 0.001 & -0.002 & -0.003 & -0.009 \\
$\mathrm{SE}$ & $(0.002)$ & $(0.002)$ & $(0.001)$ & $(0.002)$ & $(0.002)$ & $(0.003)$ & $(0.003)$ & $(0.008)$ \\
BW & 21.561 & 21.575 & 39.059 & 27.008 & 33.964 & 28.354 & 52.098 & 24.583 \\
Local-Poly. & 1 & 1 & 1 & 1 & 1 & 1 & 1 & 1 \\
$\mathrm{~N}$ & 611947 & 633963 & 1174542 & 830027 & 903716 & 604503 & 648972 & 70071 \\
& & & & & & & & \\
Coeff & 0.001 & 0 & 0.003 & $0.005 * * *$ & 0.002 & -0.003 & -0.003 & -0.01 \\
SE & $(0.002)$ & $(0.002)$ & $(0.002)$ & $(0.002)$ & $(0.002)$ & $(0.003)$ & $(0.003)$ & $(0.009)$ \\
BW & 34.802 & 43.918 & 35.076 & 52.548 & 46.979 & 60.614 & 87.288 & 46.65 \\
Local-Poly. & 2 & 2 & 2 & 2 & 2 & 2 & 2 & 2 \\
N & 962788 & 1223291 & 1067816 & 1511357 & 1230142 & 1302379 & 1181470 & 138786 \\
& & & & & & & & \\
Coeff & 0.002 & 0 & 0.002 & $0.007 * * *$ & 0.002 & -0.002 & 0.004 & -0.011 \\
SE & $(0.002)$ & $(0.002)$ & $(0.002)$ & $(0.002)$ & $(0.002)$ & $(0.003)$ & $(0.004)$ & $(0.011)$ \\
BW & 69.574 & 71.624 & 65.064 & 92.075 & 80.613 & 72.282 & 75.493 & 52.377 \\
Local-Poly. & 3 & 3 & 3 & 3 & 3 & 3 & 3 & 3 \\
N & 1706451 & 1788245 & 1770289 & 2250628 & 1961428 & 1546750 & 991828 & 158726 \\
\hline
\end{tabular}

Notes: This table presents the results of a placebo regression discontinuity design on enrollment. The final sample includes all students taking the ENEM exam between 2014 and 2015 who are expected to graduate from high school in that same year and who obtained a grade higher than zero on ENEM's essay - 2,876,864 students total. In each column, we test whether crossing a placebo eligibility threshold has a significant impact on enrollment. Row names identify the placebo threshold and $c$ represents the actual eligibility threshold. We implement a data driven non parametric version of the RD design and select optimal bandwidths according to a MSE selection procedure (Calonico, Cattaneo and Titiunik, 2015). We assess the robustness of our results using local polynomial estimators of various orders and implementing a bias-corrected robust inference procedure (Calonico, Cattaneo and Titiunik, 2014) — columns (4), (5) and (6). Row Coeff. presents the estimate of treatment effect, row S.E. presents standard errors, row B.W. presents the optimal bandwidth, row Local-Poly. presents the order of the local polynomial estimator and row $N$ presents the number of effective observations. 
Table 11: Robustness: - Enrollment in Private Higher Education Varying RD Cutoff

\begin{tabular}{ccccccccc}
\hline \hline & $(1)$ & $(2)$ & $(3)$ & $(4)$ & $(5)$ & $(6)$ & $(7)$ & $(8)$ \\
Variables & $\mathrm{c}+5$ & $\mathrm{c}+10$ & $\mathrm{c}+25$ & $\mathrm{c}+50$ & $\mathrm{c}+75$ & $\mathrm{c}+100$ & $\mathrm{c}+150$ & $\mathrm{c}+250$ \\
\hline Coeff & 0.001 & 0 & -0.002 & 0.002 & 0.002 & -0.001 & 0.004 & 0.003 \\
$\mathrm{SE}$ & $(0.002)$ & $(0.002)$ & $(0.001)$ & $(0.002)$ & $(0.002)$ & $(0.002)$ & $(0.003)$ & $(0.005)$ \\
BW & 19.065 & 19.784 & 34.909 & 36.459 & 30.617 & 28.557 & 29.509 & 29.98 \\
Local-Poly. & 1 & 1 & 1 & 1 & 1 & 1 & 1 & 1 \\
$\mathrm{~N}$ & 542973 & 583232 & 1063439 & 1097539 & 816567 & 608789 & 354053 & 86047 \\
& & & & & & & & \\
Coeff & 0 & -0.001 & 0.001 & 0.003 & 0.002 & -0.002 & 0.004 & 0.002 \\
SE & $0.002)$ & $(0.002)$ & $(0.002)$ & $(0.002)$ & $(0.002)$ & $(0.002)$ & $(0.003)$ & $(0.005)$ \\
BW & 32.317 & 42.272 & 32.56 & 51.771 & 43.09 & 53.225 & 62.46 & 51.726 \\
Local-Poly. & 2 & 2 & 2 & 2 & 2 & 2 & 2 & 2 \\
N & 898437 & 1183911 & 997707 & 1492648 & 1134641 & 1143961 & 795078 & 156510 \\
& & & & & & & & \\
Coeff & 0 & -0.001 & 0.002 & $0.005 * * *$ & 0.003 & -0.002 & $0.007 *$ & 0.004 \\
SE & $(0.002)$ & $(0.002)$ & $(0.002)$ & $(0.002)$ & $(0.002)$ & $(0.003)$ & $(0.004)$ & $(0.007)$ \\
BW & 59.293 & 74.812 & 55.406 & 95.881 & 74.527 & 70.568 & 65.942 & 57.122 \\
Local-Poly. & 3 & 3 & 3 & 3 & 3 & 3 & 3 & 3 \\
N & 1517757 & 1840021 & 1571882 & 2300745 & 1844828 & 1511495 & 846511 & 175963 \\
\hline
\end{tabular}

Notes: This table presents the results of a placebo regression discontinuity design on enrollment in private higher education. The final sample includes all students taking the ENEM exam between 2014 and 2015 who are expected to graduate from high school in that same year and who obtained a grade higher than zero on ENEM's essay - $2,876,864$ students total. In each column, we test whether crossing a placebo eligibility threshold has a significant impact on enrollment. Row names identify the placebo threshold and $c$ represents the actual eligibility threshold. We implement a data driven non parametric version of the RD design and select optimal bandwidths according to a MSE selection procedure (Calonico, Cattaneo and Titiunik, 2015). We assess the robustness of our results using local polynomial estimators of various orders and implementing a bias-corrected robust inference procedure (Calonico, Cattaneo and Titiunik, 2014) - columns (4), (5) and (6). Row Coeff. presents the estimate of treatment effect, row S.E. presents standard errors, row B.W. presents the optimal bandwidth, row Local-Poly. presents the order of the local polynomial estimator and row $N$ presents the number of effective observations. 
Table 12: Robustness: - Enrollment in Public Higher Education Varying RD Cutoff

\begin{tabular}{ccccccccc}
\hline \hline & $(1)$ & $(2)$ & $(3)$ & $(4)$ & $(5)$ & $(6)$ & $(7)$ & $(8)$ \\
Variables & $\mathrm{c}+5$ & $\mathrm{c}+10$ & $\mathrm{c}+25$ & $\mathrm{c}+50$ & $\mathrm{c}+75$ & $\mathrm{c}+100$ & $\mathrm{c}+150$ & $\mathrm{c}+250$ \\
\hline Coeff & 0 & 0 & 0.001 & $0.002 * *$ & 0 & -0.001 & -0.003 & $-0.014 *$ \\
$\mathrm{SE}$ & $(0.001)$ & $(0.001)$ & $(0.001)$ & $(0.001)$ & $(0.001)$ & $(0.001)$ & $(0.002)$ & $(0.008)$ \\
BW & 29.364 & 27.857 & 27.013 & 26.21 & 38.327 & 36.52 & 36.775 & 23.138 \\
Local-Poly. & 1 & 1 & 1 & 1 & 1 & 1 & 1 & 1 \\
$\mathrm{~N}$ & 821594 & 808327 & 839498 & 806643 & 1015724 & 780896 & 445363 & 65774 \\
& & & & & & & & \\
Coeff & 0 & 0 & 0.001 & $0.003 * * *$ & 0 & -0.001 & -0.004 & -0.013 \\
SE & $(0.001)$ & $(0.001)$ & $(0.001)$ & $(0.001)$ & $(0.001)$ & $(0.001)$ & $(0.003)$ & $(0.009)$ \\
BW & 56.655 & 56.088 & 57.778 & 57.219 & 56.94 & 62.544 & 58.957 & 44.346 \\
Local-Poly. & 2 & 2 & 2 & 2 & 2 & 2 & 2 & 2 \\
N & 1465095 & 1497228 & 1622606 & 1619226 & 1466875 & 1344057 & 744607 & 131194 \\
& & & & & & & & \\
Coeff & 0 & 0 & 0.001 & $0.002 * * *$ & 0 & -0.001 & -0.002 & -0.016 \\
SE & $(0.001)$ & $(0.001)$ & $(0.001)$ & $(0.001)$ & $(0.001)$ & $(0.002)$ & $(0.003)$ & $(0.011)$ \\
BW & 90.116 & 87.666 & 84.922 & 88.529 & 85.748 & 76.01 & 66.784 & 50.926 \\
Local-Poly. & 3 & 3 & 3 & 3 & 3 & 3 & 3 & 3 \\
N & 2009173 & 2024393 & 2094855 & 2200777 & 2053718 & 1622508 & 858829 & 153578 \\
\hline
\end{tabular}

Notes: This table presents the results of a placebo regression discontinuity design on enrollment in public higher education. The final sample includes all students taking the ENEM exam between 2014 and 2015 who are expected to graduate from high school in that same year and who obtained a grade higher than zero on ENEM's essay — $2,876,864$ students total. In each column, we test whether crossing a placebo eligibility threshold has a significant impact on enrollment. Row names identify the placebo threshold and $c$ represents the actual eligibility threshold. We implement a data driven non parametric version of the RD design and select optimal bandwidths according to a MSE selection procedure (Calonico, Cattaneo and Titiunik, 2015). We assess the robustness of our results using local polynomial estimators of various orders and implementing a bias-corrected robust inference procedure (Calonico, Cattaneo and Titiunik, 2014)—columns (4), (5) and (6). Row Coeff. presents the estimate of treatment effect, row S.E. presents standard errors, row B.W. presents the optimal bandwidth, row Local-Poly. presents the order of the local polynomial estimator and row $N$ presents the number of effective observations. 
B

Appendix: The Effect of Credit Constraints on Major Choice: Evidence from a Large Scale Student Loan Program in Brazil

\section{B.1}

\section{Definitions}

- List of Majors:

- Others

- Education

- Arts and Humanities

- Social Sciences, Business and Administration

- Sciences, Math, Statistics and Computing

- Engineering, Construction and related careers

- Agriculture and Veterinary

- Health (General Services)

- Medicine

- Odontology

- Law

- Markets: Combination (State or MSA) x Year

- Years 2009 - 2013

- State or MSA: PNAD Division

1. Acre $(\mathrm{AC})$

2. Alagoas (AL)

3. Amapá (AP)

4. Amazonas (AM)

5. Bahia (BA) - excluding MSA of Salvador

6. MSA - Salvador (BA)

7. Ceará (CE) - excluding MSA of Fortaleza

8. MSA - Fortaleza (CE)

9. RIDE Distrito Federal e Entorno

10. Espírito Santo (ES)

11. Goiás (GO) - excluding RIDE Entorno

12. Maranhão (MA)

13. Mato Grosso (MT)

14. Mato Grosso do Sul (MS)

15. Minas Gerais (MG) - excluding MSA of Belo Horizonte 
16. MSA - Belo Horizonte (MG)

17. Pará (PA) - excluding MSA of Belém

18. MSA - Belém (PA)

19. Paraíba (PB)

20. Paraná (PR) - excluding MSA of Curitiba

21. MSA - Curitiba (PR)

22. Pernambuco (PE) - excluding MSA of Recife

23. MSA - Recife (PE)

24. Piauí (PI)

25. Rio de Janeiro (RJ) - excluding MSA of Rio de Janeiro

26. MSA - Rio de Janeiro (RJ)

27. Rio Grande do Norte (RN)

28. Rio Grande do Sul (RS) - excluding MSA of Porto Alegre

29. MSA - Porto Alegre (RS)

30. Rondônia (RO)

31. Roraima (RR)

32. Santa Catarina (SC)

33. São Paulo (SP) - excluding MSA of São Paulo

34. MSA - São Paulo (SP)

35. Sergipe (SE)

36. Tocantins (TO)

\section{B.2}

\section{Elasticities}

We can sort the $J$ available majors at market $m$ in terms of cost. That is, we define $j=1, . ., J$ majors according to the following order

$$
\tau_{1 m}<\tau_{2 m}<\tau_{3 m}<\ldots<\tau_{J m}
$$

Define $j^{* *}$ as the most expensive major individual $i$ can afford.

$$
\left\{\begin{array}{l}
T_{i m} \geq \tau_{j^{* *} m} \\
T_{i m}<\tau_{\left(j^{* *}+1\right) m}
\end{array} \quad\right. \text { and }
$$

From section 2.6 we have that the probability of prospective student $i$ choosing major $j$ at market-year $m$ when educational credit is not available to students is given by: 


$$
P(j \mid i, m)=\frac{\exp \left(\delta_{i j m}\right)}{1+\sum_{k} \exp \left(\delta_{i k m}\right)}
$$

with $\delta_{i l m}$ defined as:

$$
\delta_{i l m}=\gamma_{0}+\left(\theta+\chi_{i}\right) \ln \left(T_{i m}-\tau_{l m}\right)+\theta \beta /(1-\beta) \ln \left(w_{l m}\right)+\gamma_{1} X_{l m}
$$

The the market share of major $j$ at market $m-s_{j m}$-is given by:

$$
s_{j m}=\int_{i} \mathbb{1}\left[T_{i m} \geq \tau_{j m}\right] \operatorname{Pr}(j \mid i, m) f(t i)
$$

In this framework, the price elasticity of demand $\left(\eta_{j m}\right)$ is given by the following expression:

$$
\eta_{j m}=\frac{\partial s_{j m} \tau_{j m}}{\partial \tau_{j m} s_{j m}} \approx-\frac{\tau_{j m}}{s_{j m}} \sum_{i} \mathbb{1}\left[T_{i m} \geq \tau_{j m}\right]\left(\frac{\left(\theta+\chi_{i}\right)}{T_{i m}-\tau_{j m}} s_{i j m}\left(1-s_{i j m}\right)\right)
$$

When credit is freely available to students we have that that the probability of prospective student $i$ choosing major $j$ at market-year $m$ when educational credit is not available to students is given by:

$$
P^{\prime \prime}(j \mid i, m)=\frac{\exp \left(\delta_{i j m}^{\prime \prime}\right)}{1+\sum_{k} \exp \left(\delta_{i k m}^{\prime \prime}\right)}
$$

with $\delta_{i l m}^{\prime \prime}$ defined as:

$\delta_{i l m}^{\prime \prime}=\gamma_{0}+\left(\theta+\chi_{i}\right) \ln \left(T_{i m}-\tau_{l m}+d_{i l m}\right)+\theta \frac{\beta}{(1-\beta)} \ln \left(w_{l m}-i_{i l m t}\right)+\gamma_{1} X_{l m}$

and market shares given by:

$$
s_{j m}^{\prime \prime}=\int_{i} \mathbb{1}\left[T_{i} \geq\left(1-\phi_{i}\right) \tau_{j m}\right] \operatorname{Pr}^{\prime \prime}(j \mid i, m) f(t i)
$$

In this case, the price elasticity of demand $\left(\eta_{j m}\right)$ is given by the following expression:

$$
\eta_{j m}=\frac{\partial s_{j m} \tau_{j m}}{\partial \tau_{j m} s_{j m}} \approx-\frac{\tau_{j m}}{s_{j m}} \sum_{i} \mathbb{1}\left[T_{i} \geq\left(1-\phi_{i}\right) \tau_{j m}\right]\left(\frac{\left(\theta+\chi_{i}\right)\left(1-\phi_{i}\right)}{T_{i m}-\left(1-\phi_{i}\right) \tau_{j m}}\right) s_{i j m}\left(1-s_{i j m}\right)
$$


C

Appendix: The Impact of Water Scarcity on Educational Outcomes: Evidence from a Water Rationing Policy in Brazil 
C.1

Descriptive Statistics

Table 13: Descriptive Statistics - Students' Sample

\begin{tabular}{|c|c|c|c|c|c|}
\hline Variable & Mean & S.D. & Min. & Max. & $\mathrm{N}$ \\
\hline Grade Mean - Portuguese $(0,1)$ & -0.48 & 0.91 & -9.90 & 4.70 & 312734 \\
\hline Grade Mean - Math $(0,1)$ & -0.26 & 0.85 & -8.00 & 9.90 & 312734 \\
\hline Treatment Status & 0.78 & 0.42 & 0.00 & 1.00 & 312734 \\
\hline Post-Treatment & 0.14 & 0.35 & 0.00 & 1.00 & 312734 \\
\hline 5 th graders & 0.58 & 0.49 & 0.00 & 1.00 & 312734 \\
\hline 9th graders & 0.40 & 0.49 & 0.00 & 1.00 & 312734 \\
\hline High school seniors & 0.02 & 0.14 & 0.00 & 1.00 & 312734 \\
\hline Female Student & 0.50 & 0.50 & 0.00 & 1.00 & 312734 \\
\hline White Student & 0.22 & 0.42 & 0.00 & 1.00 & 312734 \\
\hline Black Student & 0.11 & 0.31 & 0.00 & 1.00 & 312734 \\
\hline Brown Student & 0.49 & 0.50 & 0.00 & 1.00 & 312734 \\
\hline Asian Student & 0.04 & 0.19 & 0.00 & 1.00 & 312734 \\
\hline Indigenous Student & 0.02 & 0.14 & 0.00 & 1.00 & 312734 \\
\hline Race - Unknown & 0.12 & 0.32 & 0.00 & 1.00 & 312734 \\
\hline Does your family owe a car? (Y/N) & 0.61 & 0.49 & 0.00 & 1.00 & 312734 \\
\hline Do you have a computer at home? $(\mathrm{Y} / \mathrm{N})$ & 0.69 & 0.46 & 0.00 & 1.00 & 312734 \\
\hline Bathrooms at home (per capita) & 0.33 & 0.23 & 0.00 & 4.00 & 312734 \\
\hline Number of people living at home & 4.51 & 1.63 & 0.00 & 8.00 & 312734 \\
\hline Do you live with your mother/ female guardian? (Y/N) & 0.91 & 0.29 & 0.00 & 1.00 & 312734 \\
\hline Mother Education - Never Studied or Less than elementary & 0.06 & 0.23 & 0.00 & 1.00 & 312734 \\
\hline Mother Education - Elementary School & 0.14 & 0.35 & 0.00 & 1.00 & 312734 \\
\hline Mother Education - Middle School & 0.13 & 0.33 & 0.00 & 1.00 & 312734 \\
\hline Mother Education - High School & 0.22 & 0.42 & 0.00 & 1.00 & 312734 \\
\hline Mother Education - College & 0.13 & 0.33 & 0.00 & 1.00 & 312734 \\
\hline Mother Education - Don’t Know & 0.31 & 0.46 & 0.00 & 1.00 & 312734 \\
\hline Do you live with your father/ male guardian? (Y/N) & 0.66 & 0.48 & 0.00 & 1.00 & 312734 \\
\hline Father Education - Never Studied or Less than elementary & 0.07 & 0.26 & 0.00 & 1.00 & 312734 \\
\hline Father Education - Elementary School & 0.11 & 0.31 & 0.00 & 1.00 & 312734 \\
\hline Father Education - Middle School & 0.10 & 0.31 & 0.00 & 1.00 & 312734 \\
\hline Father Education - High School & 0.16 & 0.37 & 0.00 & 1.00 & 312734 \\
\hline Father Education - College & 0.12 & 0.32 & 0.00 & 1.00 & 312734 \\
\hline Father Education - Don’t Know & 0.44 & 0.50 & 0.00 & 1.00 & 312734 \\
\hline With what frequency do your parents attend PTA meetings & 2.52 & 0.81 & 0.00 & 3.00 & 312734 \\
\hline Parents Incentive Score & 4.39 & 1.07 & 0.00 & 5.00 & 312734 \\
\hline Do you work? $(\mathrm{Y} / \mathrm{N})$ & 0.09 & 0.29 & 0.00 & 1.00 & 312734 \\
\hline Have you ever failed a grade & 1.35 & 0.72 & 0.00 & 3.00 & 312734 \\
\hline Have you ever failed a grade $(\mathrm{Y} / \mathrm{N})$ & 0.30 & 0.45 & 0.00 & 1.00 & 312734 \\
\hline Have you ever dropout of school? & 1.02 & 0.35 & 0.00 & 3.00 & 312734 \\
\hline Have you ever dropout of school? $(\mathrm{Y} / \mathrm{N})$ & 0.05 & 0.21 & 0.00 & 1.00 & 312734 \\
\hline
\end{tabular}

Notes: This table presents descriptive statistics for the final students' sample. This sample includes students who took the Math and Portuguese Prova Brasil exam between 2007 and 2017 while enrolled in a school located at Distrito Federal. We do not include in our sample schools that are not identifiable in the date due to the fact that an insufficient number of students took the exam. 
Table 14: Descriptive Statistics - School Sample

\begin{tabular}{|c|c|c|c|c|c|}
\hline Variable & Mean & S.D. & Min. & Max. & $\mathrm{N}$ \\
\hline Public School & 0.94 & 0.24 & 0.00 & 1.00 & 3008 \\
\hline School Located in Urban Area & 0.91 & 0.29 & 0.00 & 1.00 & 3008 \\
\hline School Infrastructure - Roof & 3.44 & 0.72 & 1.00 & 4.00 & 2925 \\
\hline School Infrastructure - Walls & 3.61 & 0.60 & 2.00 & 4.00 & 2943 \\
\hline School Infrastructure - Floor & 3.43 & 0.74 & 1.00 & 4.00 & 2923 \\
\hline School Infrastructure - Entrance & 3.51 & 0.68 & 1.00 & 4.00 & 2928 \\
\hline School Infrastructure - Patio & 3.46 & 0.76 & 1.00 & 4.00 & 2922 \\
\hline School Infrastructure - Corridors & 3.49 & 0.78 & 1.00 & 4.00 & 2919 \\
\hline School Infrastructure - Classrooms & 3.46 & 0.66 & 2.00 & 4.00 & 2924 \\
\hline School Infrastructure - Doors & 3.39 & 0.71 & 1.00 & 4.00 & 2909 \\
\hline School Infrastructure - Windows & 3.36 & 0.76 & 1.00 & 4.00 & 2907 \\
\hline School Infrastructure - Bathrooms & 3.22 & 0.77 & 1.00 & 4.00 & 2886 \\
\hline School Infrastructure - Kitchen & 3.43 & 0.75 & 1.00 & 4.00 & 2869 \\
\hline School Infrastructure - Plumbing & 3.19 & 0.79 & 1.00 & 4.00 & 2895 \\
\hline School Infrastructure - Electric & 3.16 & 0.80 & 1.00 & 4.00 & 2894 \\
\hline School Safety - Control Access - Students & 0.44 & 0.50 & 0.00 & 1.00 & 2940 \\
\hline School Safety - Control Access & 0.42 & 0.49 & 0.00 & 1.00 & 2938 \\
\hline School Safety - Security Presence- Day & 0.36 & 0.48 & 0.00 & 1.00 & 2915 \\
\hline School Safety - Security Presence- Night & 0.45 & 0.50 & 0.00 & 1.00 & 2912 \\
\hline School Safety - Security Presence- Weekends and Holydays & 0.44 & 0.50 & 0.00 & 1.00 & 2900 \\
\hline School Safety - Police Presence- Violence Prevention & 0.11 & 0.31 & 0.00 & 1.00 & 2916 \\
\hline School Safety - Police Presence- Drug Dealing (School) & 0.11 & 0.31 & 0.00 & 1.00 & 2920 \\
\hline School Safety - Police Presence- Drug Dealing (Neighborhood) & 0.10 & 0.30 & 0.00 & 1.00 & 2894 \\
\hline School Safety - Measures to Protect Students Around the School & 0.37 & 0.48 & 0.00 & 1.00 & 2003 \\
\hline School Resources - Computers for Students & 3.08 & 1.04 & 1.00 & 4.00 & 1649 \\
\hline School Resources - Internet for Students & 2.63 & 1.23 & 1.00 & 4.00 & 1648 \\
\hline School Resources - Library & 2.89 & 1.27 & 1.00 & 4.00 & 1640 \\
\hline School Resources - Reading Room & 2.89 & 1.25 & 1.00 & 4.00 & 1649 \\
\hline School Resources - Gymnasium & 2.69 & 1.21 & 1.00 & 4.00 & 1652 \\
\hline School Resources - Computer Lab & 3.02 & 1.09 & 1.00 & 4.00 & 1644 \\
\hline School Resources - Science Lab & 1.64 & 1.14 & 1.00 & 4.00 & 1658 \\
\hline School Resources - Auditorium & 1.58 & 1.11 & 1.00 & 4.00 & 1663 \\
\hline
\end{tabular}

Notes: This table presents descriptive statistics for the final schools' sample. This sample includes all schools located in Distrito Federal that participated in the Prova Brasil survey between 2007 and 2017. The quality of school infrastructure and available resources are measured on a scale from one - nonexistent - to four-good. Safety measures are evaluated as existent or nonexistent 
Table 15: Teachers' Survey - Reasons for Students' Poor Performance

Variable Mean S.D. Min. Max. N

\begin{tabular}{lccccc}
\hline School Infrastructure & 0.42 & 0.49 & 0.00 & 1.00 & 15299 \\
Pedagical Supervision & 0.21 & 0.41 & 0.00 & 1.00 & 8954 \\
Inadequate Curriculum & 0.23 & 0.42 & 0.00 & 1.00 & 15281 \\
Past Learning & 0.28 & 0.45 & 0.00 & 1.00 & 15293 \\
Excess Work for Teachers & 0.31 & 0.46 & 0.00 & 1.00 & 15256 \\
Teachers' Lack of Motivation & 0.37 & 0.48 & 0.00 & 1.00 & 15200 \\
Students' Social Environment & 0.84 & 0.37 & 0.00 & 1.00 & 15279 \\
Parents' Cultural Level & 0.80 & 0.40 & 0.00 & 1.00 & 15277 \\
Parents' Lack of Assistance & 0.95 & 0.22 & 0.00 & 1.00 & 15295 \\
Students' Low Self Esteem & 0.75 & 0.44 & 0.00 & 1.00 & 15313 \\
Students' Poor Motivation/Effort & 0.90 & 0.30 & 0.00 & 1.00 & 15304 \\
Students' Indiscipline & 0.73 & 0.44 & 0.00 & 1.00 & 15301 \\
Students' Poor Attendance & 0.48 & 0.50 & 0.00 & 1.00 & 8958
\end{tabular}

Notes: $\overline{\overline{T h i s} \text { table presents descriptive statistics for the teachers' survey sample. In }}$ this survey, teachers are asked if they believe certain factor are to blame for their students' poor performance. This sample includes respondents that were teaching in any of the Distrito Federal schools that participated in the Prova Brasil survey between 2007 and 2017. 


\section{C.2}

\section{Additional Results - Mechanisms}

Table 16: Heterogeneous Treatment Effect by School Characteristics - Infrastructure

\begin{tabular}{|c|c|c|c|c|c|}
\hline \multirow[b]{2}{*}{ Covariate } & \multicolumn{2}{|c|}{ Language } & \multicolumn{2}{|c|}{ Math } & \multirow[t]{2}{*}{$\mathrm{N}$} \\
\hline & $\begin{array}{c}\text { Treatment } \\
\text { Effect }\end{array}$ & HTE. & $\begin{array}{c}\text { Treatment } \\
\text { Effect }\end{array}$ & HTE & \\
\hline Roof & $\begin{array}{c}-0.420 * * * \\
(0.102)\end{array}$ & $\begin{array}{c}0.091^{* * *} \\
(0.024)\end{array}$ & $\begin{array}{c}-0.432^{* * *} \\
(0.102)\end{array}$ & $\begin{array}{c}0.099 * * * \\
(0.026)\end{array}$ & 300606 \\
\hline Walls & $\begin{array}{c}-0.434^{* * *} \\
(0.105)\end{array}$ & $\begin{array}{l}0.091^{* *} \\
(0.029)\end{array}$ & $\begin{array}{c}-0.382^{* * *} \\
(0.100)\end{array}$ & $\begin{array}{l}0.080^{* *} \\
(0.027)\end{array}$ & 302253 \\
\hline Entrance & $\begin{array}{c}-0.352^{* *} \\
(0.124)\end{array}$ & $\begin{array}{l}0.068^{* *} \\
(0.031)\end{array}$ & $\begin{array}{c}-0.364^{* *} \\
(0.125)\end{array}$ & $\begin{array}{l}0.076^{* *} \\
(0.033)\end{array}$ & 300902 \\
\hline Classrooms & $\begin{array}{c}-0.418^{* * *} \\
(0.103)\end{array}$ & $\begin{array}{l}0.092^{* *} \\
(0.025)\end{array}$ & $\begin{array}{c}-0.382^{* * *} \\
(0.084)\end{array}$ & $\begin{array}{c}0.085^{* * *} \\
(0.020)\end{array}$ & 301086 \\
\hline Doors & $\begin{array}{c}-0.266^{* * *} \\
(0.070)\end{array}$ & $\begin{array}{l}0.052^{* *} \\
(0.019)\end{array}$ & $\begin{array}{c}-0.282^{* *} \\
(0.084)\end{array}$ & $\begin{array}{l}0.060^{* *} \\
(0.022)\end{array}$ & 299163 \\
\hline Windows & $\begin{array}{c}-0.368^{* * *} \\
(0.077)\end{array}$ & $\begin{array}{c}0.079^{* * *} \\
(0.019)\end{array}$ & $\begin{array}{c}-0.411^{* * *} \\
(0.053)\end{array}$ & $\begin{array}{c}0.096^{* * *} \\
(0.015)\end{array}$ & 298925 \\
\hline Bathrooms & $\begin{array}{c}-0.321^{* * *} \\
(0.073)\end{array}$ & $\begin{array}{l}0.069^{* *} \\
(0.020)\end{array}$ & $\begin{array}{c}-0.287 * * \\
(0.097)\end{array}$ & $\begin{array}{c}0.063^{*} \\
(0.031)\end{array}$ & 296846 \\
\hline Kitchen & $\begin{array}{c}-0.228^{* *} \\
(0.101)\end{array}$ & $\begin{array}{c}0.036 \\
(0.025)\end{array}$ & $\begin{array}{c}-0.301^{* *} \\
(0.100)\end{array}$ & $\begin{array}{l}0.063^{* *} \\
(0.027)\end{array}$ & 296534 \\
\hline Plumbing & $\begin{array}{c}-0.366^{* * *} \\
(0.051)\end{array}$ & $\begin{array}{c}0.083^{* * *} \\
(0.015)\end{array}$ & $\begin{array}{c}-0.368^{* * *} \\
(0.056)\end{array}$ & $\begin{array}{c}0.089^{* * *} \\
(0.020)\end{array}$ & 297719 \\
\hline Electric & $\begin{array}{c}-0.361^{* * *} \\
(0.044)\end{array}$ & $\begin{array}{c}0.088^{* * *} \\
(0.013)\end{array}$ & $\begin{array}{c}-0.354^{* * *} \\
(0.036)\end{array}$ & $\begin{array}{c}0.089 * * * \\
(0.015)\end{array}$ & 297720 \\
\hline
\end{tabular}

Notes: This table presents the results of a difference-in-differences (DD) analysis that: (i) estimates the difference in performance for students enrolled in schools located in neighborhoods impacted by the water rationing against academic performance of students enrolled in non-affected schools, i.e. the "Treatment Effect" and, (ii) estimates how the treatment effect varies with school level characteristics - the heterogeneous treatment effect or HTE. In this DD, the pre-treatment period consists of the years that precede water rationing $(2007,2009,2011,2013$, and 2015). The post-treatment period consists of the year the water rationing was implemented (2017). The first two columns consider performance in the Language evaluation as independent variable. The following two columns consider performance in the math evaluation. We include school, year and school-grade fixed effects in all specifications. We also include student level controls, such as information on gender, race, family income, parents' education, parents' support, and information on grade retention and school abandonment. Standard errors were computed with observations clustered at neighborhood level. ${ }^{* * *}$ represents $\mathrm{p}$-value $<0.01,{ }^{* *} \mathrm{p}$-value $<0.05$, and ${ }^{*} \mathrm{p}$ value $<0.1$. 
Table 17: Heterogeneous Treatment Effect by School Characteristics - Safety

\begin{tabular}{|c|c|c|c|c|c|}
\hline \multirow[b]{2}{*}{ Covariate } & \multicolumn{2}{|c|}{ Language } & \multicolumn{2}{|c|}{ Math } & \multirow[t]{2}{*}{$\mathrm{N}$} \\
\hline & $\begin{array}{c}\text { Treatment } \\
\text { Effect }\end{array}$ & HTE. & $\begin{array}{c}\text { Treatment } \\
\text { Effect }\end{array}$ & HTE & \\
\hline Control Access - Students & $\begin{array}{c}-0.170^{* *} \\
(0.067)\end{array}$ & $\begin{array}{c}0.088 \\
(0.069)\end{array}$ & $\begin{array}{c}-0.206^{* * *} \\
(0.051)\end{array}$ & $\begin{array}{l}0.147^{* *} \\
(0.052)\end{array}$ & 302385 \\
\hline Control Access & $\begin{array}{c}-0.184^{* * *} \\
(0.049)\end{array}$ & $\begin{array}{l}0.112^{* *} \\
(0.040)\end{array}$ & $\begin{array}{c}-0.148^{* *} \\
(0.056)\end{array}$ & $\begin{array}{c}0.083^{*} \\
(0.047)\end{array}$ & 302435 \\
\hline Security Presence- Day & $\begin{array}{l}-0.081^{*} \\
(0.040)\end{array}$ & $\begin{array}{c}-0.026 \\
(0.030)\end{array}$ & $\begin{array}{c}-0.079^{* *} \\
(0.026)\end{array}$ & $\begin{array}{c}-0.012 \\
(0.031)\end{array}$ & 300107 \\
\hline Security Presence- Night & $\begin{array}{c}-0.059 \\
(0.052)\end{array}$ & $\begin{array}{c}-0.041 \\
(0.044)\end{array}$ & $\begin{array}{l}-0.070^{*} \\
(0.036)\end{array}$ & $\begin{array}{c}-0.018 \\
(0.036)\end{array}$ & 299794 \\
\hline Police Presence- Violence Prevention & $\begin{array}{c}-0.077^{* *} \\
(0.028)\end{array}$ & $\begin{array}{c}-0.170^{* * *} \\
(0.034)\end{array}$ & $\begin{array}{c}-0.071^{* *} \\
(0.027)\end{array}$ & $\begin{array}{c}-0.119^{* *} \\
(0.045)\end{array}$ & 300351 \\
\hline Police Presence- Drug Dealing (School) & $\begin{array}{c}-0.070^{* *} \\
(0.028)\end{array}$ & $\begin{array}{c}-0.174^{* * *} \\
(0.045)\end{array}$ & $\begin{array}{c}-0.074^{* *} \\
(0.028)\end{array}$ & $\begin{array}{c}-0.071^{* *} \\
(0.034)\end{array}$ & 301052 \\
\hline Police Presence- Drug Dealing (Neighborhood) & $\begin{array}{c}-0.069^{* *} \\
(0.025)\end{array}$ & $\begin{array}{l}-0.156^{*} \\
(0.077)\end{array}$ & $\begin{array}{c}-0.067^{* *} \\
(0.027)\end{array}$ & $\begin{array}{c}-0.034 \\
(0.042)\end{array}$ & 297181 \\
\hline Measures to Protect Students Around School & $\begin{array}{c}-0.089^{* *} \\
(0.039)\end{array}$ & $\begin{array}{c}0.000 \\
(0.000)\end{array}$ & $\begin{array}{c}-0.082^{* *} \\
(0.030)\end{array}$ & $\begin{array}{c}0.000 \\
(0.000)\end{array}$ & 221064 \\
\hline
\end{tabular}

Notes: This table presents the results of a difference-in-differences (DD) analysis that: (i) estimates the difference in performance for students enrolled in schools located in neighborhoods impacted by the water rationing against academic performance of students enrolled in non-affected schools, i.e. the "Treatment Effect" and, (ii) estimates how the treatment effect varies with school level characteristics - the heterogeneous treatment effect or HTE. In this DD, the pre-treatment period consists of the years that precede water rationing $(2007,2009,2011,2013$, and 2015). The post-treatment period consists of the year the water rationing was implemented (2017). The first two columns consider performance in the Language evaluation as independent variable. The following two columns consider performance in the math evaluation. We include school, year and school-grade fixed effects in all specifications. We also include student level controls, such as information on gender, race, family income, parents' education, parents' support, and information on grade retention and school abandonment. Standard errors were computed with observations clustered at neighborhood level. ${ }^{* * *}$ represents p-value $<0.01,{ }^{* *}$ p-value $<0.05$, and ${ }^{*}$ pvalue $<0.1$. 
Table 18: Heterogeneous Treatment Effect by School Characteristics - Resources

\begin{tabular}{|c|c|c|c|c|c|}
\hline \multirow[b]{2}{*}{ Covariate } & \multicolumn{2}{|c|}{ Language } & \multicolumn{2}{|c|}{ Math } & \multirow[t]{2}{*}{$\mathrm{N}$} \\
\hline & $\begin{array}{c}\text { Treatment } \\
\text { Effect }\end{array}$ & HTE. & $\begin{array}{c}\text { Treatment } \\
\text { Effect }\end{array}$ & HTE & \\
\hline Computers for Students & $\begin{array}{c}-0.138^{* *} \\
(0.057)\end{array}$ & $\begin{array}{c}0.019 \\
(0.017)\end{array}$ & $\begin{array}{c}-0.128^{* *} \\
(0.058)\end{array}$ & $\begin{array}{c}0.013 \\
(0.019)\end{array}$ & 143696 \\
\hline Internet for Students & $\begin{array}{c}-0.077^{* *} \\
(0.034)\end{array}$ & $\begin{array}{c}-0.001 \\
(0.018)\end{array}$ & $\begin{array}{c}-0.078^{* *} \\
(0.036)\end{array}$ & $\begin{array}{c}-0.002 \\
(0.021)\end{array}$ & 144017 \\
\hline Library & $\begin{array}{c}0.016 \\
(0.034)\end{array}$ & $\begin{array}{l}-0.029^{*} \\
(0.016)\end{array}$ & $\begin{array}{c}0.051 \\
(0.038)\end{array}$ & $\begin{array}{c}-0.046^{* * *} \\
(0.012)\end{array}$ & 142319 \\
\hline Reading Room & $\begin{array}{c}-0.104^{* *} \\
(0.046)\end{array}$ & $\begin{array}{c}0.012 \\
(0.015)\end{array}$ & $\begin{array}{c}-0.135^{* *} \\
(0.038)\end{array}$ & $\begin{array}{c}0.017^{*} \\
(0.010)\end{array}$ & 143171 \\
\hline Gymnasium & $\begin{array}{c}-0.138^{* *} \\
(0.044)\end{array}$ & $\begin{array}{c}0.023 \\
(0.015)\end{array}$ & $\begin{array}{c}-0.153^{* *} \\
(0.046)\end{array}$ & $\begin{array}{c}0.026^{*} \\
(0.015)\end{array}$ & 143689 \\
\hline Computer Lab & $\begin{array}{c}-0.203^{* * *} \\
(0.037)\end{array}$ & $\begin{array}{c}0.038^{* * *} \\
(0.010)\end{array}$ & $\begin{array}{c}-0.131^{* * *} \\
(0.026)\end{array}$ & $\begin{array}{c}0.011 \\
(0.015)\end{array}$ & 142455 \\
\hline Science Lab & $\begin{array}{l}-0.078^{*} \\
(0.043)\end{array}$ & $\begin{array}{c}-0.001 \\
(0.027)\end{array}$ & $\begin{array}{l}-0.075^{*} \\
(0.041)\end{array}$ & $\begin{array}{c}-0.008 \\
(0.021)\end{array}$ & 144243 \\
\hline Auditorium & $\begin{array}{c}-0.125^{* *} \\
(0.051)\end{array}$ & $\begin{array}{c}0.036 \\
(0.031)\end{array}$ & $\begin{array}{c}-0.136^{* *} \\
(0.058)\end{array}$ & $\begin{array}{c}0.038 \\
(0.035)\end{array}$ & 145320 \\
\hline
\end{tabular}

Notes: This table presents the results of a difference-in-differences (DD) analysis that: (i) estimates the difference in performance for students enrolled in schools located in neighborhoods impacted by the water rationing against academic performance of students enrolled in non-affected schools, i.e. the "Treatment Effect" and, (ii) estimates how the treatment effect varies with school level characteristics - the heterogeneous treatment effect or HTE. In this DD, the pre-treatment period consists of the years that precede water rationing $(2007,2009,2011,2013$, and 2015). The post-treatment period consists of the year the water rationing was implemented (2017). The first two columns consider performance in the Language evaluation as independent variable. The following two columns consider performance in the math evaluation. We include school, year and school-grade fixed effects in all specifications. We also include student level controls, such as information on gender, race, family income, parents' education, parents' support, and information on grade retention and school abandonment. Standard errors were computed with observations clustered at neighborhood level. ${ }^{* * *}$ represents p-value $<0.01,{ }^{* *}$ p-value $<0.05$, and ${ }^{*}$ pvalue $<0.1$. 
Table 19: Heterogeneous Treatment Effect by Student Characteristics - Student

\begin{tabular}{|c|c|c|c|c|c|}
\hline \multirow[b]{2}{*}{ Covariate } & \multicolumn{2}{|c|}{ Language } & \multicolumn{2}{|c|}{ Math } & \multirow[t]{2}{*}{$\mathrm{N}$} \\
\hline & $\begin{array}{c}\text { Treatment } \\
\text { Effect }\end{array}$ & HTE. & $\begin{array}{c}\text { Treatment } \\
\text { Effect }\end{array}$ & HTE & \\
\hline Female Student & $\begin{array}{c}-0.088^{* *} \\
(0.030)\end{array}$ & $\begin{array}{c}0.005 \\
(0.019)\end{array}$ & $\begin{array}{c}-0.083^{* *} \\
(0.024)\end{array}$ & $\begin{array}{c}0.014 \\
(0.024)\end{array}$ & 312734 \\
\hline White Student & $\begin{array}{c}-0.085^{* *} \\
(0.029)\end{array}$ & $\begin{array}{c}-0.007 \\
(0.020)\end{array}$ & $\begin{array}{c}-0.073^{* *} \\
(0.027)\end{array}$ & $\begin{array}{c}-0.019 \\
(0.018)\end{array}$ & 312734 \\
\hline Black Student & $\begin{array}{c}-0.089^{* *} \\
(0.028)\end{array}$ & $\begin{array}{c}0.021 \\
(0.020)\end{array}$ & $\begin{array}{c}-0.072^{* *} \\
(0.023)\end{array}$ & $\begin{array}{c}-0.038 \\
(0.028)\end{array}$ & 312734 \\
\hline Brown Student & $\begin{array}{c}-0.095^{* *} \\
(0.033)\end{array}$ & $\begin{array}{c}0.018 \\
(0.030)\end{array}$ & $\begin{array}{c}-0.092^{* *} \\
(0.029)\end{array}$ & $\begin{array}{c}0.033^{*} \\
(0.017)\end{array}$ & 312734 \\
\hline Asian Student & $\begin{array}{c}-0.088^{* *} \\
(0.030)\end{array}$ & $\begin{array}{c}0.033 \\
(0.051)\end{array}$ & $\begin{array}{c}-0.078^{* *} \\
(0.025)\end{array}$ & $\begin{array}{c}0.041 \\
(0.029)\end{array}$ & 312734 \\
\hline Indigenous Student & $\begin{array}{c}-0.085^{* *} \\
(0.028)\end{array}$ & $\begin{array}{c}-0.025 \\
(0.040)\end{array}$ & $\begin{array}{c}-0.075^{* *} \\
(0.026)\end{array}$ & $\begin{array}{c}-0.026 \\
(0.041)\end{array}$ & 312734 \\
\hline Does your family owe a car? $(\mathrm{Y} / \mathrm{N})$ & $\begin{array}{c}-0.097^{* *} \\
(0.027)\end{array}$ & $\begin{array}{c}0.015 \\
(0.020)\end{array}$ & $\begin{array}{c}-0.083^{* *} \\
(0.025)\end{array}$ & $\begin{array}{c}0.008 \\
(0.018)\end{array}$ & 312734 \\
\hline Do you have a computer at home? $(\mathrm{Y} / \mathrm{N})$ & $\begin{array}{c}-0.093^{* *} \\
(0.028)\end{array}$ & $\begin{array}{c}0.010 \\
(0.012)\end{array}$ & $\begin{array}{c}-0.077^{* *} \\
(0.023)\end{array}$ & $\begin{array}{c}0.002 \\
(0.016)\end{array}$ & 312734 \\
\hline Bathrooms at home (per capita) & $\begin{array}{c}-0.073^{*} \\
(0.036)\end{array}$ & $\begin{array}{c}-0.035 \\
(0.037)\end{array}$ & $\begin{array}{c}-0.060^{* *} \\
(0.026)\end{array}$ & $\begin{array}{c}-0.044 \\
(0.035)\end{array}$ & 312734 \\
\hline Number of people living at home & $\begin{array}{c}-0.162^{* * *} \\
(0.040)\end{array}$ & $\begin{array}{c}0.019^{* * *} \\
(0.004)\end{array}$ & $\begin{array}{c}-0.091^{* *} \\
(0.033)\end{array}$ & $\begin{array}{c}0.004 \\
(0.005)\end{array}$ & 312734 \\
\hline Do you work? $(\mathrm{Y} / \mathrm{N})$ & $\begin{array}{c}-0.084^{* *} \\
(0.031)\end{array}$ & $\begin{array}{c}-0.030 \\
(0.054)\end{array}$ & $\begin{array}{c}-0.072^{* *} \\
(0.027)\end{array}$ & $\begin{array}{c}-0.060 \\
(0.040)\end{array}$ & 312734 \\
\hline Have you ever failed a grade & $\begin{array}{c}-0.108^{* *} \\
(0.047)\end{array}$ & $\begin{array}{c}0.014 \\
(0.016)\end{array}$ & $\begin{array}{c}-0.073^{* *} \\
(0.034)\end{array}$ & $\begin{array}{c}-0.004 \\
(0.012)\end{array}$ & 312734 \\
\hline Have you ever dropout of school? & $\begin{array}{c}-0.110^{* *} \\
(0.031)\end{array}$ & $\begin{array}{c}0.023 \\
(0.023)\end{array}$ & $\begin{array}{c}-0.104^{* * *} \\
(0.027)\end{array}$ & $\begin{array}{c}0.027 \\
(0.026)\end{array}$ & 312734 \\
\hline
\end{tabular}

Notes: This table presents the results of a difference-in-differences (DD) analysis that: (i) estimates the difference in performance for students enrolled in schools located in neighborhoods impacted by the water rationing against academic performance of students enrolled in non-affected schools, i.e. the "Treatment Effect" and, (ii) estimates how the treatment effect varies with student level characteristics - the heterogeneous treatment effect or HTE. In this DD, the pre-treatment period consists of the years that precede water rationing $(2007,2009,2011,2013$, and 2015). The post-treatment period consists of the year the water rationing was implemented (2017). The first two columns consider performance in the Language evaluation as independent variable. The following two columns consider performance in the math evaluation. We include school, year and school-grade fixed effects in all specifications. We also include student level controls, such as information on gender, race, family income, parents' education, parents' support, and information on grade retention and school abandonment. Standard errors were computed with observations clustered at neighborhood level. ${ }^{* * *}$ represents p-value $<0.01,{ }^{* *}$ p-value $<0.05$, and ${ }^{*}$ pvalue $<0.1$. 
Table 20: Heterogeneous Treatment Effect by Student Characteristics - Parents

\begin{tabular}{|c|c|c|c|c|c|}
\hline \multirow[b]{2}{*}{ Covariate } & \multicolumn{2}{|c|}{ Language } & \multicolumn{2}{|c|}{ Math } & \multirow[t]{2}{*}{$\mathrm{N}$} \\
\hline & $\begin{array}{c}\text { Treatment } \\
\text { Effect }\end{array}$ & HTE. & $\begin{array}{c}\text { Treatment } \\
\text { Effect }\end{array}$ & HTE & \\
\hline Mother Education - NLess than elementary & $\begin{array}{c}-0.086^{* *} \\
(0.029)\end{array}$ & $\begin{array}{c}-0.049^{* *} \\
(0.022)\end{array}$ & $\begin{array}{c}-0.077^{* *} \\
(0.024)\end{array}$ & $\begin{array}{c}-0.023 \\
(0.029)\end{array}$ & 312734 \\
\hline Mother Education - Elementary School & $\begin{array}{c}-0.082^{* *} \\
(0.029)\end{array}$ & $\begin{array}{c}-0.059^{* *} \\
(0.024)\end{array}$ & $\begin{array}{c}-0.073^{* *} \\
(0.027)\end{array}$ & $\begin{array}{c}-0.044 \\
(0.029)\end{array}$ & 312734 \\
\hline Mother Education - Middle School & $\begin{array}{c}-0.088^{* *} \\
(0.029)\end{array}$ & $\begin{array}{c}0.018 \\
(0.028)\end{array}$ & $\begin{array}{c}-0.076^{* *} \\
(0.026)\end{array}$ & $\begin{array}{c}-0.003 \\
(0.023)\end{array}$ & 312734 \\
\hline Mother Education - High School & $\begin{array}{c}-0.088^{* *} \\
(0.031)\end{array}$ & $\begin{array}{c}0.011 \\
(0.036)\end{array}$ & $\begin{array}{c}-0.080^{* *} \\
(0.025)\end{array}$ & $\begin{array}{c}0.017 \\
(0.015)\end{array}$ & 312734 \\
\hline Mother Education - College & $\begin{array}{c}-0.090^{* *} \\
(0.027)\end{array}$ & $\begin{array}{c}0.003 \\
(0.025)\end{array}$ & $\begin{array}{c}-0.081^{* *} \\
(0.023)\end{array}$ & $\begin{array}{c}0.011 \\
(0.022)\end{array}$ & 312734 \\
\hline Father Education - Less than elementary & $\begin{array}{c}-0.085^{* *} \\
(0.030)\end{array}$ & $\begin{array}{c}-0.028 \\
(0.034)\end{array}$ & $\begin{array}{c}-0.080^{* *} \\
(0.026)\end{array}$ & $\begin{array}{c}0.018 \\
(0.038)\end{array}$ & 312734 \\
\hline Father Education - Elementary School & $\begin{array}{c}-0.087^{* *} \\
(0.029)\end{array}$ & $\begin{array}{c}0.010 \\
(0.037)\end{array}$ & $\begin{array}{c}-0.078^{* *} \\
(0.025)\end{array}$ & $\begin{array}{c}0.019 \\
(0.023)\end{array}$ & 312734 \\
\hline Father Education - Middle School & $\begin{array}{c}-0.085^{* *} \\
(0.029)\end{array}$ & $\begin{array}{c}-0.012 \\
(0.023)\end{array}$ & $\begin{array}{c}-0.072^{* *} \\
(0.025)\end{array}$ & $\begin{array}{r}-0.052^{* *} \\
(0.016)\end{array}$ & 312734 \\
\hline Father Education - High School & $\begin{array}{c}-0.082^{* *} \\
(0.029)\end{array}$ & $\begin{array}{c}-0.024 \\
(0.022)\end{array}$ & $\begin{array}{c}-0.076^{* *} \\
(0.025)\end{array}$ & $\begin{array}{c}0.001 \\
(0.016)\end{array}$ & 312734 \\
\hline Father Education - College & $\begin{array}{c}-0.084^{* *} \\
(0.027)\end{array}$ & $\begin{array}{c}-0.041 \\
(0.027)\end{array}$ & $\begin{array}{c}-0.078^{* *} \\
(0.024)\end{array}$ & $\begin{array}{c}-0.015 \\
(0.027)\end{array}$ & 312734 \\
\hline Frequency parents attend PTA meetings & $\begin{array}{c}-0.081^{* *} \\
(0.036)\end{array}$ & $\begin{array}{c}-0.003 \\
(0.014)\end{array}$ & $\begin{array}{c}-0.119^{* *} \\
(0.044)\end{array}$ & $\begin{array}{c}0.016 \\
(0.018)\end{array}$ & 312734 \\
\hline Parents Incentive Score & $\begin{array}{l}-0.132^{*} \\
(0.065)\end{array}$ & $\begin{array}{c}0.010 \\
(0.016)\end{array}$ & $\begin{array}{c}-0.178^{* *} \\
(0.056)\end{array}$ & $\begin{array}{c}0.023 \\
(0.014)\end{array}$ & 312734 \\
\hline
\end{tabular}

Notes: This table presents the results of a difference-in-differences (DD) analysis that: (i) estimates the difference in performance for students enrolled in schools located in neighborhoods impacted by the water rationing against academic performance of students enrolled in non-affected schools, i.e. the "Treatment Effect" and, (ii) estimates how the treatment effect varies with student level characteristics - the heterogeneous treatment effect or HTE. In this DD, the pre-treatment period consists of the years that precede water rationing $(2007,2009,2011,2013$, and 2015). The post-treatment period consists of the year the water rationing was implemented (2017). The first two columns consider performance in the Language evaluation as independent variable. The following two columns consider performance in the math evaluation. We include school, year and school-grade fixed effects in all specifications. We also include student level controls, such as information on gender, race, family income, parents' education, parents' support, and information on grade retention and school abandonment. Standard errors were computed with observations clustered at neighborhood level. ${ }^{* * *}$ represents $\mathrm{p}$-value $<0.01,{ }^{* *} \mathrm{p}$-value $<0.05$, and ${ }^{*} \mathrm{p}$ value $<0.1$. 